\title{
Enterprise software and video games : an Empirical analysis
}

Citation for published version (APA):

Engelstätter, B. (2012). Enterprise software and video games : an Empirical analysis. [Doctoral Thesis, Maastricht University]. https://doi.org/10.26481/dis.20121219be

Document status and date:

Published: 01/01/2012

DOI:

10.26481/dis.20121219be

Document Version:

Publisher's PDF, also known as Version of record

\section{Please check the document version of this publication:}

- A submitted manuscript is the version of the article upon submission and before peer-review. There can be important differences between the submitted version and the official published version of record.

People interested in the research are advised to contact the author for the final version of the publication, or visit the DOI to the publisher's website.

- The final author version and the galley proof are versions of the publication after peer review.

- The final published version features the final layout of the paper including the volume, issue and page numbers.

Link to publication

\footnotetext{
General rights rights.

- You may freely distribute the URL identifying the publication in the public portal. please follow below link for the End User Agreement:

www.umlib.nl/taverne-license

Take down policy

If you believe that this document breaches copyright please contact us at:

repository@maastrichtuniversity.nl

providing details and we will investigate your claim.
}

Copyright and moral rights for the publications made accessible in the public portal are retained by the authors and/or other copyright owners and it is a condition of accessing publications that users recognise and abide by the legal requirements associated with these

- Users may download and print one copy of any publication from the public portal for the purpose of private study or research.

- You may not further distribute the material or use it for any profit-making activity or commercial gain

If the publication is distributed under the terms of Article $25 \mathrm{fa}$ of the Dutch Copyright Act, indicated by the "Taverne" license above, 


\section{Enterprise Software and Video Games: An Empirical Analysis}


ISBN 978-94-6159-201-9

(c) copyright Benjamin Engelstätter, Maastricht 2012

Printing: Datawyse / Universitaire Pers Maastricht 


\section{Enterprise Software and Video Games: An Empirical Analysis}

\section{DISSERTATION}

to obtain the degree of doctor at Maastricht University, on the authority of the Rector Magnificus Prof. Dr. L.L.G. Soete, in accordance with the decision of the Board of Deans, to be defended in public on Wednesday December $19^{\text {th }} 2012$ at 12:45 hours

by

Benjamin Engelstätter

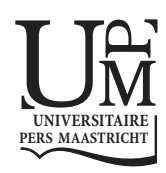


Supervisor:

Prof. Dr. Pierre Mohnen

Assesment Committee:

Prof. Dr. Martin Carree (chair)

Prof. Dr. Robin Cowan

Dr. Michaela Vecchi (Middlesex University London) 


\section{Table of Contents}

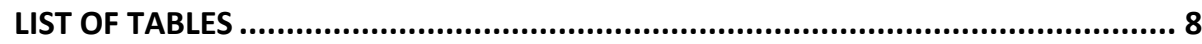

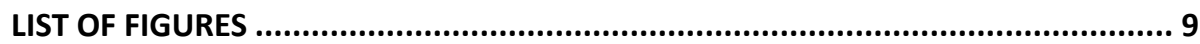

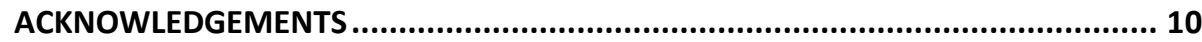

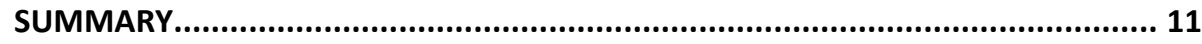

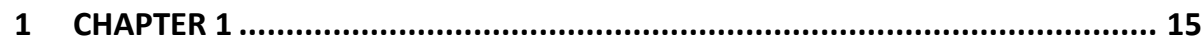

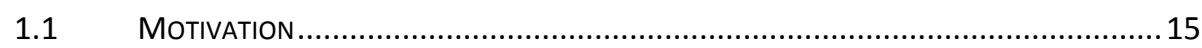

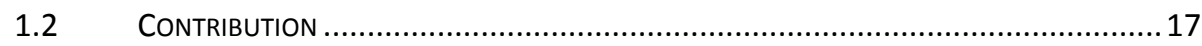

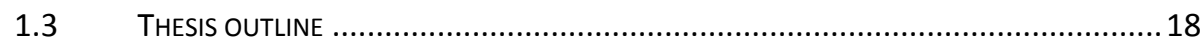

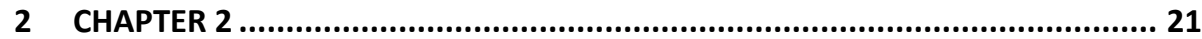

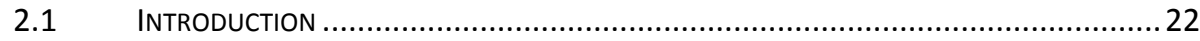

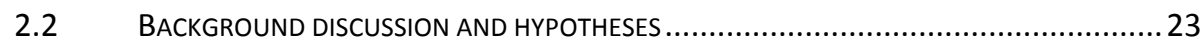

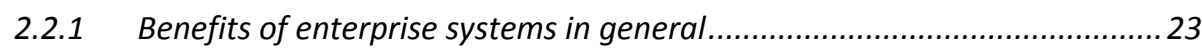

2.2.2 Complementarity between enterprise software applications .......................24

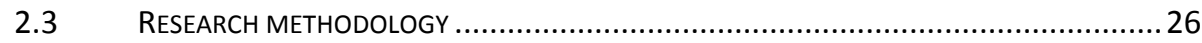

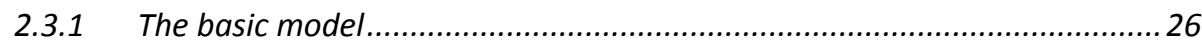

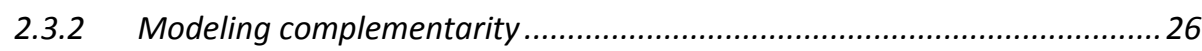

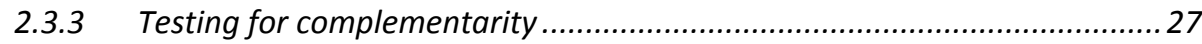

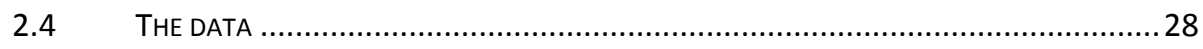

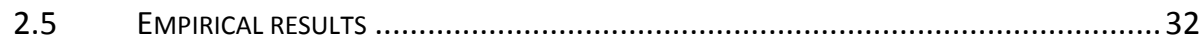

2.5.1 Returns to enterprise systems in general ................................................. 32

2.5.2 Complementarity and interaction between the enterprise systems .............35

2.5.3 Alternative procedure to test for complementarity.....................................37

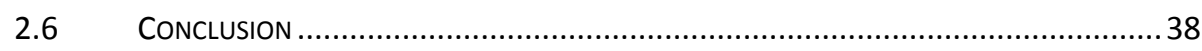

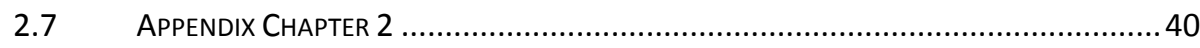

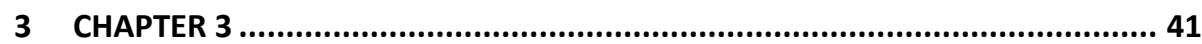

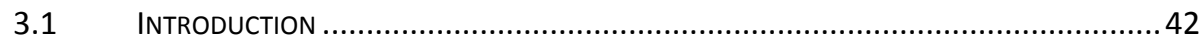

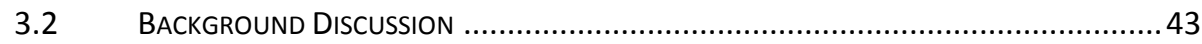

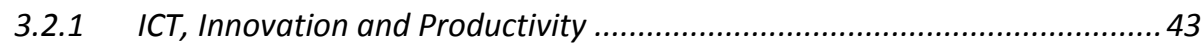

3.2.2 Earlier Research in Enterprise Systems....................................................4

3.2.3 Benefits of Enterprise Systems in general.............................................. 45

3.2.4 Effects of Enterprise Systems on Firms' Innovation Performance ................ 46

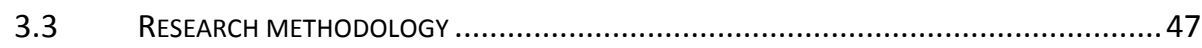




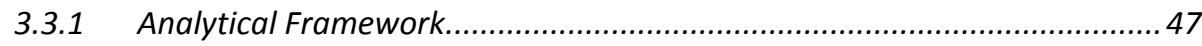

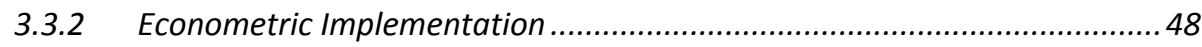

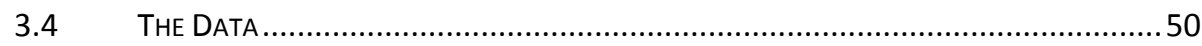

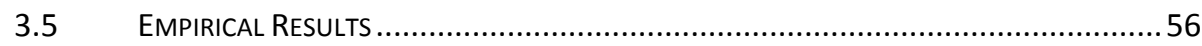

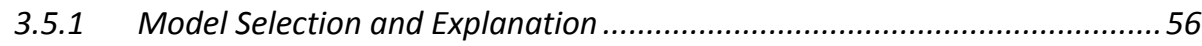

3.5.2 Impacts of Enterprise Systems on process innovations .............................. 58

3.5.3 Impacts of Enterprise Systems on product innovations.............................61

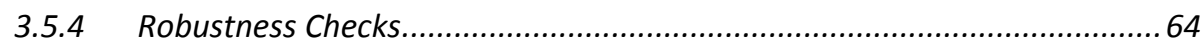

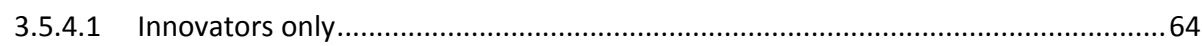

3.5.4.2 Alternative measurement of enterprise system usage ............................................66

3.5.4.3 Organizational practices and enterprise systems ..................................................67

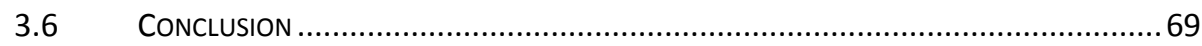

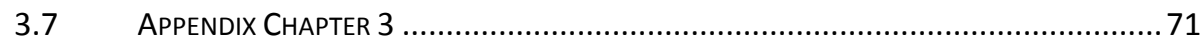

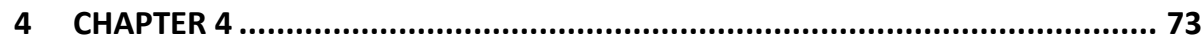

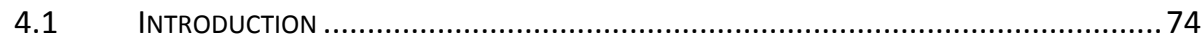

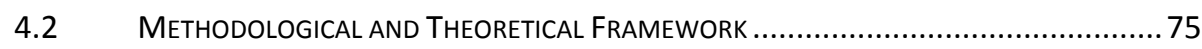

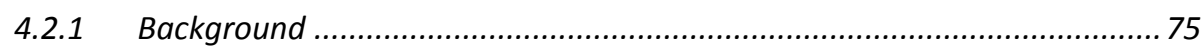

4.2.2 Service Innovations in General ................................................................ 76

4.2.3 Enterprise Software and Service Innovations ....................................... 77

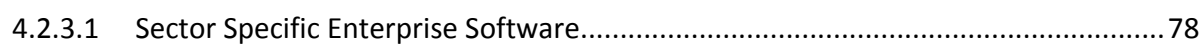

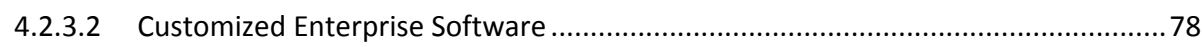

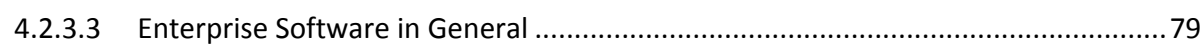

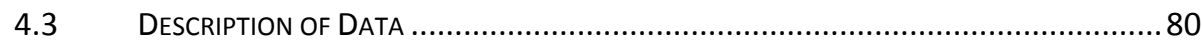

4.4 ANALYTICAL FRAMEWORK ANd ESTIMATION ProcEDURE....................................... 83

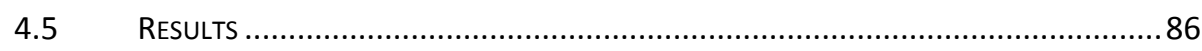

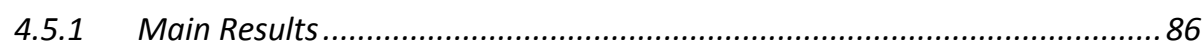

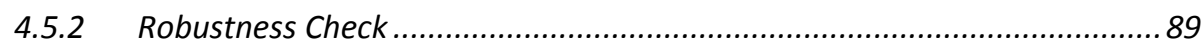

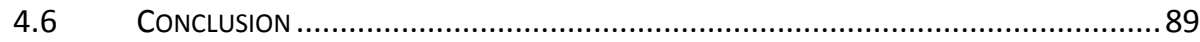

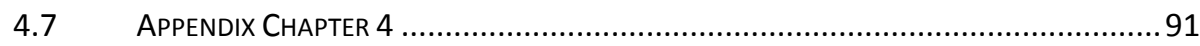

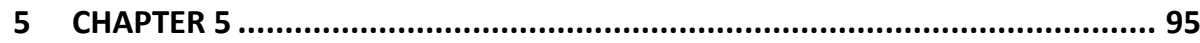

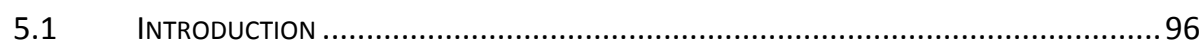

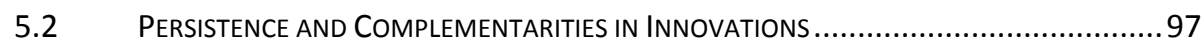

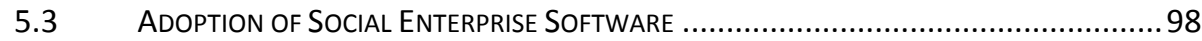

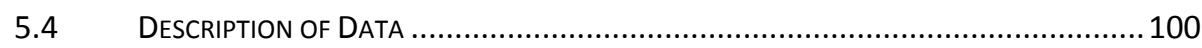

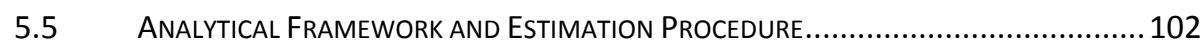

5.6 SELECTION OF EXOGENOUS VARIABLES AND EXCLUSION RESTRICTION ........................ 103

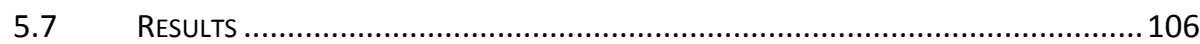




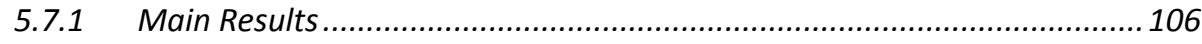

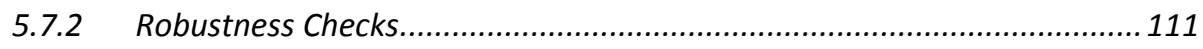

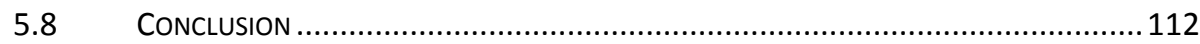

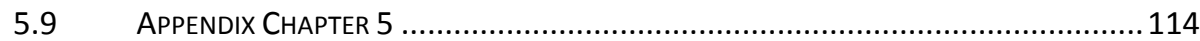

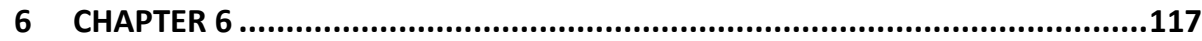

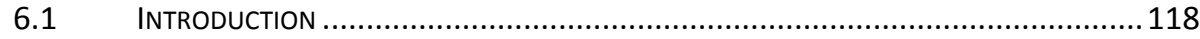

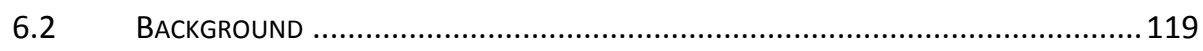

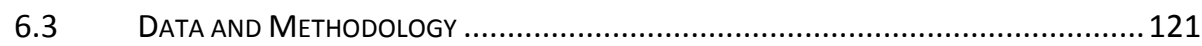

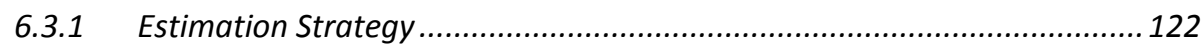

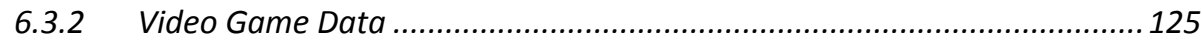

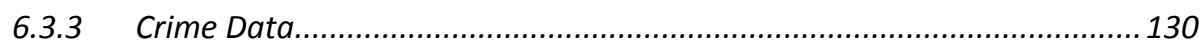

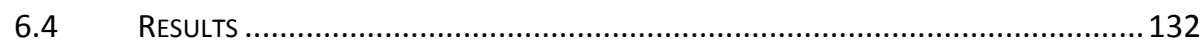

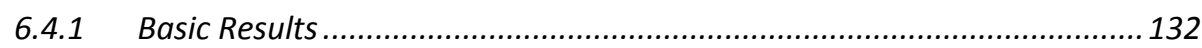

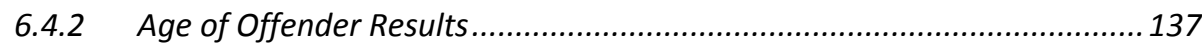

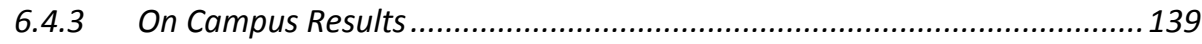

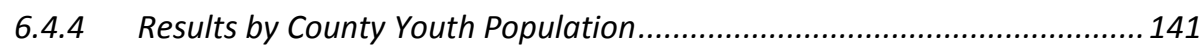

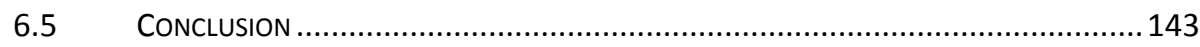

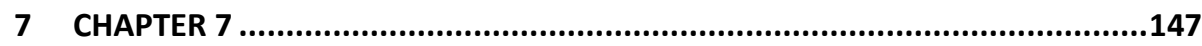

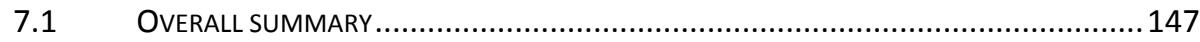

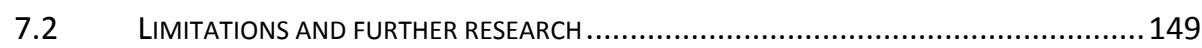

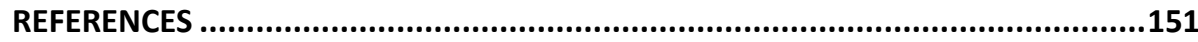

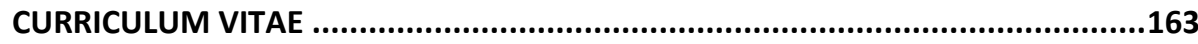




\section{List of Tables}

Table 2.1: Summary statistics 30

Table 2.2: Means and shares for the enterprise systems 32

Table 2.3: Returns of enterprise systems evaluated individually 33

Table 2.4: Returns to enterprise systems 34

Table 2.5: Returns to enterprise systems - interaction between the systems $\quad 37$

Table 2.6: Multiple restrictions test for complementarity 38

Table 2.7: Distribution of the combinations of enterprise systems 40

Table 2.8: Distribution of enterprise systems usage (in percent) 40

Table 3.1: Summary statistics

Table 3.2: Descriptive analysis $\quad 55$

Table 3.3: Determinants of the number of process innovations, zero-inflated neg. binomial estimates $\quad 60$

Table 3.4: Determinants of the number of product innovations, zero-inflated neg. binomial estimates 63

Table 3.5: Robustness check - Innovators only 65

Table 3.6: Robustness check - Alternative measurement of enterprise system $\begin{array}{ll}\text { usage } & 67\end{array}$

Table 3.7: Robustness check - Interaction effects 69

Table 3.8: Distribution of enterprise systems usage $\quad 71$

Table 4.1: Summary Statistics 83

Table 4.2: Probit Estimation Results: Average Marginal Effects 88

Table 4.3: Distribution of Industries in the Sample 91

Table 4.4: Probit Estimation Results: Coefficient Estimates 92

Table 4.5: Probit Estimation Results: Average Marginal Effects, Reduced Sample 93

Table 5.1: Summary Statistics 106

Table 5.2: Bivariate Probit with Sample Selection: Coefficients Estimates 108

Table 5.3: Bivariate Probit with Sample Selection: Average Marginal Effects $\quad 110$

Table 5.4: Probit with Sample Selection: Coefficient estimates, ID robustnesscheck, Specification 2

Table 6.1: Unit Sales of Video Games (millions) from VGChartz and ESA 126

Table 6.2: The Effect of Game Quality (Game Spot Score) on Log Sales 129

Table 6.3: Summary Statistics 132

Table 6.4: The Effects of Video Game Sales on the Log of both Violent and NonViolent Crime 134

Table 6.5: The Effects of Video Game Sales on the Log of Violent Crime 136

Table 6.6: The Cumulative Effect of Video Games on Crimes 137 
Table 6.8: Effect of Video Games by Campus Location $\quad 140$

Table 6.9: Effect of Video Games by Youth Fraction of County Population

\section{List of Figures}

Figure 1: Number of Process Innovations - Histogram.........................................5 54

Figure 2: Number of Product Innovations - Histogram.............................................. 54

Figure 3: Usage of Enterprise Software and Service Innovation .............................. 82

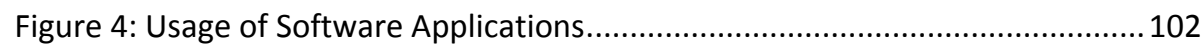

Figure 5: Number of Weeks a Game is in the Top 50 Sellers...................................126

Figure 6: Average US Video Game Unit Sales by Weeks after Release ....................127

Figure 7: Weekly Sales of Video Games ................................................................. 128

Figure 8: Total and Violent Crimes by Week ........................................................... 131 


\section{Acknowledgements}

I thank Irene Bertschek, Daniel Cerquera, Francois Laisney, Marina Rybalka and Michael R. Ward as well as my colleagues at the ZEW ICT Department, numerous conference participants and several anonymous reviewers for helpful comments and suggestions. I am also much obliged to my reviewers Martin Carree, Michela Vecchi and Robert Cowan for their helpful remarks. I thank the ZEW for the provision of a fruitful research environment to complete my thesis. I also express my gratitude to my co-authors A. Scott Cunningham, Miruna Sarbu and Michael R. Ward for their long-term support and cooperation.

Special thanks go to my supervisor, Pierre A. Mohnen, who was always eager to help and to provide most helpful feedback.

I am deeply grateful to my family, especially my parents, my brother and my sisterin-law, for their on-going comprehension and never ending empathy and support which greatly helped me to complete this thesis. 


\section{Summary}

The research presented in this work explores, in two different settings, how the usage of contemporary information and communication technology (ICT), i.e. different forms of software, can change or influence the behavior of both firms and people. In the first setting, it analyzes whether firms become more productive or feature a more active innovation behavior if they rely on recent enterprise software applications. In brief, these so-called enterprise systems are company-wide suites of business software devoted to particular process integration across the value chain and encompass a wide range of software products supporting day-to-day business operations and decision-making. The thesis also sheds light on persistence in ICT innovations with ICT innovations measured as the adoption of sophisticated social enterprise software which links enterprise systems with recent social software applications like wikis, social networks and instant messaging. Moving beyond the firm level and into the public sphere, the research further explores how entertainment software, i.e. console video games, might incapacitate potential criminal offenders by hindering them to engage in criminal activity, that is, at least as long as they are playing.

The thesis features different strands of theory: the production and knowledge production function framework as well as persistence in innovations on the firm level and the General Aggression Model (GAM) for the aggregate level analysis of the economics of crime.

Overall, the study relies on three different unique data bases. Two of the data bases featured are surveys among German companies collected by the Centre for European Economic Research (ZEW) which the firm-level analysis in the chapters 2 to 5 builds on. The surveys are the "ICT survey" which is based on telephone interviews and the letter based survey among the "service providers of the information society".

The analysis of the economics of crime in chapter 6 is based on a dataset compiled from four different sources, each featuring data from the US. In brief, the dataset consists of the publicly available National Incident Based Reporting System capturing violent and non-violent crime incidents, the VGChartz-Website picturing console game unit sales, the Entertainment Software Rating Board providing age appropriateness rating and content classification for the featured games and the GamespotWebsite, which offers a quality rating for each game. 
The results on firm-level in chapters 2 to 5 reveal that the adoption of enterprise systems positively impacts productivity and innovation activity of firms. Also, different enterprise systems complement each other, with regard to their impact on productivity. As for innovation performance, more product focused enterprise systems enhance product innovation performance whereas inventory and supply focused systems positively impact process innovations. Furthermore, using customized enterprise software helps firms of the service sector to realize service innovations. In case of social enterprise software the results reveal persistence in ICT innovations along two channels, i.e., via the adoption of prior ICT innovations and prior process innovation success. The estimated correlations also offer weak evidence for complementarity between prior ICT innovations, prior process innovations and social enterprise software.

Exploring the determinants of crime the results show that an increase in non-violent games is associated with a decrease in overall crime as well as violent crime in particular. Intensely violent games appear to have no effect on crime rates. While violent video games may increase aggression, the intensity of time use associated with popular video games appears to disrupt the social determinants of crime, at least in the short to medium run. 


\section{Samenvatting}

Het in dit werk voorgesteld onderzoek behandelt in twee verschillende omgevingen, hoe het gebruik van hedendaagse informatie en communicatietechnologie (ICT), d.w.z. verschillende soorten software, het gedrag van zowel bedrijven als mensen kan veranderen of beïnvloeden. In de eerste omgeving wordt geanalyseerd of bedrijven productiever worden of een actiever innovatiegedrag vertonen als ze vertrouwen op recente bedrijfssoftware. Kort gezegd zijn deze zogenoemde bedrijfssystemen bedrijfsoverspannende reeksen business-software die gewijd zijn aan specifieke proces-integratie over de waardeketen en omvatten ze een ruim gamma softwareproducten die de dagelijkse gang van zaken en het beslissingsproces ondersteunen. Het proefschrift werpt ook een licht op de persistentie in de ICTinnovaties, waarbij de ICT-innovaties gemeten worden als de toepassing van complexe sociale bedrijfssoftware die de bedrijfsssystemen verbindt met recente sociale software-applicaties zoals wiki's, sociale netwerken en instant messaging. Het onderzoek verlaat daarop het bedrijfsniveau en begeeft zich in de openbare sfeer. Het verkent daar verder hoe entertainmentsoftware, meer bepaald videogames voor spelcomputers (consoles), verhindert dat potentiële misdadigers overgaan tot criminele activiteiten, of op zijn minst zolang als ze aan het spelen zijn.

Het proefschrift presenteert verschillende theoretische aspecten: het functionele kader van de productie en de kennisproductie komen aan bod, evenals de persistentie in innovaties op het bedrijfsniveau en het Algemene Agressiemodel (AAM) voor de volledige analyse van de economie van de misdaad.

In het algemeen is de studie gebaseerd op drie verschillende unieke databases. Twee van de gebruikte databases zijn enquêtes van Duitse bedrijven uitgevoerd door het Centre for European Economic Research (ZEW) waar de analyse op bedrijfsniveau van hoofdstuk 2 tot 5 op voortbouwt. De enquêtes bestaan uit de "ICTenquête" die gebaseerd is op telefonische ondervragingen en op de enquête per brief onder de "serviceproviders van de informatiegemeenschap".

De analyse van de economie van de misdaad in hoofdstuk 6 is gebaseerd op een gegevensset opgemaakt uit vier verschillende bronnen, die allemaal gegevens bevatten uit de V.S. Kort gezegd bestaat de gegevensset uit het openbaar beschikbare Nationaal Op Incidenten Gebaseerd Rapportsysteem ("National Incident Based Reporting System (NIBRS)") dat gewelddadige en niet-gewelddadige misdaadincidenten registreert, de VGChartz-website die de verkoop van spelconsoles weergeeft, het Entertainment Software Rating Board dat classificaties opstelt voor de 
leeftijdsgeschiktheid en de inhoud van de games in kwestie en de Gamespotwebsite, die een kwaliteitsbeoordeling geeft voor elke game.

De resultaten op het bedrijfsniveau in de hoofdstukken 2 tot 5 onthullen dat de toepassing van bedrijfssystemen een positieve impact heeft op de productiviteit en innovatie-activiteit van bedrijven. Verschillende bedrijfssystemen vullen elkaar bovendien aan op het vlak van hun impact op de productiviteit. Wat de innovatieprestatie betreft verbeteren bedrijfssystemen die meer op het product focussen de prestatie van de productinnovatie, terwijl systemen die meer op inventaris en levering focussen een positieve invloed hebben op procesinnovaties. Bovendien helpt het gebruik van op maat gesneden bedrijfssoftware bedrijven in de dienstverlening bij het realiseren van innovaties van hun diensten. In het geval van sociale bedrijfssoftware wijzen de resultaten op persistentie in de ICT-innovaties langs de twee kanalen, d.w.z., via de toepassing van eerdere ICT-innovaties en eerdere geslaagde procesinnovaties. De geschatte correlaties bieden ook zwak bewijs voor de complementariteit tussen eerdere ICT-innovaties, eerdere procesinnovaties en sociale bedrijfssoftware.

Bij het onderzoek van de misdaaddeterminanten tonen de resultaten dat een stijging in niet-gewelddadige games geassocieerd wordt met een daling in zowel de misdaad in het algemeen als in specifiek gewelddadige misdaad. Intens gewelddadige games lijken geen invloed te hebben op de misdaadcijfers. Hoewel gewelddadige videogames kunnen leiden tot stijgende agressie, lijkt de intensiteit van het tijdgebruik bij populaire videogames op zijn minst op korte en middellange termijn de sociale determinanten van misdaad te verstoren. 


\section{Chapter 1}

\section{Introduction}

\subsection{Motivation}

Several firms nowadays rely on enterprise systems, company-wide applications of business software, to support their day-to-day business activities or help in decision-making by providing crucial information as e.g., sales or cost figures, in time if needed. Common enterprise systems as Enterprise Resource Planning (ERP), Supply Chain Management (SCM) and Customer Relationship Management (CRM) are widespread throughout many industries in numerous areas around the world. Each of these software systems automates and accelerates business operations as supply management, inventory control, manufacturing scheduling, sales force automation or almost any other data-oriented management process. Following SAP, the largest global enterprise software vendor, the global market for all enterprise software applications amounts to roughly $\$ 110$ billion $2010^{1}$.

In general, there are several different types of enterprise systems as each could either be a generic application such as an enterprise resource planning system purchased in standardized form from a vendor, a software system or particular module specifically designed to fit one business sector or a completely customized unique application developed for a single firm in particular and adopted to its specific needs. In addition to enterprise systems, a new type of innovative enterprise software emerged in 2008 (Chess Media Group 2010) linking firms' social software applications with their established enterprise systems. This ICT innovation called social enterprise software (SES) is in general obtained as an upgrade for already implemented enterprise software. It offers a novel and remarkably rapid real-time information transfer, e.g. by combining business collaboration, content sharing and instant messaging into a single, easy-to-use interface. Today, 15 percent of companies engaged in business to business e-commerce already implemented SES. By 2014, this number is expected to grow up to 70 percent (Gartner 2012).

\footnotetext{
${ }^{1}$ See SAP presentation, available at:

http://www.sap.com/about/investor/presentations/pdf/WB_DB_London_8Sep2010.pdf.
} 
Enterprise systems commonly replace the firms' legacy software systems, usually poorly connected applications spread out all over the firm, which results in improvements in operational integration affecting the entire organization. In brief, ERP systems help towards automation of transactions, SCM systems lead to sophisticated real-time planning capabilities and CRM systems facilitate all aspects of customer relationship management. However, ERP and SCM systems might not only benefit efficiency but could also foster innovation activity as both systems reduce idle times and save data mining or can identify bottlenecks and shortages thereby providing information for process enhancements. In addition, as ERP and SCM systems allow for real time updates of all databases firms can compare and control the effects of process innovations. The database created by a CRM system, which features specific customer information and feedback, provides a useful source for product innovations. Most recent SES application enhance the management of relations with customer even further by tracking data out of customer surveys, feedback, reviews or user profiles on social networks or blogs. Based on this data firms should be able to identify new customers, new market segments and observe recent trends. SES packages also offer various communication channels fostering a two-way interaction between the companies and their customers thereby offering the customers a direct communication channel to the firm.

Overall, empirical analyses (e.g. Aral et al. 2006; Hendricks et al. 2007; Hitt et al. 2002) confirm that enterprise systems positively impact firm performance. However, performance benefits based on potential complementary advantages resulting from the adoption of different enterprise systems in combination are still not investigated as most analyses put an exclusive focus on one single system (e.g. Dehning et al. 2007; Hitt et al. 2002; Nicolaou 2004) disregarding potential complementarities. Besides fostering firm performance the usage of information and communication technology (ICT) applications is also suspected to enhance firms' innovation performance (Brynjolfsson and Sanders 2010; Hempell and Zwick 2008). However, a potential impact of enterprise systems on innovation performance in particular is still not investigated. Based on recent German firm level data gathered in two independent surveys ${ }^{2}$ conducted by the Centre for European Economic Research (ZEW) the thesis will shed light on both, the potential complementarities among enterprise systems in their impact on firm performance and the impact of enterprise on the firms' innovation activity. As for the innovation activity product, process as well as service innovations are concerned. For SES, on the other hand, there is nearly no data available as this technology is still in its infancy state. Without sufficient data the benefits of SES for adopting firms are not directly measurable. However, as SES

\footnotetext{
${ }^{2}$ The surveys are briefly explained in section 1.3. In depth descriptions of each survey are part of each corresponding chapter.
} 
represents a most recent ICT innovation information about its adoption allows to check for persistence in ICT innovations.

Overall, software applications are not only affecting firms as many applications like social software or video games are widely used in private households as well. Especially video games face a growing policy interest as there is evidence that continued exposure to violent virtual depictions desensitizes gamers to actual violence (Anderson et al. (2007)). The desensitization of gamers by violent video games has been documented extensively in experimental trials and largely support the conclusion that exposure to violent video games increases the viewer's measured aggression. Based on this evidence it is suspected that the rise in violent video games could have caused acts of even extreme aggression, such as crimes, homicide or even High School shootings (Anderson 2004).

Despite psychological aspects of violent video games potentially changing the behaviors of gamers typical video game play also consumes time as playing typically involves hours of attention. This time use effect tends to crowd out other activities, including those linked to aggression as video gamers voluntarily incapacitate themselves while playing. With a suspected time use and behavioral effect the net effect of violent games on crime is ambiguous. Overall, the time gamers consume while playing violent games may reduce violent crime in ways that laboratory experiments are not designed to reveal as they do not incorporate time use into the research design. Accordingly, they may lack external validity for inferring the effects of violent games on crime. Based on recent US data the thesis explores the net effect of violent video games on crime and disentangles this effect into a behavioral and a time use part.

\subsection{Contribution}

Exploring the impacts of recent software applications on firms and the public alike the thesis contributes to several different literature strands, i.e. the impact of enterprise software systems on firm performance and innovation, the adoption of recent ICT, the determinants of crime and the analysis of violence in media.

The chapters 2 to 4 contribute to understanding the performance impacts of enterprise systems. Based on recent German firm level data collected by the ZEW, the analysis in chapter 2 confirms the expected positive impacts of enterprise software applications on labor productivity as pictured in, e.g., Shin (2006) or Aral et al. (2006) and shows that parts of this impact are realized via complementarities between different enterprise systems. Chapter 3 and 4 enrich the traditional analyses of performance impacts by a new dimension as the analyses introduce innovation as 
a performance measure. Using two different surveys among German firms conducted by the ZEW as data bases the analyses in both chapters show that established enterprise software systems increase the firm's innovative activity and innovative performance.

Even with the performance impacts of particular ICTs, i.e. enterprise systems, confirmed it still remains unclear if there is persistence in ICT innovations. Contributing to the literature of persistence in innovations chapter 5 of the thesis explores persistence in a very particular type of ICT innovations, i.e. the adoption of SES. Relying on a survey among German firms conducted by the ZEW as dataset for a firm-level analysis, the results confirm persistence in ICT innovations along two channels, i.e., via the adoption of prior ICT innovations and prior process innovation success.

Chapter 6 uses US crime data matched with publicly available information of video game sales and content to analyze the possible impact of video game play on crimes. As the data allows identifying the grade of violence in each game the analysis not only contributes to the literature exploring the determinants of crime, but can also analyze the impact of violence in media on the behavior of individuals, i.e. offenders in this case. In addition to the effects of movies (Dahl and DellaVigna, 2009) or football games (David and Dahl, 2011) on the number of crimes the results confirm that non-violent video game play is also associated with a reduction in the number of crimes. A reason for this might be that the voluntary incapacitation gamers subject themselves to while gaming captures their attention to such an extent that keeps them from doing anything else like, e.g., committing crimes. However, the results suggest that violent video game play has no effect on crime rates. This indicates that there may be a behavioral effect towards more aggression induced from violent video games as proclaimed in, e.g., Anderson and Bushman (2002). However, this effect seems to be dominated by the time use effect.

\subsection{Thesis outline}

This thesis features six additional chapters. Each chapter except the last one presents a specific analysis as outlined before and features an introduction, a literature analysis, model specifications and data descriptions. A section reporting the estimation results and a conclusion form the end of each chapter. Chapters 2 to 5 present the firm-level analyses described above. These analyses are based on two different surveys among German companies conducted by the ZEW between 2004 and 2010. Specifically, the surveys are the ICT survey based on telephone interviews with about 4000 companies and the letter based survey among the "service providers of the information society" targeting up to 6000 companies. 
On firm-level, the results show that the usage of enterprise systems positively impacts the productivity, the innovation activity and the innovative performance of firms. Also, regarding their impact on productivity, different enterprise systems perform as complements resulting in a higher productivity increase if the systems are adopted in concert. Concerning innovation performance, resource and supply focused systems positively impact process innovations while more product focused enterprise systems enhance the firms' product innovation performance. Also, firms of the service sector seem to be more likely to realize service innovations if they use customized enterprise software. As for persistence in ICT innovations the results confirm that persistence occurs along the two channels prior process as well as prior ICT innovations.

In chapter 6 the analysis moves on to the aggregate level exploring the impact of video games with and without violent content on violent and non-violent crimes. This analysis is solely based on publicly available data consisting of the National Incident Based Reporting System reporting violent and non-violent crime incidents, the VGChartz-Website collecting console game unit sales, the Entertainment Software Rating Board providing age appropriateness rating and content classification for the featured games and the Gamespot-Website which offers a quality rating for each game. The results of the analysis in chapter 6 reveal that an increase in nonviolent games is associated with a decrease in overall crime and violent crime in particular. However, intensely violent games seem to not affect crime rates at all.

Chapter 7 concludes providing an overall summary of the results and pointing out limitations. This chapter also briefly discusses opportunities and directions for further research. 



\title{
Chapter 2
}

\section{Enterprise Systems and Labor Productivity: \\ Disentangling Combination Effects $^{\S}$}

\begin{abstract}
This study analyzes the relationship between labor productivity and the three widely established enterprise software systems, i.e. Enterprise Resource Planning, Supply Chain Management and Customer Relationship Management, revealing performance gains incurred through the varying combinations of the systems with an exclusive focus on complementarities and interactions among them. Using German firm-level data, the results show that the highest productivity gains based on enterprise system usage are realized through the use of the three enterprise software systems in concert and not by relying on one or two of the systems alone. Concerning complementarity the results indicate that Supply Chain Management and Customer Relationship Management function as complements if the firms already have an Enterprise Resource Planning System running or get the system in conjunction. The results stay robust to different model specifications and complementarity testing procedures.
\end{abstract}

Keywords: Labor Productivity; Enterprise Systems; Complementarity; Enterprise Resource Planning; Supply Chain Management; Customer Relationship Management JEL Classification: C00, D24, M20.

\footnotetext{
$\S$ This Chapter is accepted for publication in International Journal of Engineering Research and Applications.
} 


\subsection{Introduction}

Enterprise systems, company-wide suites of business software devoted to particular process integration across the value chain, encompass a wide range of software products supporting day-to-day business operations and decision-making. The three main enterprise systems, Enterprise Resource Planning (ERP), Supply Chain Management (SCM) and Customer Relationship Management (CRM), serve many industries in numerous areas. They are designed to automate operations from supply management, inventory control, manufacturing scheduling or sales force automation and almost any other data-oriented management process. In 2006, the global market for ERP systems accounts for approximately \$29 billion (Jacobsen et al. 2007). SAP, the largest global enterprise software vendor, estimates the addressable market for all enterprise software applications to be roughly $\$ 110$ billion $2010^{3}$.

Enterprise systems are often adopted to replace the usually poorly connected legacy software and are expected to reduce infrastructure support costs (Hendricks et al. 2007). These support costs originate from the need for costly programmed interfaces to connect legacy applications. Also, costs might occur in form of waiting time since legacy software is generally not efficiently programmed and therefore requires more time to execute orders compared to enterprise systems. In line with this legacy software can be expected to face more downtimes than enterprise systems based on its inefficient programming code. In addition, improvements in operational integration realized through enterprise software can affect the entire organization and therefore might positively affect firm performance. ERP systems provide benefits in the area of transaction automation, SCM systems lead to more sophisticated planning capabilities and CRM systems simplify customer relationship management.

Although many studies (e.g. Aral et al. 2006; Hendricks et al. 2007; Hitt et al. 2002) argue that adopted enterprise systems, in general, positively impact firm performance, performance benefits based on potential complementarity driven advantages resulting from the usage of different enterprise systems in combination are still not investigated. Overall, the majority of the existing analysis lays an exclusive focus on the adoption of a single system (e.g. Dehning et al. 2007; Hitt et al. 2002; Nicolaou 2004), thereby completely disregarding these complementarity based performance gains. This focus might turn out to produce biased results as enterprise systems nowadays are often adopted in concert and are expected to interact, complement or in rare cases even substitute each other to some extent.

\footnotetext{
3 SAP Presentation, available at http://www.sap.com/about/investor/presentations/pdf/WB_DB_London_8Sep2010.pdf. Accessed 1 December 2011
} 
The goals of this study therefore are to disentangle the performance effects attributed to the combinations and interactions of enterprise systems using a unique database consisting of German firms from the manufacturing industry and from service sectors.

Based on a production function approach, the results provide empirical evidence about the productivity gains resulting from the use of enterprise system usage with respect particularly to the interacting nature of the systems. Contrary to former analysis, the highest productivity gain is achieved by using all three enterprise systems in concert. In addition, a complementary relationship between SCM and CRM is revealed once an ERP is also in use or acquired in conjunction. The results imply that analyzing the influence of the enterprise systems independently, whereby one disregards possible benefits stemming from the combination of systems, turns out to be insufficient for depicting the performance effects of enterprise software.

The study proceeds as follows. Section 2.2 gives an overview of the literature and derives hypotheses. Section 2.3 pictures the basic model and covers the issues concerning complementarity. The dataset is presented in section 2.4 whereas section 2.5 contains the estimation results. Section 2.6 concludes.

\subsection{Background discussion and hypotheses}

\subsubsection{Benefits of enterprise systems in general}

ERP systems replace complex interfaces between different systems with standardized cross-functional transaction automation. They use a source of data that integrates enterprise functions such as sales and distribution, materials management, production planning, financial accounting, cost control and human resource management (Aral et al. 2006). By using an ERP system, order cycle times can be reduced, which might lead to improved throughput, customer response times and delivery speeds (Cotteleer and Bendoly 2006; McAfee 2002). In addition, cash-tocash cycle times and the time needed to reconcile financial data at the end of the quarter or year can be reduced through automated financial transactions (Mabert et al. 2000). With an ERP system, all enterprise data is collected once during the initial transaction, stored centrally and updated in real time. This ensures that all levels of planning are based on the same data, allowing the resulting plans to realistically reflect the prevailing operating conditions of the firm (Hendricks et al. 2007). All in all, standardized firm-wide transactions and centrally stored enterprise data greatly facilitate the governance of the firm (McAfee and Upton 1996; Scott and Vessey 2000). Providing managers with clear oversight of the relative performance of different parts of the company, ERP reports can be used to identify necessary improvements and to take advantage of market opportunities (Mehrjerdi 2010). 
IT-based SCM systems coordinate and integrate the flow of information, materials and finances along the value chain and enhance operational and business planning (Dehning et al. 2007). With the real-time planning capabilities offered by SCM systems, firms can react quickly to supply and demand changes and are able to serve customers in a timely and comprehensive fashion (Cachon and Fisher 2000; Hendricks et al. 2007). In addition, SCM systems can directly improve inventory management by reducing inventory levels, holding costs, spoilage and lead times. This results in increased profitability by reducing costs, avoiding lost sales and improving customer satisfaction (Cachon and Fisher 2000). SCM systems may also have indirect effects on firm performance due to lower coordination, sales, general and administrative costs as well as improved decision-making or forecasting (Dehning et al. 2007).

CRM is a synthesis of customer focused management and many existing principles from relationship marketing (Jancic and Zabkar 2002; Morgan and Hunt 1994; Sheth et al. 2000). The key focus of CRM systems is to facilitate the creation of long-term relationships with customers by providing the appropriate infrastructure, e.g., enabling effective sales force automation, centralized customer data warehousing and data mining paired with decision support and reporting tools (Engelstätter 2012a). Offering a complete view of customer needs and wants, a CRM system is also expected to lead to superior customer loyalty, reduced cost of sales and services and improved bottom-line profits (Chen 2001). In addition, a CRM system reduces duplication in data entry and maintenance by providing a centralized firm-wide database of customer information. This database replaces systems maintained by individual sales people, institutionalizes customer relationships, prevents the loss of organizational customer knowledge when sales staff leaves the firm and can reduce costs by streamlining repetitive transactions and sales processes (Cohen et al. 2006; Hendricks et al. 2007).

\subsubsection{Complementarity between enterprise software applications}

As the three main enterprise systems show many linkages among each other, this section will cover the possible combinations of enterprise systems and their special interactions separately. For instance, the integrated data, processes and interfaces provided by an ERP system, facilitate the effective implementation of supply chain activities. This planning of internal production activities through the ERP system can be directly influenced or automated by information inputs from supply chain partners via use of an SCM system (Aral et al. 2006). The two-way information exchange between ERP and SCM systems enables companies to optimize processes across the product lifecycle. Based on the rapid data transfer between these two enterprise systems information about resource usage and product life cycles can be accessed 
by correspondent employees in real time as needed. Based on this information room for process improvements and product enhancements is easy to identify (Engelstätter 2012a). Especially the usage of best-of-breed SCM applications with ERP, as opposed to relying on the innate SCM functionality of some ERP systems, provides firms with specialized SCM features which could even forecast expected supply and demand. Accordingly, firms that use the advanced features of SCM systems in conjunction with ERP systems are expected to realize complementary benefits and a higher firm performance as it is argued in Wieder et al. (2006).

The centralized customer data provided by CRM systems can be used as source for ERP systems and is particularly valuable to the management of multiple product lines are managed (Hendricks et al. 2007). The flow of information between the two systems will, generally, ease the firms' data management effort as the shared information avoids redundant data keeping. In addition, the CRM system can utilize the data mining capabilities of ERP systems and data warehousing to reveal profiles of key customers, customer profitability and purchasing patterns (Conlon 1999). Companies might also gain additional insights into customer orders, contracts and buying behaviour if they use ERP applications in conjunction with CRM systems, possibly allowing them to establish more focused sales and marketing strategies based on in-depth analysis of customer behaviour, interests and context. Hence, deploying ERP systems in conjunction with CRM systems should, based on complementary benefits, increase a firms' performance.

A firm can utilize the insights into customer behaviour and demand patterns provided by a CRM system to streamline manufacturing and distribution, if the CRM system is connected with the firm's SCM applications. Especially information on customer segmentation can provide advice for the structuring of the purchase of raw materials, scheduling manufacturing, managing inventory and running of the supply chain in general, possibly resulting in reduced costs. A streamlined supply chain based on connected CRM and SCM systems is key for reaching out to the right customer at the right time and should benefit the company additionally through improved resource allocation potentially reducing inventory stocks. In this context, Mithas et al. (2005) reveal that firms are more likely to benefit from CRM systems if they have a greater supply chain integration, e.g. based on an SCM system already installed. Therefore, using SCM and CRM systems in conjunction can be expected to increase firm performance based on a complementarity relationship.

According to (Charkari and Abdolvand 2004), the isolated use of SCM or CRM systems separately might result in missed opportunities and poor performance. To put it short, ERP systems generally determine the business processes, the two other applications optimize these business processes in a specific area, especially by link- 
ing the front office of the enterprise, e.g., sales, marketing, customer services, with the back office, e.g., operations, logistics, financials, human resources. As an example showing the linkages between the three applications, let a company be supposed to deliver an order to ten clients the next day. The SCM solution now calculates that the company can only deliver to five customers in the given time span, the ERP can then pull the data from the CRM system to determine which orders should be fulfilled (Horwitt 2009). In conclusion, it can be expected that firms using all three main enterprise systems will probably realize larger productivity increases compared to those companies which rely on less enterprise software applications or no enterprise systems at all.

\subsection{Research methodology}

\subsubsection{The basic model}

Following e.g. Aral et al. (2006) or Hitt et al. (2002), a production function specification is used to estimate the effects of enterprise system usage on firm performance. Throughout this paper I use the performance measure labor productivity $Y_{i} / L_{i}$, i.e. sales over employees. The inputs are capital $\left(K_{i}\right)$, labor $\left(L_{i}\right)$ and other firm characteristics. These additional characteristics, e.g., enterprise software adoption $\left(E S_{i}\right)$, capture differences in performance and can simply be added to the production function in its log-log form (Hitt et al. 2002). The coefficients of these added terms can then accordingly be interpreted as percentage differences in productivity. In case of software adoption, the coefficient captures the enterprise software's effect on firmlevel productivity other things being equal (Shin, 2006). Besides software adoption I control for East German heritage, industry sector and for ICT capital captured in $X_{i}$. The according production function in its log-log form results in:

$$
\ln \left(Y_{i} / L_{i}\right)=c+\alpha \ln \left(K_{i}\right)+B \ln \left(L_{i}\right)+\gamma E S_{i}+\delta X_{i}+\varepsilon_{i}
$$

\subsubsection{Modeling complementarity}

Taking the potential complementarity between the enterprise software systems into account, this section outlines the definitions and conditions regarding complementarity and substitutability for the cases of discrete practices. Throughout this paper, each practice represents the use of a different enterprise system. Complementarity is defined as in Baumol et al. (1988) and Athey and Stern (1998) ${ }^{4}$ :

\footnotetext{
${ }^{4}$ This definition is also referred to as strict supermodularity (Milgrom and Roberts 1990) and is equal to complementarity in the conventional sense of scope economics (adoption of practice B strictly increases the marginal returns of adoption of practice $A$ ). If supermodularity is not defined strictly, it fails to exclude the possibility that practice $B$ has no impact on the returns to practice $A$.
} 
Practices $x_{i}$ and $x_{j}$ are considered complementary in the function $f$ if and only if $\partial^{2} f /$ $\partial x_{i} \partial x_{j}$ is always larger or equal to zero, and larger than zero for at least one value of $\left(x_{1}, \ldots, x_{n}\right)$.

Following (Carree et al. 2007), an objective function $f$ is considered as a starting point. The value of $f$ is determined by the practices $x_{p}=(p=1, \ldots, n)$ with $\mathrm{n}=3$ in the present case of enterprise software system usage. A cross-term specification of the objective function $f$ allows testing for complementarity or substitutability. This implies the following expression for $n$ equal to 3 :

$$
f\left(x_{1}, x_{2}, x_{3}\right)=\vartheta_{0}+\vartheta_{1} x_{1}+\vartheta_{2} x_{2}+\vartheta_{12} x_{1} x_{2}+\vartheta_{3} x_{3}+\vartheta_{13} x_{1} x_{3}+\vartheta_{23} x_{2} x_{3}+\vartheta_{123} x_{1} x_{2} x_{3}
$$

In the present case of observed enterprise system usage, the practices are measured dichotomously, i.e. variables take the value one if the practice is used and zero otherwise. In that case, function (2) can be conveniently rewritten in terms of possible combinations of practices (Mohnen and Röller 2005). The collection of possible combinations considering three practices is defined in the usual binary order as $D=$ $\{(0,0,0),(1,0,0),(0,1,0),(0,0,1),(1,1,0),(1,0,1),(0,1,1),(1,1,1)\}$, with the indicator function for three practices $I_{D=(r, s, t)}$ being equal to one whenever the combination is $(r, s, t)$ and zero otherwise. The function $f$ can accordingly be rewritten as:

$$
f\left(x_{1}, x_{2}, x_{3}\right)=\sum_{r=0}^{1} \sum_{s=0}^{1} \sum_{t=0}^{1} \lambda_{r s t} I_{\left(x_{1}, x_{2}, x_{3}\right)=(r, s, t)}
$$

The conditions of pairwise complementarity between practice 1 and 2 then correspond to $\vartheta_{12}=\lambda_{110}+\lambda_{000}-\lambda_{100}-\lambda_{010} \geq 0$ and $\vartheta_{12}+\vartheta_{123}=\lambda_{111}+\lambda_{001}-\lambda_{101}-\lambda_{011} \geq 0$, with at least one inequality holding strictly. Similar inequalities apply for the pairs $(1,3)$ and $(2,3)$. For substitutability, the inequalities are reversed.

\subsubsection{Testing for complementarity}

The most established and convenient method to check for complementarity, even for discrete practices, is the standard interaction term approach as proposed in Athey and Stern (2002). Alternatively, one can use a Wald type test based on a minimum distance estimator derived in Mohnen and Röller (2005) to verify a complementarity relationship. For this purpose, two independent tests are conducted which test separately for complementarity and substitutability. Carree et al. (2007) advanced this method and derived a test which decides between complementarity and substitutability in one run. Their multiple restrictions test uses a Likelihoodratio test procedure which specifically tests for the two inequalities derived above 
but faces a computational demanding test-statistic. As the test-statistic follows a mixed chi-square distribution under the null hypothesis of no complementarity or no substitutability, exact $p$-values need to be computed using specific weights (Shapiro 1985). A first appliance of this test in empirical analysis can be found in Belderbos et al. (2006). As the likelihood-ratio test approach is most recent and has not been tested in several different settings and simulation I stick to the well established interaction terms as a baseline in the empirical analysis employing the likelihood-ratio test merely as robustness check.

\subsection{The data}

This study is based on a dataset resulting from two computer-aided telephone surveys conducted in 2004 and 2007 by the Centre for European Economic Research (ZEW). These surveys laid a specific focus on the use and diffusion of ICT in German firms. The interviewee was, in general, the chief executive officer of the companies who could also pass on questions to a corresponding employee such as, e.g., the head of the ICT department. Each wave of this ICT-dataset originally contained information of about 4,000 firms with five or more employees which were representatively chosen from important service and manufacturing sectors in Germany. The data basis for the sample originates from the credit rating agency Creditreform. This agency offers the largest data base on firms available in Germany. Creditreform collects some basic information like address, sector and firm size on all enterprises that ever applied for a bank credit. The selection from the population of German firms was stratified according to three size classes, to industries (seven branches of the manufacturing industry and seven selected service sectors) and to two regions (East/West Germany). As many firms as necessary were asked until all strata were filled.

Besides detailed information on the use of ICT, the dataset contains additional information about total sales, the firms' workforce, the total investments and various other variables. The questionnaire also covered the usage level of the three main enterprise software applications ERP, SCM and CRM. The level of usage could be none, minor or broad ${ }^{5}$. Minor usage could be referring to software which is only employed by a small number of employees, departments or subsidies whereas broad usage might describe software packages in use by the entire firm (Engelstätter 2012a). However, the questionnaire did not make any distinctions between these categories and provides no additional explanations for minor and broad usage. Without additional information, an interpretation of a productivity effect due

\footnotetext{
${ }^{5}$ The exact wording of the questions covering the enterprise systems and the detailed distribution of all answering options are outlined in the appendix in Table 2.8 .
} 
to minor software use in comparison to no or broad usage cannot be illustrated appropriately. Accordingly, I constructed a dummy variable for the use of each software application, which takes the value one if a firm uses the software at least to a minor degree or broadly and zero otherwise.

The survey in 2007 covers total sales and the number of employees for 2006 only. However, the answers on enterprise system usage in that survey relate to the year 2007. Since the survey is organized as a panel dataset, I use the software usage level reported in 2004 to construct the dummy variables necessary. This two-year difference between software use and firm performance forms a well-defined temporal sequence which should be adequate to measure the productivity effects of enterprise systems, given that multiple analyses concluded that enterprise software needs about two years to generate some kind of performance effect (e.g. Matolcsy et al. 2005; Nicolaou 2004; Nicolaou et al. 2003).

Due to panel mortality and item-nonresponse, matching the data for the two periods results in nearly 1,000 observations. By dropping the banking sector, I obtained 927 observations for my final data set. As there is no data available to measure the firms' physical capital stock, I follow e.g. Bertschek et al. (2006) and Hall et al. (2009) by using the gross investment figures as an empirical proxy for the capital stock. A potential problem with this method arises as some firms report zero investments in 2004, although the occurrence of zero investments is explained by Bond and Van Reenen (2007) and is therefore not surprising at all. However, with an econometric specification of the production function in logarithmic values for the factor inputs, these firms must be excluded from the final sample. To do away with this problem and to avoid losing further observations, I follow the approach used in Ohnemus (2007) and determine the value of investment for the firms reporting zero investments as the 10 percent quantile of their respective industry and size class ${ }^{6}$.

Table 2.1 shows the descriptive statistics for the variables of the production function estimation in this study. Table 2.1 also includes two additional variables, namely export activity and the existence of a works council which will be used for additional analysis in the next section. Sales, labor and the labor productivity ratio refer to the year 2006, all other inputs, like e.g. capital, refer to the year 2004. In addition, Table 2.1 also provides the descriptive statistics for the industry affiliations of the firms in the final sample.

\footnotetext{
${ }^{6} 71$ replacements were made.
} 
Table 2.1: Summary statistics

\begin{tabular}{|c|c|c|c|}
\hline Variable & Mean & Std. Dev. & $\mathrm{DV}^{4}$ \\
\hline Output (sales) & $46,667.2$ & $169,785.8$ & \\
\hline labor productivity ${ }^{1}$ & 192.2 & 229.7 & \\
\hline capital $^{2}$ & 2282.6 & 9843.0 & \\
\hline labor $^{3}$ & 245.7 & 916.5 & \\
\hline In (output) & 8.879 & 1.914 & \\
\hline In (labor productivity) & 4.891 & 0.811 & \\
\hline In (capital) & 5.366 & 2.230 & \\
\hline In (labor) & 3.987 & 1.644 & \\
\hline share of computer workers & 0.467 & 0.328 & \\
\hline East Germany & 0.273 & & yes \\
\hline export share & 0.557 & & yes \\
\hline works council & 0.368 & & yes \\
\hline consumer goods & 0.093 & & yes \\
\hline chemical industry & 0.052 & & yes \\
\hline other raw materials & 0.081 & & yes \\
\hline metal and machine construction & 0.118 & & yes \\
\hline electrical engineering & 0.076 & & yes \\
\hline precision instruments & 0.066 & & yes \\
\hline automobile & 0.073 & & yes \\
\hline complete manufacturing sector & 0.559 & & yes \\
\hline whole sale trade & 0.054 & & yes \\
\hline retail trade & 0.051 & & yes \\
\hline transport and postal services & 0.065 & & yes \\
\hline electronic data transfer & 0.097 & & yes \\
\hline technical services & 0.102 & & yes \\
\hline other business-related services & 0.073 & & yes \\
\hline Number of observations & \multicolumn{3}{|c|}{927} \\
\hline
\end{tabular}

Notes: ${ }^{1}$ Sales per employee (in 2006) in $€ 1,000 .{ }^{2}$ Capital is proxied by gross investment in $€ 1,000$. ${ }^{3}$ Labor is measured in amount of total employees. ${ }^{4}$ Dummy variable

Source: ZEW ICT survey 2004, 2007 and own calculations.

In 2006, mean sales amount to $€ 46,667,200$ and the average firm size results in 246 employees. For 2004, the mean investment is $€ 2,382,600$. The mean share of workers mainly using a personal computer for their work, as proxy for the ICT capital of the firm, is around 47 percent in the used sample. This ICT capital measure should be included in the estimation to reduce omitted variable bias, as working with a computer can be expected to positively impact productivity (Greenan and 
Mairesse, 1996; Astrostic and Nyugen, 2005). Nearly 27 percent of the firms are located in East Germany. Export activity is reported by 56 percent of the firms and 47 percent of the sample firms have established a works council. Regarding the industry affiliation of the firms, the largest share of 12 percent does business in metal and machine construction, whereas only a small number is associated with the wholesale or retail trade industry (5 percent each).

Table 2.2 provides the summary statistics for the dummy variables of enterprise system usage and shows additional statistics of the firms using these systems ${ }^{7}$. In addition, it lays a specific focus on the group of firms using either no enterprise systems at all or the full suite of enterprise systems. It is striking that around one quarter of firms (28 percent) in the sample use all three enterprise systems in concert or no enterprise software at all (24 percent). The use of ERP is widespread (64 percent), around 44 percent apply SCM software and about 51 percent of the firms have adopted CRM software. Providing initial descriptive evidence by comparing the average labor productivity for each group with the overall sample mean reported in Table 2.1, it stands out that the firms' labor productivity exceeds the average productivity of $€ 192.200$ once they adopt some kind of enterprise software. Especially firms using all three systems in concert achieve the highest average labor productivity, reaching $€ 234.200$. Unsurprisingly, companies using no enterprise systems at all seem to fall behind in terms of labor productivity ( $€ 167.000$ ). In addition, it seems to be the case that large firms choose to use all three systems together. These firms engage the services of an average of 566 employees, as shown in Table 2.2 However, as the available sample suggests smaller firms also seem to have confidence in the full suite of enterprise software applications as about 43 percent of the firms which use all three enterprise systems have 100 or less employees (not reported).

\footnotetext{
${ }^{7}$ In addition to the aggregated Table 2.2, Table 2.7 in the appendix reports the distribution of all possible combinations of enterprise systems for all firms. This disaggregated arrangement of dummy variables is used to conduct the complementarity testing based on the method of Carree et al. (2007).
} 
Table 2.2: Means and shares for the enterprise systems

\begin{tabular}{|c|c|c|c|c|c|}
\hline & No system & All systems & ERP & SCM & CRM \\
\hline Share of entire population & 0.236 & 0.278 & 0.636 & 0.442 & 0.513 \\
\hline \multirow[t]{2}{*}{ Labor Productivity Mean } & 167.0 & 234.2 & 205.6 & 217.1 & 204.8 \\
\hline & $(269.0)$ & $(245.8)$ & $(215.8)$ & $(219.8)$ & $(229.4)$ \\
\hline \multirow[t]{2}{*}{ Size Mean } & 43.1 & 566.3 & 359.5 & 441.3 & 357.8 \\
\hline & (70.1) & $(1605.1)$ & $(1132.1)$ & $(1319.7)$ & $(1229.6)$ \\
\hline share of manufacturing sector ${ }^{1}$ & 0.457 & 0.667 & 0.625 & 0.676 & 0.538 \\
\hline
\end{tabular}

Notes: Standard errors in parentheses. ${ }^{1}$ indicates the percentage of manufacturing firms among the firms which use a particular software system, e.g. $45.7 \%$ of the firms using no enterprise system at all stem from the manufacturing sector.

Source: ZEW ICT survey 2004, 2007 and own calculations.

\subsection{Empirical results ${ }^{8}$}

\subsubsection{Returns to enterprise systems in general}

Table 2.3 reports the basic estimation results, using the regression formulation described in equation (1). The firm-level labor productivity is regressed on production input variables and an indicator of each enterprise software application with additional controlling for industry and the geographical region of East Germany. As the current analysis focuses particularly on the impacts of enterprise systems on firm performance, I will discuss other factors influencing labor productivity only briefly. Overall, the input factors labor, capital and the share of computers per worker turn out to be highly significant at the one percent level in every single one of the following specifications, indicating a high impact of all three factors on labor productivity.

In order to provide a suitable baseline, I firstly introduce the three enterprise systems one by one in the production function estimation. Overall, I find that firms using ERP or SCM show greater performance in terms of labor productivity than firms without these systems. Both point estimates are statistically significant at the one percent level. For instance, the estimate of 0.152 in Column (1) of Table 2.3 indicates that ERP users demonstrate a greater labor productivity, averaging 15.2 percent above those firms which do not use ERP. Both coefficients show a similar order of magnitude, with SCM having the highest impact. The coefficient of CRM, on the other hand, turns out to be only weakly significant at the ten percent level as shown in Column (3).

\footnotetext{
${ }^{8}$ As a further robustness check to take care of potential large outliers all estimations are additionally conducted for a sample without large firms which have 500 or more employees (101 observations). The results stay qualitatively the same and are available from the Author upon request.
} 
Table 2.3: Returns of enterprise systems evaluated individually

Dependent Variable:

Labor Productivity

(1)

(2)

(3)

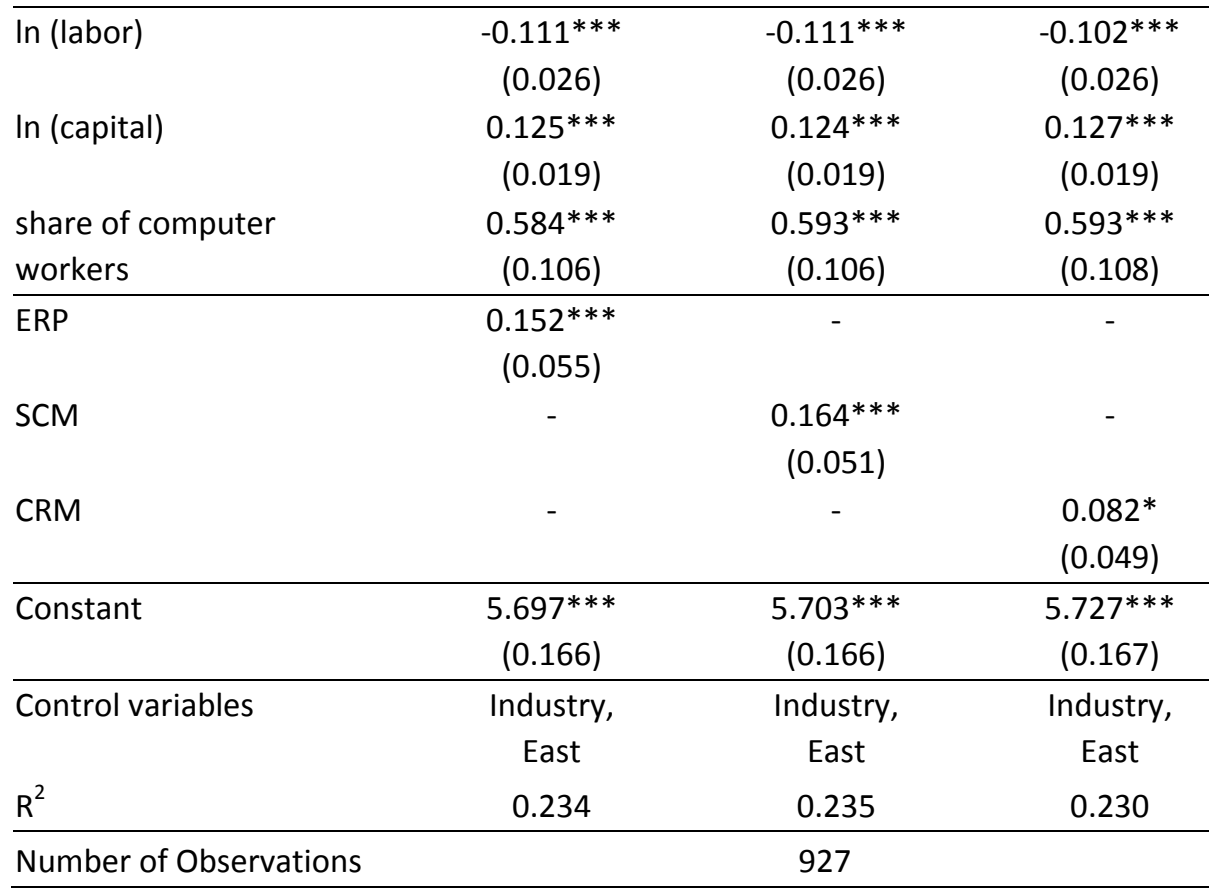

Notes: ${ }^{* * *} \mathrm{p}<0.01 ;{ }^{* *} \mathrm{p}<0.05 ;{ }^{*} \mathrm{p}<0.1$; robust standard errors in parentheses.

Source: ZEW ICT survey 2004, 2007 and own calculations.

As all three systems are expected to contribute to performance enhancement, omitting one of them could upwardly bias all the returns of the observed one (Aral et al. 2006). In order to check for this potentially omitted variable bias and to give a first insight of the interacting nature of enterprise systems, Table 2.4 reports the regression results taking all possible combinations of enterprise systems into account. If the assumption of omitted variable bias is true, one would expect a decrease in significance and in the size of the coefficients ${ }^{9}$ once all enterprise systems are integrated together in the regression. Overall, ERP and SCM stay significant if one additionally controls for CRM. Abstracting from SCM leads to a higher significance of ERP, as shown in Column (2) of Table 2.4. The coefficient of CRM stays insignificant in all regressions. Moreover, every coefficient decreases in magnitude once the adoption of another enterprise system is controlled for. This result confirms the

\footnotetext{
${ }^{9}$ This is only true if the variables are positively correlated which is confirmed for the enterprise systems using the Pearson correlation coefficient (not reported). Each of the three coefficients turns out to be larger than zero which is statistically significant at the one percent level.
} 
assumption of omitted variable bias implying that once the enterprise systems are considered simultaneously in the regressions the performance impact of one enterprise system is to some extent explained by the other one with SCM explaining the major part in the available dataset. The bias might even turn out to be larger if the systems are used in combination as potential performance gains resulting from a complementary relationship among these interacting systems are not explicitly revealed. The possible complementarity relation between the systems is addressed in the next section.

Table 2.4: Returns to enterprise systems

Dependent Variable:

Labor Productivity

(2)

(3)

(4)

\begin{tabular}{lcccc}
\hline In (labor) & $-0.119 * * *$ & $-0.112^{* * *}$ & $-0.111^{* * *}$ & $-0.119^{* * *}$ \\
& $(0.026)$ & $(0.026)$ & $(0.026)$ & $(0.026)$ \\
In (capital) & $0.120^{* * *}$ & $0.123^{* * *}$ & $0.123^{* * *}$ & $0.120^{* * *}$ \\
& $(0.019)$ & $(0.019)$ & $(0.019)$ & $(0.019)$ \\
share of computer & $0.584^{* * *}$ & $0.570^{* * *}$ & $0.584^{* * *}$ & $0.566^{* * *}$ \\
workers & $(0.105)$ & $(0.107)$ & $(0.107)$ & $(0.106)$ \\
\hline ERP & $0.120^{* *}$ & $0.138^{* *}$ & - & $0.118^{* *}$ \\
& $(0.055)$ & $(0.057)$ & & $(0.057)$ \\
SCM & $0.139 * * *$ & - & $0.152^{* * *}$ & $0.135^{* *}$ \\
& $(0.051)$ & & $(0.054)$ & $(0.053)$ \\
CRM & - & 0.049 & 0.034 & 0.012 \\
& & $(0.050)$ & $(0.052)$ & $(0.053)$ \\
\hline Constant & $5.669 * * *$ & $5.688^{* * *}$ & $5.697^{* * *}$ & $5.667 * * *$ \\
& $(0.166)$ & $(0.167)$ & $(0.167)$ & $(0.167)$ \\
\hline Control variables & Industry, & Industry, & Industry, & Industry, \\
& East & East & East & East \\
$\mathrm{R}^{2}$ & 0.239 & 0.234 & 0.236 & 0.239 \\
\hline
\end{tabular}

Number of Observations 927

Notes: ${ }^{* * *} \mathrm{p}<0.01 ;{ }^{* *} \mathrm{p}<0.05 ;{ }^{*} \mathrm{p}<0.1$; robust standard errors in parentheses.

Source: ZEW ICT survey 2004, 2007 and own calculations.

The large impact of SCM is not surprising at all, bearing in mind the potential benefits a SCM system has to offer and the positive impacts of SCM on firm performance, as reported by many studies focusing on SCM usage, e g. Dehning et al. (2007) or Hendricks et al. (2007). For CRM usage, however, there is nearly no evidence of positive impacts. The performance effect of ERP, on the other hand, might already be generated much earlier. Thus, it does not show high significance anymore, as most firms install their ERP system first and adopt SCM and CRM applications a few 
years later. Unfortunately, the data does not provide any information about the date of purchase or implementation of the enterprise systems. However, without an ERP system already installed, the firms would need to feed their SCM and CRM systems from legacy systems, often in form of spreadsheets spread out over different departments and subsidiaries of the firm. Without a reliable information basis in form of an ERP system the information from all areas of the company cannot be accessed quickly, which could result in bottle necks and idle times ${ }^{10}$.

\subsubsection{Complementarity and interaction between the enterprise systems}

To test for complementarity Table 2.5 reports the interaction terms controlling for the adoption of any two systems together in Column (1) to (3). Indicating no complementarity between any two enterprise software applications at a first glance no interaction term turns out to be significant in the regressions containing two different enterprise systems. Even the performance impact of the enterprise systems individually drops down to zero with the exception of ERP which shows a small impact in Column (2). However, the specifications in Column (1) to (3) only control for two systems at a time neglecting potential influence of the third system. Accordingly, the specification used in Column (4) controls for all possible interactions between the three software systems. In this specification, the influence of ERP turns out to be significant, indicating an increase in labor productivity for firms using this kind of system. Striking, however, is the significance, even only at the ten percent level, of the interaction term which captures the use of all three software systems together. According to this term, firms using ERP and additionally employing SCM and CRM systems demonstrate a considerable increase in labor productivity. Complementarity between the three different systems seems not to be directly realized through the adoption of only two systems, but SCM and CRM complement each other once ERP is already in use or implemented in conjunction. The result confirms the complementary benefits outlined in section 2.2 that utilizing SCM and CRM without an ERP system running might not be as useful as otherwise. Linking front and back office an ERP system provides the necessary infrastructure to feed the needed data to the SCM and CRM system. The performance effects generated through the use of an ERP system are increased even further once the firms adopt the other two systems. Therefore, adopting the full suite of enterprise systems turns out to be most useful for firms if they can rely on the needed data infrastructure provided by an ERP system in first place.

\footnotetext{
${ }^{10}$ Table 2.7 in the appendix provides supportive descriptive evidence for this issue as only a few firms in the sample use no ERP but either SCM and CRM individually or in combination (between 2 to 6 percent).
} 
As specification (1) of section 2.3 is rather parsimonious in terms of variables which affect labor productivity besides enterprise systems and traditional inputs, the results might to some extent be driven by unobserved heterogeneity with respect to firm characteristics. Therefore, a reduction of the heterogeneity bias by introducing more variables affecting productivity seems reasonable, especially as the evidence is based on weak significance. For this kind of robustness check I introduce two additional dummy variables in the estimation, the first one taking the value one if the firm reports any exporting activity and zero elsewise. Compared to firms that are only active in their home market, firms engaged in export activities are more exposed to international market pressure. Those firms are generally used to making quick adjustments in response to changes in the market environment. They rely on a highly flexible workforce as worldwide demand may change more rapidly and drastically than domestic demand. Therefore, export activity is argued to positively impact labor productivity (Baldwin and Gu 2004; Bernard and Jensen 2004). The second dummy variable introduced takes the value one if the firm has established a works council. With an established works council, employees are expected to show a higher degree of identification with their enterprise and the corresponding decisions made, encouraging them to feel more committed to the company and consequently do a better job. In addition, employee participation in decision-making might balance production more effectively to eliminate bottle-necks or interruptions of the production process. Hence, the establishment of a works council should also lead to higher labor productivity (Zwick 2003). Column (5) of Table 2.5 reports the result once works council and export activity is controlled for. As expected, both estimates show a significant positive impact on labor productivity. Concerning complementarity between the enterprise systems, the two newly introduced variables do not affect the relationship much. Both relevant coefficients, ERP and the interaction term of all three systems, decrease in size but still show a significant impact on labor productivity. 
Table 2.5: Returns to enterprise systems - interaction between the systems Dependent Variable:

\begin{tabular}{|c|c|c|c|c|c|}
\hline Labor Prod & (1) & $(2)$ & (3) & (4) & (5) \\
\hline In (labor) & $\begin{array}{c}-0.120 * * * \\
(0.026)\end{array}$ & $\begin{array}{c}-0.112^{* * *} \\
(0.026)\end{array}$ & $\begin{array}{c}-0.110 * * * \\
(0.026)\end{array}$ & $\begin{array}{c}-0.121 * * * \\
(0.026)\end{array}$ & $\begin{array}{c}-0.146^{* * *} \\
(0.028)\end{array}$ \\
\hline In (capital) & $\begin{array}{c}0.120 * * * \\
(0.019)\end{array}$ & $\begin{array}{c}0.123 * * * \\
(0.019)\end{array}$ & $\begin{array}{c}0.122 * * * \\
(0.019)\end{array}$ & $\begin{array}{c}0.120 * * * \\
(0.019)\end{array}$ & $\begin{array}{c}0.110 * * * \\
(0.019)\end{array}$ \\
\hline $\begin{array}{l}\text { share of computer } \\
\text { workers }\end{array}$ & $\begin{array}{c}0.568 * * * \\
(0.105)\end{array}$ & $\begin{array}{c}0.571^{* * *} \\
(0.107)\end{array}$ & $\begin{array}{c}0.582^{* * *} \\
(0.107)\end{array}$ & $\begin{array}{c}0.572 * * * \\
(0.107)\end{array}$ & $\begin{array}{c}0.572 * * * \\
(0.106)\end{array}$ \\
\hline export activity & - & - & - & - & $\begin{array}{c}0.148 * * * \\
(0.057)\end{array}$ \\
\hline works council & - & - & - & - & $\begin{array}{l}0.171^{* *} \\
(0.069)\end{array}$ \\
\hline ERP & $\begin{array}{c}0.107 \\
(0.068)\end{array}$ & $\begin{array}{l}0.135^{*} \\
(0.072)\end{array}$ & - & $\begin{array}{l}0.185^{* *} \\
(0.084)\end{array}$ & $\begin{array}{l}0.154 * \\
(0.085)\end{array}$ \\
\hline SCM & $\begin{array}{c}0.103 \\
(0.085)\end{array}$ & - & $\begin{array}{c}0.072 \\
(0.076)\end{array}$ & $\begin{array}{c}0.171 \\
(0.116)\end{array}$ & $\begin{array}{c}0.139 \\
(0.118)\end{array}$ \\
\hline CRM & - & $\begin{array}{c}0.044 \\
(0.089)\end{array}$ & $\begin{array}{l}-0.023 \\
(0.070)\end{array}$ & $\begin{array}{c}0.046 \\
(0.121)\end{array}$ & $\begin{array}{c}0.045 \\
(0.123)\end{array}$ \\
\hline ERP \& SCM & $\begin{array}{c}0.049 \\
(0.104)\end{array}$ & - & - & $\begin{array}{l}-0.196 \\
(0.151)\end{array}$ & $\begin{array}{l}-0.186 \\
(0.151)\end{array}$ \\
\hline ERP \& CRM & - & $\begin{array}{c}0.007 \\
(0.106)\end{array}$ & - & $\begin{array}{l}-0.179 \\
(0.149)\end{array}$ & $\begin{array}{l}-0.189 \\
(0.150)\end{array}$ \\
\hline SCM \& CRM & - & - & $\begin{array}{c}0.138 \\
(0.100)\end{array}$ & $\begin{array}{l}-0.134 \\
(0.180)\end{array}$ & $\begin{array}{l}-0.110 \\
(0.183)\end{array}$ \\
\hline All three systems & - & - & - & $\begin{array}{l}0.419 * \\
(0.219)\end{array}$ & $\begin{array}{l}0.408^{*} \\
(0.220)\end{array}$ \\
\hline Constant & $\begin{array}{c}5.678 * * * \\
(0.169)\end{array}$ & $\begin{array}{c}5.690 * * * \\
(0.168)\end{array}$ & $\begin{array}{c}5.711^{* * *} \\
(0.167)\end{array}$ & $\begin{array}{c}5.664 * * * \\
(0.169)\end{array}$ & $\begin{array}{c}5.574 * * * \\
(0.171)\end{array}$ \\
\hline Control variables & $\begin{array}{c}\text { Industry, } \\
\text { East }\end{array}$ & $\begin{array}{c}\text { Industry, } \\
\text { East }\end{array}$ & $\begin{array}{c}\text { Industry, } \\
\text { East }\end{array}$ & $\begin{array}{c}\text { Industry, } \\
\text { East }\end{array}$ & $\begin{array}{c}\text { Industry, } \\
\text { East }\end{array}$ \\
\hline$R^{2}$ & 0.239 & 0.234 & 0.237 & 0.244 & 0.255 \\
\hline
\end{tabular}

Number of Observations 927

Notes: ${ }^{* * *} \mathrm{p}<0.01 ;{ }^{* *} \mathrm{p}<0.05 ;{ }^{*} \mathrm{p}<0.1$; robust standard errors in parentheses. Source: ZEW ICT survey 2004, 2007 and own calculations.

\subsubsection{Alternative procedure to test for complementarity}

As a robustness check I conduct the likelihood-ratio test from Lokshin et al. (2007). Table 2.6 reports the computed log-likelihood values of the unconstrained and constrained models, the likelihood-ratio statistics and $p$-values. I rely on the method 
developed by Shapiro (1985) to generate the needed weights. Overall, the likelihood-ratio statistics turn out to be small in the first two cases and the test rejects the hypothesis of pairwise complementarity for the combinations of ERP and either SCM or CRM. However, in the third case, the test reports a highly significant complementarity relationship between SCM and CRM. The complementarity relationship is unconditional on ERP adoption indicating that complementary benefits are realized even if an ERP system is not installed. Overall, this result is slightly different to the results obtained based on the interaction term specification. However, this recent testing method still lacks empirical evidence. Accordingly, one has to treat the results with appropriate care. As this robustness check is not sufficient I also conducted the likelihood-ratio testing procedure for two practices, namely SCM and CRM, but only if ERP is also in use. The appropriate one-sided t-test reports a complementarity relationship significant at the one percent level and thus strengthens the results of Table $2.5^{11}$.

Table 2.6: Multiple restrictions test for complementarity

\begin{tabular}{|c|c|c|c|c|c|c|}
\hline $\begin{array}{l}\text { Complemen- } \\
\text { tarity Rela- } \\
\text { tion }\end{array}$ & $\begin{array}{l}\text { Uncon- } \\
\text { strained }\end{array}$ & $\begin{array}{c}\text { Inequality } \\
\text { Constrained } \geq \\
0\end{array}$ & $\begin{array}{c}\text { Inequality } \\
\text { Constrained } \leq \\
0\end{array}$ & $\begin{array}{l}\text { Equality } \\
\text { Con- } \\
\text { strained }\end{array}$ & $\begin{array}{c}\text { LR- } \\
\text { Statistic }\end{array}$ & P-Valc \\
\hline ERP - SCM & -658.475 & -659.319 & -659.804 & -660.653 & 2.668 & 0.117 \\
\hline ERP - CRM & -658.475 & -659.694 & -659.499 & -660.709 & 2.420 & 0.134 \\
\hline SCM - CRM & -658.475 & -658.768 & -662.311 & -662.604 & 7.672 & 0.010 \\
\hline
\end{tabular}

Note: In the LR tests the null corresponds to the value in italics and the alternative corresponds to the equality constraint. In order to conclude in favor of complementarity or substitability the Log-Likelihood value with the inequality constraints should be significantly larger than the Log-Likelihood value with the equality constraint.

Source: ZEW ICT survey 2004, 2007 and own calculations.

\subsection{Conclusion}

With the first wave of implementations dating back to the early 1990s, enterprise systems are nowadays widely spread and broadly accepted among industries and firms of all sizes. Their exact influence on firm performance, however, remains to be discovered and revealed as it is still unknown whether the interactions between various enterprise systems affect performance in a different way than the reliance on a single application.

\footnotetext{
${ }^{11}$ Both multiple restrictions tests, the one conditioned and the one unconditioned on ERP usage, stay also significant at the one percent level if export activity and works council is additionally controlled for (not reported).
} 
The paper approaches this question from a different and novel angle as it focuses explicitly on disentangling the productivity impacts caused by the combinations of different enterprise systems. The results provide empirical evidence of the impacts of the three major enterprise systems on labor productivity and display possible complementarities among the systems. It is shown that SCM and CRM function as complements, especially if an ERP system is already in place and provides the necessary IT-infrastructure for both enterprise software applications. The complementarity relationship turns out to be robust even if a non-parsimonious labor productivity specification is used for inference. Hence, the productivity gains caused by enterprise system implementation are not only generated by the usage of one single system, but rather augmented and increased by adopting the three major enterprise systems together. In consequence, previous estimations of the productivity impacts due to enterprise software usage might be biased as long as any interaction effects of the systems are not taken into account and pictured adequately.

This analysis faces a few caveats which are primarily related to data restriction. First, a potential short-coming of this analysis might be the fact that I could only check for the effects of adopting different enterprise software systems without controlling for other obstacles interfering with enterprise system usage. This may be a drawback since not only the adoption of other enterprise systems might influence the productivity gains of one system. Special IT-training or the quality of updates and maintenance, to name only a few examples, may also affect the performance effects of enterprise software. The dataset also doesn't contain information on the usage of Enterprise Application Integration (EAI) software. This software enhances the communication between the different enterprise systems and enables them to check for redundant information thereby increasing the performance of the systems. Without information about EAl the estimated impacts of enterprise systems might be downwardly biased as with EAl software running the impacts of enterprise software on labor productivity can be expected to be larger. However, due to data constraints I have to pass the exploration of the productivity effects generated by EAI software usage on to future research with newly obtained data. Besides EAI software, it may also be the case that some companies might have less legacy systems compared to other firms, allowing them to implement next generation enterprise software faster and consequently realizing performance benefits earlier. Future availability of new data may provide evidence even for these cases. Lastly, a potential endogeneity bias cannot be excluded completely. Although based on a well-defined temporal sequence incorporating a two year lag between software usage and performance measured it is not clear if the firms possess the software to increase performance or because they are already performing well acquiring the software as an additional asset. However, the works council captures such strategic firm decisions to some extent as it has the option to confirm or deny certain deci- 
sions. Accordingly, as the estimations control for the establishment of a works council the mentioned bias due to unobserved strategic decisions of firms can be expected to be negligibly small in size.

\subsection{Appendix Chapter 2}

Table 2.7: Distribution of the combinations of enterprise systems

\begin{tabular}{l|cc} 
& Frequency & Percent \\
\hline no enterprise system & 219 & 23.62 \\
Only ERP & 121 & 13.05 \\
Only SCM & 23 & 2.48 \\
Only CRM & 54 & 5.83 \\
Only ERP and SCM & 88 & 9.49 \\
Only ERP and CRM & 123 & 13.27 \\
Only CRM and SCM & 41 & 4.42 \\
All three systems & 258 & 27.83 \\
\hline number of observations & 927 & 100 \\
\hline
\end{tabular}

Source: ZEW ICT survey 2004.

\section{Survey-Question for enterprise system usage:}

Which application or system do you use in your daily business routine? Please state if the application or system is used to minor degree, broadly or not at all.

software for planning and controlling, e.g. SAP/R3 (ERP system from SAP) customer relationship management (CRM) supply chain management (SCM)

Table 2.8: Distribution of enterprise systems usage (in percent)

\begin{tabular}{l|ccc} 
& ERP & SCM & CRM \\
\hline no usage & 36.35 & 55.77 & 47.65 \\
minor usage & 16.83 & 25.46 & 32.79 \\
broad usage & 46.82 & 18.77 & 18.55 \\
\hline number of observations & 927 & 927 & 927 \\
\hline
\end{tabular}

Source: ZEW ICT survey 2004. 


\title{
Chapter 3
}

\section{It's not all about Performance Gains - Enterprise Software and Innovations ${ }^{\S}$}

\begin{abstract}
This paper analyzes the relationship between the three enterprise software systems (Enterprise Resource Planning (ERP), Supply Chain Management (SCM), Customer Relationship Management (CRM)) and firms' innovative performance for process as well as product innovations. Using German firm-level data and a two part model, the results reveal that SCM systems foster the firms' likelihood of becoming a potential process innovator. In addition, ERP systems increase the number of process innovations a firm realizes. Concerning product innovation performance CRM systems increase the firms' likelihood to acquire product innovations whereas the number of expected product innovations is increased if firms use a SCM system.
\end{abstract}

Keywords: Innovation, Product Innovation, Process Innovation, Enterprise Software, Enterprise Systems, Enterprise Resource Planning, Supply Chain Management, Customer Relationship Management

JEL Classification: D22, M20, O31

\footnotetext{
${ }^{\S}$ This chapter was published in Economics of Innovation and New Technology 21, no. 3: 223-245.
} 


\subsection{Introduction}

Covering a large range of software products supporting day-to-day business operations and decision-making, company-wide suites of business software, namely enterprise systems in short, are devoted to particular process integration across the value chain. Especially the three enterprise systems Enterprise Resource Planning (ERP), Supply Chain Management (SCM) and Customer Relationship Management (CRM) are widespread throughout many industries in numerous areas around the world. The purpose of these systems is to automate operations from supply management, inventory control, manufacturing scheduling, sales force automation and almost any other data-oriented management process. SAP, the largest global enterprise software vendor, estimates the global market for all enterprise software applications to be roughly $\$ 110$ billion $2010^{12}$.

In general, firms adopt enterprise systems expecting fast evolving efficiency and productivity gains. Replacing the firms' legacy software systems, which are usually poorly connected and spread out all over the firm, enterprise systems additionally generate improvements in operational integration affecting the entire organization. Along with expected efficiency gains ERP and SCM systems might also foster innovation activity as they reduce idle times and save data mining or identify bottlenecks and shortages, thus providing information for process enhancements. Both systems enable the firms to update all their databases in real time allowing them to directly picture, compare and control the effects of process innovations. CRM systems, on the other hand, yield a database of customer preferences which can be a useful source for product innovations.

Although the usage of information and communication technology (ICT) applications in general is suspected to enhance firms' innovation performance (Brynjolfsson and Sanders 2010; Hempell and Zwick 2008) the potential impact of enterprise software systems on innovation performance in particular is still not investigated. The literature in this field is scarce, offering only a few studies that examine the benefits of ICT-based enterprise systems for innovation activity. Empirical evidence on the basis of firm-level data covering this topic is still lacking at present. Therefore, this study aims at providing the first empirical evidence of the impact of adopting any of the three enterprise systems on firms' innovation performance. In order to achieve useful results, the present study relies on a unique database consisting of German firms from the manufacturing industry and from the service sector. Based on this database the current paper focuses exclusively on ICT-based tools for ERP, SCM or CRM and appropriate software systems. Management practices and business mod-

\footnotetext{
${ }^{12}$ See SAP presentation, available at:

http://www.sap.com/about/investor/presentations/pdf/WB_DB_London_8Sep2010.pdf.
} 
els covering supply chain management and customer relationship management are not discussed.

Using a two step approach, the results provide first evidence of innovation activity entailed by enterprise system usage. The adoption of SCM systems increases the propensity to realize process innovations and positively affects the number of realized product innovations. ERP system usage, on the other hand, has a positive impact on the number of acquired process innovations but fails to directly impact the firms' product innovation performance. However, the expected number of product innovations is positively affected by ERP system usage if firms rely also on a decentralized decision structure as both tools show a complementary impact on innovation performance. The usage of CRM systems, on the other hand, does not have an impact on process innovations but positively impacts the propensity to realize product innovations.

The paper proceeds as follows: Section 3.22.2 gives an overview of the appropriate literature covering the benefits of enterprise systems in general and their potential effects on innovation performance in particular. In addition, Section 2 derives the main hypotheses of the analysis. Section 3.3 regards the estimation approach whereas section 3.4 presents the dataset. Section 3.5 contains the estimation results and several robustness checks to clarify the validity of the results. Concluding remarks are given in section 3.6.

\subsection{Background Discussion}

\subsubsection{ICT, Innovation and Productivity}

This study is related to several strands of literature including the impacts of ICT in general and the impacts of enterprise system usage in particular on firm performance and innovation activity. Overall, ICT is expected to support firms in reshaping and optimizing their business processes in order to achieve productivity and performance gains, see e.g. Brynjolfsson and Hitt (2000). Innovation activity, however, can be viewed as a prerequisite for these productivity gains (Crépon et al. 1998; Hall et al. 2009). Although ICT might foster innovation activity the link between ICT and innovation is not as extensively studied in the empirical literature as the relationship between ICT and productivity ${ }^{13}$. The studies investigating the relationship between innovation and ICT investment at the firm level usually report a positive and significant relationship. For example, Bresnahan and Trajtenberg (1995) confirm, in line with Bresnahan et al. (2002), that ICT enables complementary innovations in ICT-

\footnotetext{
${ }^{13}$ See for instance the survey by Draca et al. (2007) or the recent survey of Brynjolfsson and Sanders (2010) for an overview of both mentioned links, i.e. IT and innovation as well as IT and productivity.
} 
using industry sectors. More recently, Van Reenen et al. (2010) point out the role of ICT for building intangible capital which in turn contributes to firms' innovation capabilities. Polder et al. (2010) consider investment in ICT and R\&D as input factors for innovative output measured as process, product and organizational innovation. ICT turns out to play a significant role for all three innovation measures in manufacturing as well as in service firms. Hempell and Zwick (2008) focus on organizational flexibility as the link between ICT investment and innovations as they emphasize that organizational flexibility comprises different dimensions of employee participation. They confirm that employee participation is positively associated with product and process innovations. Gera and Gu (2004) show a positive effect of ICT investment per worker on product and process innovation. Concerning new specific ICT practices like recent software applications or open source operating systems the empirical evidence is even scarcer. Focusing on the recent phenomenon social software, i.e. applications such as blogs, wikis or online communities, Meyer (2010) reveals that there is a positive relationship between social software applications and service innovation. Her results suggest that the causality runs from social software to innovation.

\subsubsection{Earlier Research in Enterprise Systems}

Concerning enterprise software systems in particular the literature is similarly divided as the general ICT literature, i.e. there are many studies extensively examining the performance impacts of the systems (e.g. Aral et al. 2006; Hendricks et al. 2007; Hitt et al. 2002) and nearly no analysis examining potential innovation impacts. Regarding the analysis of the performance impacts, a wide range of performance measures is concerned, e.g. several return measures like return on equity, investment, assets or sales (Hunton et al. 2003; Hunton and Wier 2007; Hendricks et al. 2007) as well as labor productivity, net profit margin or value added (Hitt et al. 2002; Shin 2006; Wieder et al. 2006). Overall, the results suggest positive performance impacts of ERP and SCM usage, for CRM on the other hand the studies cannot show any performance effects. The confirmed performance impacts are based on the benefits the enterprise systems provide to a using firm, e.g. facilitating transaction handling or enhancing operational and business planning. However, enterprise systems could also enhance the firms' innovation activity and improve productivity indirectly via increased innovational performance. To give an overview of both paths through which enterprise systems might increase performance the next section will cover the benefits of the enterprise systems in general followed by a section which highlights the potential benefits of enterprise systems for innovational performance. 


\subsubsection{Benefits of Enterprise Systems in general}

Replacing complex interfaces between different systems with standardized crossfunctional transaction automation, ERP systems use a source of data that integrates enterprise functions such as sales and distribution, materials management, production planning, financial accounting, cost control and human resource management (Aral et al. 2006). An ERP system is expected to reduce order cycle times, which in return might lead to improved throughput, customer response times and delivery speeds (Cotteleer and Bendoly 2006; McAfee 2002). Due to automated financial transactions, cash-to-cash cycle times and the time needed to reconcile financial data at the end of a quarter or year can be minimized (Mabert et al. 2000; McAfee 1999). The ERP system collects all enterprise data once during the initial transaction, stores the data centrally and performs updates in real time. The standardized firmwide transactions and centrally stored enterprise data will also greatly facilitate the governance of the firm (McAfee and Upton 1996; Scott and Vessey 2000).

ICT-based SCM systems coordinate and integrate the complete flow of information, materials and finances and improve operational as well as business planning (Dehning et al. 2007). The real-time planning capabilities of SCM systems enable firms to react quickly to supply and demand changes (Hendrick et al. 2007), thereby serving customers in a timely and comprehensive manner (Cachon and Fisher 2000). By reducing inventory levels, holding costs, spoilage and lead times, SCM systems can directly improve inventory management and increase profitability through a reduction of costs, avoiding lost sales and improving customer satisfaction (Cachon and Fisher 2000). Lower general and administrative, coordination and sales costs as well as improved decision-making and forecasting are additional benefits generated through SCM system usage (Dehning et al. 2007). Based on its ability of information sharing, collaborative planning and forecasting replenishment, a SCM system will also lead to improvements in decisions concerning order quantity, lowered time and costs of order processing or increased order frequencies combined with reduction in lead time.

Providing the appropriate infrastructure, e.g. enabling effective sales force automation, centralized customer data warehousing and data mining paired with decision support and reporting tools, CRM software systems facilitate the development of medium-term relationships with customers (Katz 2002; Suresh 2004). An ICT-based CRM system is also expected to lead to superior customer loyalty, reduced cost of sales and services or improved bottom-line profits (Chen 2001). It reduces duplication in data entry and maintenance by providing a centralized firm-wide database of customer information, capturing all their wants and needs. In addition, this database replaces systems maintained by individual salespeople, institutionalizes customer relationships and prevents the loss of organizational customer knowledge 
when sales staff leaves the firm (Hendricks et al. 2007). The database might also reduce costs via streamlining repetitive transactions and sales processes (Cohen et al. 2006).

\subsubsection{Effects of Enterprise Systems on Firms' Innovation Performance}

Enterprise systems can affect the firms' innovation performance through different channels. First of all, enterprise systems promote further innovations directly based on the benefits they provide. The firm-wide database generated and updated by the ERP system, for example, provides every employee with necessary data in real-time, thus making data-mining obsolete and enabling the workers to be more innovative and flexible (Davenport and Brooks 2004). ERP systems are also expected to provide strategic benefits and build additional business innovations, for example by enabling new market strategies or building up new process chains (Shang and Seddon 2002). Using a SCM system all departments receive in time information about the resources necessary, therefore bottlenecks and idle time should be reduced to a minimum. Both systems combined generate a suitable and more flexible (Dehning et al. 2007; McAfee 2002) working environment and, with product lifecycles and resource usage shown in real-time, room for process improvements and product enhancements is easy to identify. In addition, with the firm wide database updated in real time, the results of the innovations can be directly pictured, controlled and compared, providing even greater room for improvement. A CRM system, on the other hand, might be particularly useful for successful product innovations as its data offers a complete picture of the customers' wants and needs. In general, this knowledge of customers' preferences is expected to shape the firms' innovation success (Joshi and Sharma 2004). Therefore, firms with CRM systems in use are expected to experience significant advantages in product enhancement and design as they can rely on a rich database of customer information and adjust their production accordingly.

Leaving direct effects aside, enterprise systems might also indirectly increase innovation performance as the systems may encourage the introduction of some organizational enhancements which have been proven to facilitate the generation of more innovations. Tsai (2001) proclaims that business units are more innovative once they reach a more centralized network position that enables them to access new knowledge generated by other units faster. Enterprise systems fit perfectly into this context as ERP, in particular, enhances the intern network capabilities of the firms by providing a centralized database with access for every employee and business unit and intensifying connections between them. As the communication between the units is accelerated with an ERP system in use, the innovation activity of the firm might, according to Tsai (2001), also increase. Criscuolo et al. (2005) show that firms 
generate more innovations with established upstream and/or downstream contacts to suppliers and customers. Roper et al. (2006) support this argument as they emphasize the great value of backward and horizontal knowledge linkages for process innovations. With their focus on communication with suppliers and customers, SCM and CRM systems are expected to maintain current and generate new upstream and downstream contacts far easier, generating more knowledge linkages for acquiring diverse and novel information from beyond the organization's boundaries in the process. Being greatly important in the innovation literature (Chesbrough 2003) this outside knowledge pool accessible for firms using SCM and CRM systems will be helpful to create more innovations. Summing up all potential benefits of enterprise systems for the firms' innovation activity, one cannot clearly assess which enterprise system benefits which type of innovation. Therefore, being appropriately cautious one has to expect all enterprise systems to positively impact the innovation process for product as well as process innovations.

\subsection{Research methodology}

\subsubsection{Analytical Framework}

As a starting point, the present study is based on the established and widely used innovation or knowledge production function introduced by Griliches (1979). The basic assumption is that the output of the innovation process represents a result of several inputs linked to research and ongoing knowledge accumulation, such as, e.g., investments in research and development or human capital (Vinding 2006). Recent literature using the knowledge production, however, does not only focus on $R \& D$ indicators but also on other knowledge sources and ways through which the ingredients of innovation activity can be obtained. For example, Freel (2006) uses a modified innovation production function where innovation is a function of internally and externally sourced technological competence alongside directly measured firm R\&D. Roper et al. (2008) augment this function with even more inputs like enterprise characteristics, firm resources and organizational capabilities to take the different routes through which knowledge might influence the firms' innovation activities into account. In the current analysis, enterprise systems are additionally included in the knowledge production function, providing first insights of the relationship between enterprise system adoption and the firm's innovation activity. The innovation measure used is the number of realized innovations for each firm. This splits the innovation production function in two parts: one part dealing with the decision to innovate and the second part focusing on the number of innovations realized. To summarize, the probability that a firm will generate either product or process innovations is given by 
where $z_{\mathrm{i}}{ }^{*}$ is a latent variable reflecting the ith firm's decision to product or process innovate, respectively. $X_{\mathrm{i}}$ covers firm characteristics expected to impact the innovation activity of firm $i$, e.g., size, ICT capital, human capital and East German heritage. $I D_{\mathrm{i}}$ includes the control dummies for industry sectors and $E S_{\mathrm{i}}$ contains the enterprise systems used by firm $i . \varepsilon_{\mathrm{i}}$ is a standard identical distributed error term.

As the selection equation (1) shows to what extent enterprise system usage fosters the firms' innovation propensity, the next consecutive step will be to reveal the impacts of enterprise systems on the number of innovations realized by the firm. This form of innovation intensity can be specified as

$$
y_{\mathrm{i}}{ }^{*}=z_{\mathrm{i}}{ }^{\prime} \lambda_{1}+I D_{\mathrm{i}}{ }^{\prime} \lambda_{2}+E S_{\mathrm{i}}{ }^{\prime} \lambda_{3}+\gamma_{\mathrm{i}} \quad y_{\mathrm{i}}=y_{\mathrm{i}}{ }^{*} \text { if } z_{\mathrm{i}}=1 ; y_{\mathrm{i}}=0 \text { if } z_{\mathrm{i}}=0
$$

where $y_{i}^{*}$ is the unobserved latent variable accounting for the ith firm's number of process or product innovations, respectively. $Z_{i}$ is a set of determinants expected to affect the number of innovations and contains, in general, the same variables as in equation (1). In addition to $E S_{\mathrm{i}}$ depicting enterprise system usage of firm $i, I D_{\mathrm{i}}$ contains the industry control dummies and $\gamma_{\mathrm{i}}$ is a standard identically distributed error term.

\subsubsection{Econometric Implementation}

Estimating equations (1) and (2) via maximum likelihood, count data methods have to be used for inference as the innovation intensity is measured by the number of innovations realized. However, using this proxy leads to a so called corner solution, featuring a potentially large proportion of zeros in the dependent variable. These zeros might arise for different reasons, e.g. having no need for innovation in general or having failed in introducing new innovations. Therefore, I consider two models as possible data generating processes, namely the hurdle and the zero-inflated model which both explicitly allow for a separate treatment of zeros and strictly positive outcomes (Winkelmann 1998). Each model is shortly described in the following. The model selection based on appropriate tests takes place in section 3.5.

In the hurdle or two-part model, the zeros are determined by the density $f_{1}(\cdot)$, so that

$\operatorname{Pr}(y=0)=f_{1}(0)$ and $\operatorname{Pr}(y>0)=1-f_{1}(0)$ (Cameron and Trivedi 2009). The positive counts, however, stem from the truncated density $f_{2}(y \mid y>0)=f_{2}(y) /\left\{1-f_{2}(0)\right\}$, 
which is multiplied by $\operatorname{Pr}(y>0)$ to ensure that the probabilities sum to 1 . Hence, suppressing regressors for notational simplicity, the density of the hurdle model is

$$
f(y)=\left\{\begin{array}{cc}
f_{1}(0) & \text { if } y=0, \\
\frac{1-f_{1}(0)}{1-f_{2}(0)} f_{2}(y) & \text { if } y \geq 1
\end{array}\right.
$$

A hurdle model is interpreted as reflecting a two-stage decision-making process, each part being a model of one decision. The two parts of the model are functionally independent. Therefore, the hurdle model can be estimated via maximum likelihood by separately maximizing two terms, one corresponding to the zeros and the other one to the positive values. The first part uses the full sample, the second part uses only the positive count observations.

The zero-inflated model, on the other hand, differs from the hurdle-model in that with $p_{\mathrm{i}}=\operatorname{Pr}\left(y_{\mathrm{i}}=1\right), y_{\mathrm{i}}$ is equal to $y_{\mathrm{i}}{ }^{*}$ for the full range of $y_{\mathrm{i}}{ }^{*}$ and not just for strictly positive values. Like the hurdle-model, the zero-inflated one combines a count density, $f_{2}(\cdot)$, and a binary process with a density of $f_{1}(\cdot)$ (Cameron and Trivedi 2009). In case the binary process takes value zero, with a probability of $f_{1}(0)$, then y is equal to zero. On the contrary, if the binary process takes value one, with correspondent probability of $f_{1}(1)$, then y takes count values ascending from 0 onwards from the count density $f_{2}(\cdot)$. Therefore, the zeros occur in two ways in this model. One type of zeros arises as a realization of the binary process, the other type as a realization of the count process when the binary random variable takes value 1 . Suppressing regressors for notational simplicity, the density of the zero-inflated model results in

$$
f(y)= \begin{cases}f_{1}(0)+\left\{1-f_{1}(0)\right\} f_{2}(0) & \text { if } y=0, \\ \left.11-f_{1}(0)\right\} f_{2}(y) & \text { if } y \geq 1\end{cases}
$$

As the zero-inflated model allows for two different types of zeros and does not state both stages of the decision-making process as completely independent, it is expected to be the better choice for inference in the current analysis. Nevertheless, a vuong test is used in the following to identify whether the hurdle or the zeroinflated model is suitable in the given setup.

For both models, the probability $f_{1}(0)$ may be a constant or may be parameterized through a binomial model like logit or probit. The second part of both models, i.e. the count process, can either be based on the Poisson or the negative binomial distribution. Allowing for overdispersion, frequently occurring in applied economics, 
the negative binomial distribution seems to be the more reasonable choice in the present analysis. In section 3.5, an appropriate likelihood ratio test clarifies which distribution to use.

\subsection{The Data}

The dataset used in this study results from two computer-aided telephone surveys conducted in 2004 and 2007 by the Centre for European Economic Research (ZEW). These ICT surveys laid a specific focus on the diffusion and use of ICT in German companies. In general, the interviewee was the chief executive officer of the firms who could also decide to pass on questions to a corresponding employee like, e.g., the head of the ICT department. Each wave of this ICT dataset originally contains information of about 4,000 firms with five or more employees, representatively chosen from important service and manufacturing sectors in Germany. The database for the sample stems from the credit rating agency Creditreform. This agency provides the largest database on firms available in Germany. Creditreform collects some basic information like address, sector and firm size on all enterprises that ever applied for a bank credit. The selection from the population of German firms was stratified according to industries, i.e. seven branches of the manufacturing industry and seven selected service sectors, to three size classes and to two regions, namely East and West Germany. As many firms as needed have been asked until all strata were filled.

Besides detailed information on the usage of several other ICT applications, the dataset provides the usage level of the three enterprise software applications ERP, SCM and CRM. The possible level of usage in the questionnaire was none, minor or broad $^{14}$. For this study, I built a dummy variable for the use of each software application which takes the value one if a firm uses the software at least to a minor degree or broadly and zero otherwise ${ }^{15}$. In addition, the surveys contain information about the firms' workforce, like the share of highly skilled workers, and other variables, e.g. organizational practices.

Although the ICT surveys are organized as a panel dataset this asset could turn out to be problematic as the zero-inflated model is as a fixed effects model based on the assumption of independence among the responses of repeated questionnaires (Hall 2000). This assumption can be expected to be violated in these surveys as there may be independence between two different firms but there is almost cer-

\footnotetext{
${ }^{14}$ The exact wording of the questions covering the enterprise systems and the detailed distribution of all answering options are outlined in the appendix in Table 3.8.

${ }^{15}$ The interpretation of an impact due to minor software use in comparison to no or broad use is impossible as the questionnaire does not make any distinctions between the levels of usage.
} 
tainly correlation among repeated observations of the same firm. As random effects zero-inflated models are not established in empirical analysis and as the ICT surveys in general suffer from panel mortality and item non-response I employ a specific cross-section which consists of a combination of the survey waves conducted in 2004 and 2007 for inference. Combining two surveys is necessary as the survey of 2007 covers the reported product and process innovations in the time of 2004 to 2006 but only the enterprise system usage of 2007. Based on this timing issue the software usage reported in the survey of 2007 turns out to be unsuitable as an explanatory variable. However, exploiting the panel character of the survey, I use the software usage reported in 2004 to construct the required dummy variables.

Suffering from panel mortality and item-nonresponse, matching the data for the two periods returns 1454 observations. Table 3.1 shows the descriptive statistics for the variables used in this study. To employ a well-defined temporal sequence in line with the reported enterprise system usage, all other explanatory variables also refer to the year 2004. Therefore, only the innovation measures are taken from the survey of 2007 and capture the innovations in the time of 2004 to 2006. In addition, Table 3.1 also contains the descriptive statistics for the industry affiliations and the location in the east or west part of Germany for the firms in the final sample. 
Table 3.1: Summary statistics

\begin{tabular}{|c|c|c|c|}
\hline Variable & Mean & Std. Dev. & $\mathbf{D V}^{3}$ \\
\hline process innovations acquired in 2004 to 2006 & 0.662 & & yes \\
\hline number of process innovations & 5.727 & 5.452 & \\
\hline product innovations acquired in 2004 to 2006 & 0.589 & & yes \\
\hline number of product innovations & 10.72 & 16.91 & \\
\hline process innovations in 2001 to 2003 & 0.735 & & yes \\
\hline product innovations in 2001 to 2003 & 0.633 & & yes \\
\hline labor $^{1}$ & 203.4 & 633.9 & \\
\hline capital $^{2}$ & 1850.9 & 6480.0 & \\
\hline share of computer workers & 0.511 & 0.338 & \\
\hline share of highly skilled employees & 0.236 & 0.264 & \\
\hline share of medium skilled employees & 0.567 & 0.266 & \\
\hline East German heritage & 0.269 & & yes \\
\hline no enterprise system & 0.244 & & yes \\
\hline Enterprise Resource Planning (ERP) & 0.610 & & yes \\
\hline Supply Chain Management (SCM) & 0.402 & & yes \\
\hline Customer Relationship Management (CRM) & 0.522 & & yes \\
\hline all three enterprise systems & 0.258 & & yes \\
\hline job rotation & 0.190 & & yes \\
\hline quality circles & 0.413 & & yes \\
\hline performance related payment & 0.564 & & yes \\
\hline self dependent working groups & 0.619 & & yes \\
\hline change in management in 2001 to 2003 & 0.261 & & yes \\
\hline hierarchy flattening in 2001 to 2003 & 0.126 & & yes \\
\hline \multicolumn{4}{|l|}{$\begin{array}{ll}\text { Industry affiliation } \\
\end{array}$} \\
\hline consumer goods & 0.076 & & yes \\
\hline chemical industry & 0.047 & & yes \\
\hline other raw materials & 0.065 & & yes \\
\hline metal and machine construction & 0.091 & & yes \\
\hline electrical engineering & 0.067 & & yes \\
\hline precision instruments & 0.065 & & yes \\
\hline automobile & 0.062 & & yes \\
\hline whole sale trade & 0.057 & & yes \\
\hline retail trade & 0.063 & & yes \\
\hline
\end{tabular}


Variable

transport and postal services

banks and insurances

electronic data transfer

technical services

other business-related services

number of observations

Notes: ${ }^{1}$ Labor is measured in total number of employees. ${ }^{2}$ Capital is proxied by gross investment in $€ 1,000$. ${ }^{3}$ Dummy variable

Source: ZEW ICT survey 2004, 2007 and own calculations.

With regard to process innovative performance, around 66 percent of the firms reported process innovations in the observed time period with a mean of nearly 6 process innovations realized. Abstracting from non-innovators, Figure 1 presents the distribution of the number of process innovations in form of a histogram for process innovating firms only. Most firms report between one and ten process innovations, only a few enterprises have realized 20 or even 30 process innovations between 2004 and 2006. Product innovations on the other hand are realized by about 59 percent of the surveyed firms. On average, the firms report nearly 11 product innovations. For these product innovators Figure 2 covers the distribution of the number of product innovations. In general, most firms in the sample seem to realize between 1 and 20 product innovations, with 13 firms realizing even 100 product innovations in the sample period. 
Figure 1: Number of Process Innovations - Histogram

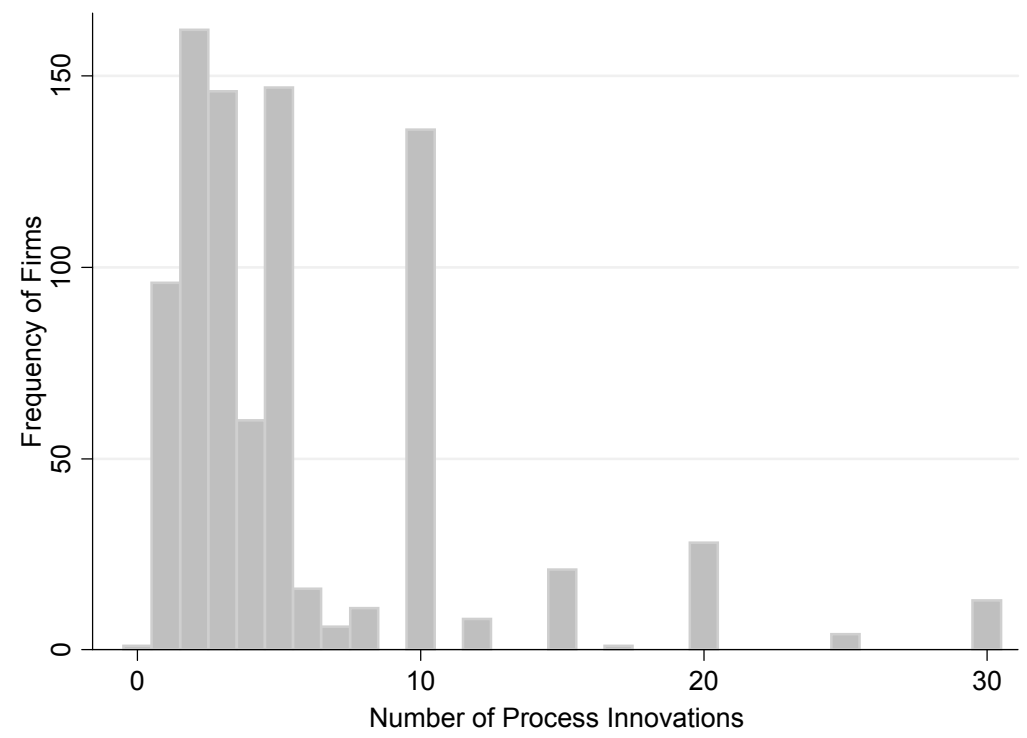

Figure 2: Number of Product Innovations - Histogram

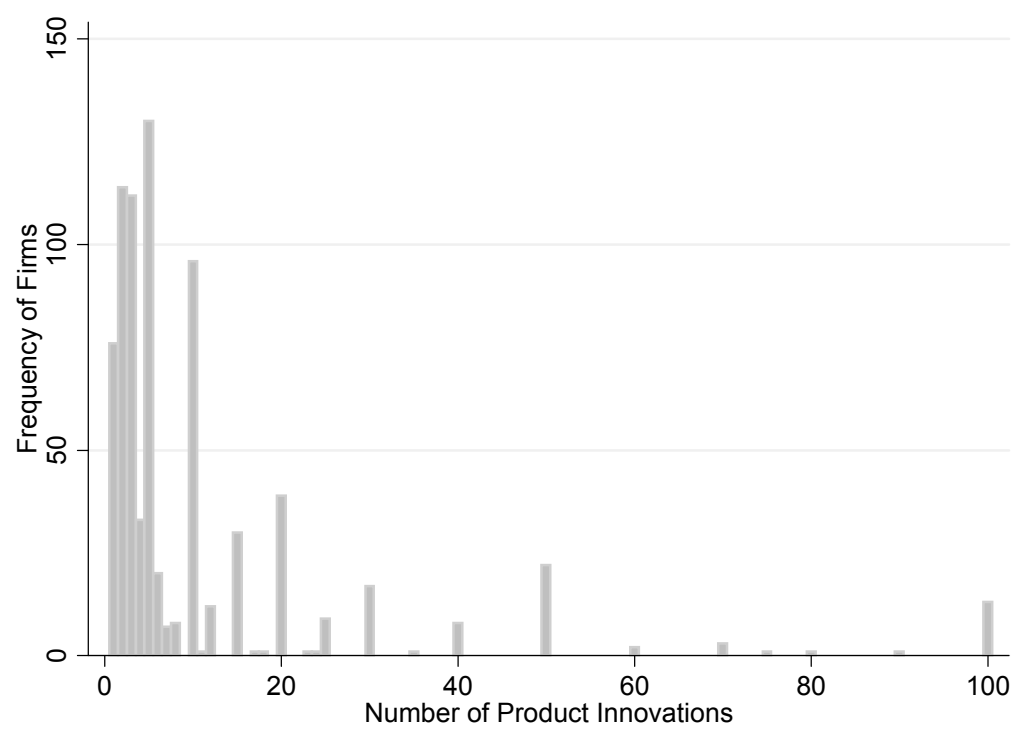


The main explanatory variables, enterprise systems, are widely spread in the used sample, only around one quarter of the firms reports not using enterprise systems at all. The use of ERP is especially common, around 61 percent of the observed firms rely on this system. SCM systems are adopted by around 40 percent of the firms and about half of the firms use CRM systems. Comparing these numbers with other studies focusing on enterprise systems to get an overview about enterprise system adoption is rather difficult, as most studies focus exclusively on firms using the software systems (Hendricks et al. 2007) or present an equally sized control group (Hunton et al. 2003) of non-users. The only study reporting the share of enterprise systems used in the sample employed is provided from Shin (2006). However, the sample he uses stems from small and medium sized enterprises in Korea, which report, not unexpectedly, far smaller shares of the employed enterprise systems compared to the German firms in the sample used for this study. In detail, 29 percent of the firms in Shin's analysis use ERP, 12 percent CRM and 8 percent SCM systems.

Firstly, to offer descriptive evidence for potential impacts of enterprise systems on innovation performance, Table 3.2 shows additional statistics of the firms using enterprise systems. In addition, a specific focus lies on the group of firms using no enterprise systems at all or the full suite of all three systems. Comparing the average innovation performance for each group with the entire sample means reported in Table 3.1, it seems that once the firms use enterprise software, every innovation measure slightly exceeds the sample mean. Firms which use all three enterprise systems together show the highest mean values. In contrast, using no enterprise system at all results in values lower than the sample mean. This result may be viewed as a first clue pointing towards the expected positive impact of enterprise systems on innovation performance. In addition, it seems like all enterprise systems support innovative activity equally, given that no enterprise system seems to excel at increasing a single specific type of innovation.

Table 3.2: Descriptive analysis

\begin{tabular}{l|ccccc} 
& No system All systems & ERP & SCM & CRM \\
\hline recent process innovator & 0.513 & 0.787 & 0.728 & 0.752 & 0.736 \\
number of process innovations mean & 5.047 & 6.482 & 6.116 & 6.214 & 5.936 \\
& $(5.865)$ & $(6.096)$ & $(5.477)$ & $(5.765)$ & $(5.473)$ \\
recent product innovator & 0.427 & 0.721 & 0.648 & 0.682 & 0.672 \\
number of product innovations mean & 8.603 & 12.48 & 11.27 & 12.76 & 11.11 \\
& $(16.74)$ & $(17.17)$ & $(16.48)$ & $(18.83)$ & $(16.62)$ \\
\hline
\end{tabular}

Notes: Standard errors in parentheses.

Source: ZEW ICT survey 2004, 2007 and own calculations. 
In addition to the main explanatory variables several additional control variables are employed including basic firm characteristic like firm size, capital ${ }^{16}$ and location in East or West Germany. As innovation performance is highly influenced by former innovation experience (Flaig and Stadler 1994; Hempell 2005), the dataset also includes two dummy variables covering whether a firm was a process or product innovator in the time span of 2001 to 2003. About 74 percent of the firms in the dataset are former process innovators, 63 percent of the firms can build on the experience of former product innovations. The mean share of workers mainly using a personal computer for their work, as a proxy for the ICT intensity of the firm which is expected to positively affect a firms' innovation performance (Hempell and Zwick 2008), is also included as an additional control variable as it might cover already realized benefits from old legacy software systems and mitigate the impact of the enterprise systems. The firms' human capital as a main driver of innovative performance is measured via the share of highly skilled workers, including degrees from universities and technical colleges, and the share of medium skilled workers, including finished apprenticeships, in-firm trainings or technical degrees. As mentioned in section 3.2, the firms' innovation activity is not only influenced by the employment of ICT but also positively affected by certain organizational factors which allow for more employee flexibility (Hempell and Zwick 2008). To capture the potential influence of these factors on firms' innovation activity, five organizational practices are included as controls in the estimation procedure. These organizational variables report if a firm employs a performance-related payment scheme, uses job rotation, has established quality circles or relies on self dependent working groups. In addition, organizational improvements which might result in more innovativeness are also captured by controlling for a flattening of hierarchies between 2001 and 2003. Nevertheless, none of these control variables capture a strategic firm decision to buy a new enterprise system, possibly with the aim to fasten processes or collect consumer data for a new product line. Therefore, a potential strategic redirection decision is controlled for by proxying it with a change in the executive board occurring between 2001 and 2003.

\subsection{Empirical Results}

\subsubsection{Model Selection and Explanation}

As a first step of the estimation procedure, an appropriate model for the given estimation setup has to be chosen. According to Hall et al. (2009), a bivariate model should be used for process and product innovations but the hypothesis of independence of both error terms, given the employed covariates, is not rejected in the current dataset. Therefore, two separate models, one for each type of innovation,

\footnotetext{
${ }^{16}$ Capital is proxied using gross investment figures following Bertschek et al. (2006) and Hall et al. (2009).
} 
will be used for inference. In the following estimations, I use two specifications. The first one is a parsimonious specification containing, besides enterprise systems, only basic firm characteristics like size, capital, ICT capital and the qualification of the workforce. The second one captures the impacts of the additional control variables like organizational factors and firm strategy as well. For the estimation of the binary process given in equation (1), I choose a probit ${ }^{17}$ model. Deciding the appropriate estimation method for equation (2), a likelihood ratio test evaluating the Poisson model (dispersion parameter alpha $=0$ ) against the negative binomial distributed alternative, given the employed covariates, rejects the hypothesis of Poisson distribution usage in favor of the negative binomial distribution significantly at the one percent level for both types of innovations. Testing the zero-inflated against the hurdle model the Vuong-Test (Vuong 1998) finally shows that the zero-inflated model describes the data best for process as well as product innovations. The test statistics are displayed alongside the estimation results presented in the following sections in

Table 3.3 and Table 3.4 Given these results, I stick to the zero-inflated negative binomial model for inference ${ }^{18}$, which indicates that each firm could possibly report two different types of zero innovations. The first type corresponds to the noninnovators, who decide not to innovate all. The second type of zeros, however, captures potential innovators, who report zero innovations not because they are not willing to innovate but perhaps because of failure to introduce the innovations in their firm, possibly due to resistance of the management or based on the results of stress tests the potential innovations failed to pass. Hence, the binary process which is estimated in the probit part of the zero-inflated model is built in the following way: the value one captures all non-innovators, i.e. those firms which are not willing to innovate at all. The complementary event, expressed by the value zero in the binary process, contains all potential innovators, i.e. those firms which have realized some innovations and those firms willing to innovate but face zero innovations due to the failure of realizing them. The negative binomial part of the model then uses only potential innovators, hence its coefficients must be interpreted based on this condition. Besides allowing for these two different kinds of zeros, the zero-inflated model is also completely identified even if the same covariates are employed in both parts of the model (Lambert 1992).

\footnotetext{
${ }^{17}$ A logit specification could also be used to estimate equation (1). However, as the results are virtually the same compared to the ones obtained from the probit approach, they are not pictured in this study.

${ }^{18}$ Estimating the negative binomial hurdle model as a robustness check offers similar results to the ones obtained from the zero-inflated alternative. The results of the hurdle variant are available from the author upon request.
} 


\subsubsection{Impacts of Enterprise Systems on process innovations}

Table 3.3 presents the estimation results of the zero-inflated negative binomial model for process innovations. The original setup of the probit part of the model is to predict the probability of being a non-innovator. However, for convenience of comparing the results to those of the negative binomial regression model that estimates the number of realized innovations among the potential innovators, following Sheu et al. (2004), the signs of the coefficients have been changed so that the probit model reflects the probability of being in the potential innovator group. Column (1) and (3) of

Table 3.3 display both specifications, the parsimonious one and the one including the additional control variables, for the propensity of being a potential innovator. Column (2) and (4) of

Table 3.3, on the other hand, report the estimation results of both specifications for the negative binomial part of the model. As this study focuses especially on the impacts of enterprise systems on innovation performance, I will discuss other factors influencing innovation activity only briefly.

Overall, the results of

Table $\mathbf{3 . 3}$

Table $\mathbf{3 . 3}$ reveal that from all three enterprise systems only the adoption of a SCM system significantly increases the probability of being a potential process innovator. Nevertheless, this positive impact seems to suffer from omitted variable bias as it decreases in size and significance once additional organizational practices are controlled for. However, staying insignificant in the negative binomial part of the model, SCM system usage fails to significantly increase the number of process innovation a firm realizes. ERP system usage shows no impact on the probability to become a potential innovator. But for those firms which have already realized at least one process innovation or are willing to innovate an established ERP system pays off and increases the expected number of innovations by a factor of $1.30(=\exp (0.265))$, that is to say by 130 percent, in the parsimonious specification ${ }^{19}$. The adoption of a CRM system, on the other hand, offers no additional performance for realizing process innovations as the coefficient stays insignificant in both model parts. Considering the other covariates, former process innovators and firms with established quality circles experience a higher probability of innovation compared to firms without former experience in generating process innovations or no quality circles. A change in the executive board of the firms also increases the probability of becoming a process innovator, possibly due to the new executive board establishing a new working culture with more openness to innovations or encouraging process chang-

\footnotetext{
${ }^{19}$ In the second specification this factor decreases to 1.27 (=exp (0.240)), i.e. 127 percent.
} 
es. The impact of the flattening of hierarchies may appear puzzling. Decreasing the overall probability to realize process innovations at all, the actual number of process innovations is increased if the firms try to improve their organizational structure with a more flattened hierarchy system. Nevertheless, as both model parts are two independent decision steps the two coefficients are not forced to point in the same direction. Interpreting these two coefficients carefully one could conclude that flattening of hierarchies is not suitable for small innovators or firms who want to start out with innovations. However, firms with a large number of process innovations running can rely on hierarchy flattening to enhance their innovative activity. Establishing self dependent work groups, however, turns out to be fruitful for the firms' innovative activity as it increases the expected number of realized process innovations. Being located in East Germany, however, seems to hamper the firms' innovation performance as this coefficient shows a significant negative influence on the number of realized process innovations in the parsimonious as well as in the specification including additional control variables. 
Table 3.3: Determinants of the number of process innovations, zero-inflated neg. binomial estimates

\begin{tabular}{|c|c|c|c|c|}
\hline & \multicolumn{2}{|c|}{ Specification 1} & \multicolumn{2}{|c|}{ Specification 2} \\
\hline & $\begin{array}{l}\text { Probit } \\
\text { Model }\end{array}$ & $\begin{array}{l}\text { Neg. Bin. } \\
\text { Model }\end{array}$ & $\begin{array}{l}\text { Probit } \\
\text { Model }\end{array}$ & $\begin{array}{l}\text { Neg. Bin. } \\
\text { Model }\end{array}$ \\
\hline In (labor) & $\begin{array}{c}0.079 \\
(0.068)\end{array}$ & $\begin{array}{c}0.032 \\
(0.045)\end{array}$ & $\begin{array}{c}0.027 \\
(0.071)\end{array}$ & $\begin{array}{c}0.019 \\
(0.045)\end{array}$ \\
\hline In (capital) & $\begin{array}{c}0.011 \\
(0.051)\end{array}$ & $\begin{array}{c}0.046 \\
(0.037)\end{array}$ & $\begin{array}{c}0.010 \\
(0.051)\end{array}$ & $\begin{array}{c}0.032 \\
(0.035)\end{array}$ \\
\hline share of computer workers & $\begin{array}{c}0.210 \\
(0.298)\end{array}$ & $\begin{array}{c}0.232 \\
(0.185)\end{array}$ & $\begin{array}{c}0.148 \\
(0.295)\end{array}$ & $\begin{array}{c}0.210 \\
(0.185)\end{array}$ \\
\hline & -0.563 & -0.350 & -0.702 & -0.212 \\
\hline share of high skilled workers & $(0.439)$ & $(0.281)$ & $(0.423)$ & $(0.287)$ \\
\hline $\begin{array}{l}\text { share of medium skilled work- } \\
\text { ers }\end{array}$ & $\begin{array}{l}-0.157 \\
(0.330)\end{array}$ & $\begin{array}{l}-0.099 \\
(0.244)\end{array}$ & $\begin{array}{l}-0.112 \\
(0.334)\end{array}$ & $\begin{array}{l}-0.040 \\
(0.236)\end{array}$ \\
\hline $\begin{array}{l}\text { firm had process innovations } \\
\text { last period }\end{array}$ & $\begin{array}{c}0.463^{* * *} \\
(0.136)\end{array}$ & $\begin{array}{c}0.127 \\
(0.112)\end{array}$ & $\begin{array}{c}0.409 * * * \\
(0.142)\end{array}$ & $\begin{array}{c}0.084 \\
(0.113)\end{array}$ \\
\hline East & $\begin{array}{l}-0.035 \\
(0.146)\end{array}$ & $\begin{array}{c}-0.271 * * * \\
(0.104)\end{array}$ & $\begin{array}{l}-0.040 \\
(0.146)\end{array}$ & $\begin{array}{c}-0.241 * * \\
(0.106)\end{array}$ \\
\hline ERP & $\begin{array}{c}0.115 \\
(0.154)\end{array}$ & $\begin{array}{c}0.265^{* *} \\
(0.107)\end{array}$ & $\begin{array}{l}-0.108 \\
(0.152)\end{array}$ & $\begin{array}{l}0.240 * * \\
(0.107)\end{array}$ \\
\hline SCM & $\begin{array}{c}0.308 * * \\
(0.153)\end{array}$ & $\begin{array}{c}0.044 \\
(0.094)\end{array}$ & $\begin{array}{l}-0.305^{*} \\
(0.167)\end{array}$ & $\begin{array}{l}-0.010 \\
(0.098)\end{array}$ \\
\hline CRM & $\begin{array}{c}0.101 \\
(0.147) \\
\end{array}$ & $\begin{array}{l}-0.090 \\
(0.092)\end{array}$ & $\begin{array}{c}0.112 \\
(0.144) \\
\end{array}$ & $\begin{array}{l}-0.120 \\
(0.094)\end{array}$ \\
\hline job rotation & - & - & $\begin{array}{c}0.053 \\
(0.181)\end{array}$ & $\begin{array}{c}0.177 \\
(0.116)\end{array}$ \\
\hline quality circles & - & - & $\begin{array}{c}0.500 * * * \\
(0.156)\end{array}$ & $\begin{array}{c}0.044 \\
(0.092)\end{array}$ \\
\hline performance related payment & - & - & $\begin{array}{c}0.144 \\
(0.133)\end{array}$ & $\begin{array}{c}0.018 \\
(0.092)\end{array}$ \\
\hline self dependent working groups & - & - & $\begin{array}{l}-0.029 \\
(0.140)\end{array}$ & $\begin{array}{l}0.211^{* *} \\
(0.096)\end{array}$ \\
\hline change in management & - & - & $\begin{array}{l}0.408 * * \\
(0.172)\end{array}$ & $\begin{array}{l}-0.042 \\
(0.103)\end{array}$ \\
\hline hierarchy flattening & - & - & $\begin{array}{l}-0.393^{*} \\
(0.207)\end{array}$ & $\begin{array}{l}0.218 * \\
(0.126)\end{array}$ \\
\hline constant & $\begin{array}{c}0.315 \\
(0.531)\end{array}$ & $\begin{array}{c}0.960 * * * \\
(0.327)\end{array}$ & $\begin{array}{c}0.208 \\
(0.567)\end{array}$ & $\begin{array}{c}1.194 * * * \\
(0.259)\end{array}$ \\
\hline
\end{tabular}




\begin{tabular}{|c|c|c|c|}
\hline & Specification 1 & \multicolumn{2}{|c|}{ Specification 2} \\
\hline & $\begin{array}{lc}\text { Probit } & \text { Neg. Bin. } \\
\text { Model } & \text { Model }\end{array}$ & $\begin{array}{l}\text { Probit } \\
\text { Model }\end{array}$ & $\begin{array}{l}\text { Neg. Bin. } \\
\text { Model }\end{array}$ \\
\hline alpha & $\begin{array}{c}0.720 * * * \\
(0.119)\end{array}$ & \multicolumn{2}{|c|}{$\begin{array}{c}0.681^{* * *} \\
(0.117)\end{array}$} \\
\hline additional controls & Industry & \multicolumn{2}{|c|}{ Industry } \\
\hline Vuong test & $5.410 * * *$ & \multicolumn{2}{|c|}{$5.990 * * *$} \\
\hline LR test & $1025.7^{* * *}$ & \multicolumn{2}{|c|}{$954.5^{* * *}$} \\
\hline number of observations & 1006 & \multicolumn{2}{|c|}{982} \\
\hline nonzero observations & 637 & \multicolumn{2}{|c|}{621} \\
\hline zero observations & 369 & \multicolumn{2}{|c|}{361} \\
\hline
\end{tabular}

Notes: ${ }^{* * *} \mathrm{p}<0.01,{ }^{* *} \mathrm{p}<0.05,{ }^{*} \mathrm{p}<0.1$; robust standard errors in parentheses.

Source: ZEW ICT survey 2004, 2007 and own calculations.

\subsubsection{Impacts of Enterprise Systems on product innovations}

Moving on to product innovations, Column (1) and (3) of Table 3.4 picture the results of the probit part of the zero-inflated model for both specifications. Accordingly, Column (2) and (4) of Table 3.4 report the estimation results for the negative binomial model part. The impacts of enterprise systems on the probability to become a potential product innovator differ completely compared to the impacts on the decision to process innovate. ERP and SCM systems seem to have no effect on the firms' decision to realize product innovations. However, the significant coefficient of CRM confirms that firms which adopt CRM systems are more likely to acquire new product innovations compared to firms without CRM software systems. This impact stays robust even if one controls for additional organizational practices and firm strategy but does not carry on to increase the expected number of product innovations as the coefficient stays insignificant in the negative binomial model part pictured in Column (2) and (4) of Table 3.4 Although insignificant in the probit part of the model, the adoption of an SCM system significantly increases the expected number of product innovations by the factor of $1.36(=\exp (0.311))$ for the firms in questions. This effect also stays robust if organizational practices and strategy is control for. Firms using ERP systems, however, gain no additional performance in realizing product innovations. Considering the other coefficients in Column (1) and (3) of Table 3.4, the results show that former product innovators and firms relying on a higher capital base face a higher probability of being a potential innovator than firms without product innovations in the last period or a poor capital stock, although this coefficient fails to reach significance in the parsimonious specification. Taking a look at human capital a bigger share of highly skilled workers positively impacts the number of realized product innovations. The education of the highly 
skilled workforce seems to pay off, possibly due to higher creative activity and market knowledge of these workers which in turn results in more product innovations. For product innovation activity, the impact of quality circles, however, turns out to be puzzling. Significantly increasing the overall probability to realize product innovations overall, the expected number of product innovations is significantly decreased if firms rely on established quality circles within their workforce. Interpreting both coefficients carefully together the conclusion could be that quality circles help firms to get started with product innovations or to keep a small number of process innovations ongoing. However, firms with a large pool of product innovations should not expect quality circles to increase their product innovation performance. Similar to the case of process innovations, the regional coefficient turns out to be negatively significant in the negative binomial model part indicating that a firm located in East Germany realizes fewer product innovations compared to firm doing business in the western part of the country.

In addition, the dispersion coefficient alpha stays highly significant throughout all estimations for process as well as product innovations in

Table 3.3 and Table 3.4. The magnitude of these four coefficients indicates a high overdispersion in the data and therefore strengthens the choice of the negative binomial distribution against the alternative of an underlying Poisson distribution. The overdispersion turns out to be larger in case of process compared to product innovations. 
Table 3.4: Determinants of the number of product innovations, zero-inflated neg. binomial estimates

\begin{tabular}{|c|c|c|c|c|}
\hline & \multicolumn{2}{|c|}{ Specification 1} & \multicolumn{2}{|c|}{ Specification 2} \\
\hline & $\begin{array}{l}\text { Probit } \\
\text { Model }\end{array}$ & $\begin{array}{c}\text { Neg. Bin. } \\
\text { Model }\end{array}$ & $\begin{array}{l}\text { Probit } \\
\text { Model }\end{array}$ & $\begin{array}{l}\text { Neg. Bin. } \\
\text { Model }\end{array}$ \\
\hline \multirow[t]{2}{*}{$\ln$ (labor) } & 0.032 & 0.059 & -0.083 & 0.064 \\
\hline & $(0.092)$ & $(0.079)$ & $(0.116)$ & $(0.093)$ \\
\hline \multirow[t]{3}{*}{ In (capital) } & 0.084 & -0.011 & $0.115^{*}$ & -0.009 \\
\hline & $(0.065)$ & $(0.059)$ & $(0.063)$ & $(0.059)$ \\
\hline & 0.081 & -0.172 & 0.038 & -0.120 \\
\hline \multirow[t]{2}{*}{ share of computer workers } & $(0.326)$ & $(0.302)$ & $(0.326)$ & $(0.289)$ \\
\hline & 0.055 & $1.088^{* *}$ & 0.266 & $0.896^{* *}$ \\
\hline \multirow[t]{2}{*}{ share of high skilled workers } & $(0.635)$ & $(0.429)$ & $(0.630)$ & $(0.420)$ \\
\hline & -0.290 & 0.303 & -0.074 & 0.148 \\
\hline share of medium skilled workers & $(0.484)$ & $(0.380)$ & $(0.453)$ & $(0.367)$ \\
\hline firm had product innovations last & $1.363^{* * *}$ & -0.212 & $1.194^{* * *}$ & -0.106 \\
\hline period & $(0.222)$ & $(0.188)$ & $(0.194)$ & $(0.210)$ \\
\hline \multirow[t]{2}{*}{ East } & 0.019 & $-0.395 * * *$ & 0.069 & $-0.419 * * *$ \\
\hline & (0.199) & $(0.141)$ & $(0.204)$ & $(0.142)$ \\
\hline \multirow[t]{2}{*}{ ERP } & -0.113 & 0.149 & -0.130 & 0.195 \\
\hline & $(0.197)$ & $(0.165)$ & $(0.242)$ & $(0.173)$ \\
\hline \multirow[t]{2}{*}{ SCM } & -0.098 & $0.311^{*}$ & -0.170 & $0.331 * *$ \\
\hline & $(0.239)$ & $(0.156)$ & $(0.223)$ & $(0.147)$ \\
\hline \multirow[t]{2}{*}{ CRM } & $0.373 * *$ & -0.034 & $0.353^{*}$ & -0.009 \\
\hline & $(0.201)$ & $(0.148)$ & $(0.214)$ & $(0.146)$ \\
\hline \multirow[t]{2}{*}{ job rotation } & - & - & 0.144 & 0.040 \\
\hline & & & $(0.247)$ & $(0.147)$ \\
\hline \multirow[t]{3}{*}{ quality circles } & - & - & $0.446 * *$ & $-0.357 * *$ \\
\hline & & & $(0.190)$ & $(0.142)$ \\
\hline & - & - & 0.186 & 0.154 \\
\hline \multirow[t]{2}{*}{ performance related payment } & & & (0.199) & $(0.158)$ \\
\hline & - & - & -0.191 & -0.069 \\
\hline self dependent working groups & & & (0.174) & $(0.140)$ \\
\hline \multirow[t]{2}{*}{ change in management } & - & - & 0.013 & 0.086 \\
\hline & & & $(0.206)$ & $(0.153)$ \\
\hline \multirow[t]{2}{*}{ hierarchy flattening } & - & - & -1.012 & 0.160 \\
\hline & & & $(0.731)$ & $(0.201)$ \\
\hline constant & 0.534 & $1.461 * * *$ & 0.700 & $1.056 * *$ \\
\hline
\end{tabular}




\begin{tabular}{|c|c|c|c|c|}
\hline & \multicolumn{2}{|c|}{ Specification 1} & \multicolumn{2}{|c|}{ Specification 2} \\
\hline & $\begin{array}{l}\text { Probit } \\
\text { Model }\end{array}$ & $\begin{array}{c}\text { Neg. Bin. } \\
\text { Model }\end{array}$ & $\begin{array}{l}\text { Probit } \\
\text { Model }\end{array}$ & $\begin{array}{c}\text { Neg. Bin. } \\
\text { Model }\end{array}$ \\
\hline & $(0.975)$ & $(0.392)$ & $(1.205)$ & $(0.540)$ \\
\hline alpha & \multicolumn{2}{|c|}{$\begin{array}{c}1.751^{* * *} \\
(0.100)\end{array}$} & \multicolumn{2}{|c|}{$\begin{array}{c}1.705^{* * *} \\
(0.098)\end{array}$} \\
\hline additional controls & \multicolumn{2}{|c|}{ Industry } & \multicolumn{2}{|c|}{ Industry } \\
\hline Vuong test & \multicolumn{2}{|c|}{$7.070 * * *$} & \multicolumn{2}{|c|}{$7.760 * * *$} \\
\hline LR test & \multicolumn{2}{|c|}{$6202.6^{* * *}$} & \multicolumn{2}{|c|}{$6084.6^{* * *}$} \\
\hline number of observations & \multicolumn{2}{|c|}{1012} & \multicolumn{2}{|c|}{989} \\
\hline nonzero observations & \multicolumn{2}{|c|}{571} & \multicolumn{2}{|c|}{555} \\
\hline zero observations & \multicolumn{2}{|c|}{441} & \multicolumn{2}{|c|}{434} \\
\hline
\end{tabular}

Notes: $* * * p<0.01, * * p<0.05, * p<0.1$; robust standard errors in parentheses.

Source: ZEW ICT survey 2004, 2007 and own calculations.

\subsubsection{Robustness Checks}

In this section I employ several robustness checks to secure the validity of the results obtained above. The first check offers a test of the results if only innovators are concerned. The second check proves the results if the dummies for enterprise system usage are measured differently. The last check explores a potential complementarity or substitability relationship between the employed organizational practices and the enterprise system in use.

\subsubsection{Innovators only}

Given that the reported number of innovations seems to form clusters and show a large variance, especially for reported product innovations, I employ an additional robustness check by taking only innovators into account and moving from count data to continuous values. To obtain continuous values I use the number of innovations in logarithms ${ }^{20}$ as the dependent variable and estimate the research specification for process and product innovations using ordinary least squares. This estimation approach is roughly comparable to the negative binomial part of the zeroinflated model and should provide qualitatively similar results. Table 3.5 captures the results for this robustness check, picturing the parsimonious specification ${ }^{21}$ and

\footnotetext{
${ }^{20}$ For firms reporting only one innovation I set the number to 1.0001 in order not to lose additional observations when applying the logarithm.

${ }^{21}$ The results of the specification including the additional organizational control variables are neglected here as they turn out to be qualitatively similar to the ones obtained from the parsimonious specification. However, these results are available from the author upon request.
} 
covering process innovations in the left and product innovations in the right column. Overall, the coefficients of the same enterprise systems which positively impacted the expected number of innovations in the negative binomial model part in the main results pictured in

Table 3.3 and Table 3.4, i.e. ERP for process and SCM for product innovations, turn out to be positive and significant, confirming the results. However, as the sample is reduced by one half most of the variation of the number of innovations in logarithms is explained by the industry sector control dummies (not reported), rendering most other coefficients insignificant. Therefore, the potentially big impact of enterprise system usage on innovation performance is confirmed even further as their coefficients stay significant even in this reduced sample.

Table 3.5: Robustness check - Innovators only

\begin{tabular}{lcc} 
& Process Innovation & Product Innovation \\
\hline In (labor) & $0.066^{*}$ & 0.076 \\
& $(0.035)$ & $(0.051)$ \\
In (capital) & 0.011 & -0.018 \\
& $(0.028)$ & $(0.039)$ \\
share of computer workers & 0.132 & 0.031 \\
& $(0.138)$ & $(0.203)$ \\
share of high skilled workers & -0.100 & $0.535^{*}$ \\
share of medium skilled work- & $(0.217)$ & $(0.315)$ \\
ers & -0.061 & 0.179 \\
firm had process/product & $(0.184)$ & $(0.258)$ \\
innovations last period & 0.129 & -0.101 \\
East & $(0.085)$ & $(0.130)$ \\
& -0.223 & $-0.191^{*}$ \\
ERP & $(0.244)$ & $(0.104)$ \\
& $0.174^{* *}$ & 0.067 \\
SCM & $(0.077)$ & $(0.111)$ \\
& 0.039 & $0.217^{* *}$ \\
CRM & $(0.075)$ & $(0.108)$ \\
& -0.071 & -0.035 \\
constant & $(0.073)$ & $(0.103)$ \\
\hline number of observations & $1.109 * * *$ & $1.730^{* * *}$ \\
\hline Notes:*** p 0.413$)$ \\
\hline
\end{tabular}

Notes: ${ }^{* *} \mathrm{p}<0.01,{ }^{*} \mathrm{p}<0.05,{ }^{*} \mathrm{p}<0.1$; robust standard errors in parentheses.

Source: ZEW ICT survey 2004, 2007 and own calculations. 


\subsubsection{Alternative measurement of enterprise system usage}

A second robustness check concerns the measurement of the enterprise systems as explanatory variables. As stated in section 3.4 the firms could not use the system at all, to a minor degree or broadly. Therefore, the definition of these explanatory variables is arbitrary, to some extent, and one could also construct a dummy variable comprising the broad usage in the value one and minor or no use in the zero value. Additionally, one could also observe minor software usage in the value one of the dummy variable compared to no or broad usage captured in the zero. Repeating the estimation procedure with all these new dummy variables for enterprise system usage included should provide hints for the impacts of minor as opposed to broad software usage. Minor usage could be interpreted as software which is only used by some employees, departments or subsidies whereas broad describes the usage all over the firm. However, the questionnaire did not make any distinction between these categories and did not provide additional information for minor and broad usage offering no sustainable basis for this interpretation.

Table 3.6 pictures the results of this second robustness check for process and product innovations for the parsimonious specification, reporting only the coefficients of interest, i.e. the coefficients of enterprise systems usage, and neglecting all other coefficients as they are qualitatively similar compared to the results obtained in section 3.5.2 and 3.5.322. Overall, the direction of the coefficients seems to be similar as before as most of them turn out to be positive. However, the significance of all enterprise system coefficients vanishes for the probit part of the model. The SCM usage coefficients for process innovations and the coefficients for CRM usage in the case of product innovations are nearly weakly significant ${ }^{23}$ though, pointing in the direction of robust results for the SCM and CRM coefficients in the main estimations. Nevertheless, the probit part coefficients obtained in the main estimates should be interpreted carefully. Concerning the negative binomial model the positive significant impact of ERP on process innovation activity and of SCM on product innovation activity turns out to be strongly in accordance with the results obtained before, although it is based on broad software usage in this robustness check. Given these results and the results of the first robustness check, the ERP and SCM coefficients in the negative model part of the main estimations in section 3.5.2 and 3.5.3 behave robust to different specifications and offer no concern for potential biases.

\footnotetext{
${ }^{22}$ The complete tables of this robustness check are available from the author upon request.

${ }^{23}$ The p-values are 0.185 (broad) and 0.105 (minor) for SCM usage. For CRM usage the respective pvalues are 0.136 (broad) and 0.112 (minor).
} 
Table 3.6: Robustness check - Alternative measurement of enterprise system usage

\begin{tabular}{l|cc|cc} 
& \multicolumn{2}{c}{ Process Innovations } & \multicolumn{2}{c}{ Product Innovations } \\
& Probit Model & Neg. Bin. Model & Probit Model & Neg. Bin. Model \\
\hline ERP broad & 0.119 & $0.314^{* * *}$ & -0.06 & 0.289 \\
& $(0.166)$ & $(0.117)$ & $(0.236)$ & $(0.190)$ \\
SCM broad & 0.310 & -0.135 & -0.137 & $0.440^{* *}$ \\
& $(0.234)$ & $(0.133)$ & $(0.292)$ & $(0.190)$ \\
CRM broad & 0.256 & -0.071 & 0.381 & 0.007 \\
& $(0.223)$ & $(0.115)$ & $(0.255)$ & $(0.196)$ \\
ERP minor & 0.132 & 0.181 & -0.161 & -0.017 \\
& $(0.197)$ & $(0.129)$ & $(0.228)$ & $(0.187)$ \\
SCM minor & 0.297 & 0.129 & -0.123 & 0.234 \\
& $(0.183)$ & $(0.104)$ & $(0.265)$ & $(0.168)$ \\
CRM minor & 0.037 & -0.113 & 0.386 & -0.115 \\
& $(0.162)$ & $(0.105)$ & $(0.243)$ & $(0.160)$ \\
\hline
\end{tabular}

Notes: ${ }^{* * *} \mathrm{p}<0.01,{ }^{*} \mathrm{p}<0.05, * \mathrm{p}<0.1$; robust standard errors in parentheses.

Source: ZEW ICT survey 2004, 2007 and own calculations.

\subsubsection{Organizational practices and enterprise systems}

In general, the organizational practices firms rely on can also be expected to be enabled by IT-usage as complementary investments (e.g. Black and Lynch 2001; Bresnahan et al. 2002). Therefore, it may be the case that the organizational practices employed and the enterprise systems used by firms act as complements to some extent, even for their impacts on innovation performance. Especially the indirect impacts of enterprise systems on innovation performance pictured in section 3.2 might in parts run through adopted organizational practices as these practices might also enhance and facilitate communication and the flow of information forming knowledge spillovers which increase innovation performance.

To test for complementarity I rely on the established standard interaction terms as used in, e.g., Athey and Stern (2002). However, covering five organizational practices and three enterprise systems clear-cut results cannot emerge as these many interactions are not suited for the given model framework. Therefore, in order to achieve useful results, and being careful concerning the degrees of freedom as there is no evidence for the performance of the zero-inflated model with interactions based on appropriate Monte Carlo experiments at the moment, I use one measure of decentralization as proposed in Acemoglu et al. (2007) instead of five different organizational practices for inference. Decentralization, in general, en- 
compasses organizational practices which allow for decision autonomy and self dependence of employees as well as managers and is henceforth argued to positively impact innovation and firm performance (Ettlie et al 1984; Chang and Harrington Jr 2000). To cover the decentralization efforts of firms I construct a dummy variable capturing the organizational practices of self dependent working groups and hierarchy flattening which both allow for increased autonomy in decision making for employees and managers alike. If a firm reports the usage of at least one of those practices the decentralization dummy is assigned one and zero elsewise. The interaction terms are then built via multiplying the enterprise software usage dummies with the decentralization measure, summing up to three interaction terms.

To obtain first baseline results concerning potential complementarity I repeat the estimation procedure for process and product innovations using the interaction terms in the zero-inflated model. However, including all interactions in one model returns highly biased coefficients or achieves no convergence of the likelihood function at all, possibly due to high multicollinearity among the interaction terms and the dummy variables. Therefore, being appropriately careful I run one estimation based on the parsimonious specification for each interaction, including the other two enterprise system measures, the other organizational practices and the change in the management board as additional controls. Table 3.7 reports the results for these additional regressions for product and process innovations, however, for an overview, only the coefficients of interest, i.e. the interaction terms of enterprise systems and the decentralization dummy are pictured ${ }^{24}$. The interpretation of these interaction terms is straightforward as positive significant coefficients indicate complementarity relationships whereas negative significant coefficients capture substitutability relationships. Overall, only one significant result emerges, showing a complementarity relationship between ERP usage and the decentralization efforts of a firm in their impact on the number of product innovations realized. Establishing an ERP system in combination with decentralization techniques increases the number of expected product innovations by the factor of 2.14 (=exp(0.765)) for a utilizing firm. In addition, ERP does not directly impact product innovation performance as the coefficient turns out to be insignificant in the main estimation results pictured in Table 3.4 and is still insignificant in the specification included the interaction term (not depicted). Therefore, this complementarity relation highlights the mentioned indirect impacts of enterprise systems on the innovation performance which seem to emerge only if appropriate organizational practices are also in use. In case of ERP, the enhanced network capabilities and fastened connections between the business

\footnotetext{
${ }^{24}$ The complete tables are available from the author upon request. Overall, the results do not change qualitatively compared to the main results pictured in
}

Table $\mathbf{3 . 3}$ and Table 3.4. 
units are only effective if the utilizing firm capitalize these benefits with an additional decentralized decision structure, thereby enhancing information processing and communication even further. For SCM and CRM software systems, on the other hand, additional complementary benefits based on the employed organizational practices do not emerge.

Table 3.7: Robustness check - Interaction effects

\begin{tabular}{l|cc|ccc}
\multicolumn{3}{c}{} & \multicolumn{2}{c}{ Process Innovations } & \multicolumn{2}{c}{ Product Innova- } \\
& Probit & Neg. Bin. & Probit & Neg. Bin. \\
& Model & Model & Model & Model \\
\hline Interaction of decentralization with & 0.161 & -0.115 & 0.275 & $0.765^{* * *}$ \\
ERP & $(0.264)$ & $(0.197)$ & $(0.327)$ & $(0.292)$ \\
Interaction of decentralization with & 0.040 & 0.193 & 0.068 & -0.126 \\
SCM & $(0.390)$ & $(0.210)$ & $(0.426)$ & $(0.326)$ \\
Interaction of decentralization with & 0.017 & 0.280 & -0.157 & 0.354 \\
CRM & $(0.288)$ & $(0.189)$ & $(0.377)$ & $(0.317)$ \\
\hline
\end{tabular}

Notes: $* * * p<0.01, * * p<0.05, * p<0.1$; robust standard errors in parentheses.

Source: ZEW ICT survey 2004, 2007 and own calculations

\subsection{Conclusion}

Enterprise systems are nowadays widely spread among different industries around the world. Although it is argued that enterprise systems increase firm performance (e.g. Aral et al. 2006; Engelstätter 2012b; Hitt et al. 2002) their impact on innovation performance is momentarily only suspected. Empirical evidence concerning a relationship between enterprise systems and innovation performance is still missing at present.

The current study aims at filling this gap by empirically exploring the impact of the three enterprise systems ERP, SCM and CRM on the innovation performance of firms for process as well as product innovations. Using a zero-inflated negative binomial model consisting of two parts, one explaining the decision to innovate and the other explaining the number of innovations for potential innovators, the results confirm the expected positive impacts of enterprise system usage on the firms' innovation performance. The results also stay robust to several different specifications including different model approaches. Concerning process innovations, the results reveal that firms with established SCM systems face a higher probability of being a potential innovator compared to firms without SCM systems in use. In addition, the adoption of an ERP system positively affects the number of realized pro- 
cess innovations. In the case of product innovations, firms using a CRM system, on the other hand, face an overall higher probability of realizing production innovations in comparison with firms lacking running CRM systems. In addition, an established SCM system significantly increases the expected number of realized product innovations. The number of expected product innovations is also increased if firms rely on an ERP system in combination with decentralized decision structure as the results confirm a complementarity relationship between an ERP software system and organizational practices focusing on decentralization.

The results reveal a new aspect of benefits through enterprise system usage as, leaving the expected fast evolving productivity and efficiency gains aside, enterprise systems also foster the firms' innovation performance. In addition to this theoretical contribution the results have several practical implications: First of all, managers should not only focus on costs and expected fast evolving performance benefits when deciding to buy or upgrade enterprise systems, as the performance increase in innovation activity due to enterprise software usage takes time to develop. Especially the increased process innovation performance via ERP and SCM adoption might, after a few years, even cut down costs for the firm in a larger amount overall compared to the investments in enterprise systems. On the other hand, new product innovations developed from CRM data and managed with the information processing capabilities of SCM and ERP might directly increase firms' financial performance via opening up new market segments or simply by increasing sales.

A potential short-coming of the analysis is a timing issue. The current dataset offers no way to control for the age of the enterprise systems in use as the purchase time or the time of introduction were not explicitly inquired. In line with that, one has to assume that innovations evolve regularly from having an enterprise system installed and probably do so for a long time. Based on this assumption the results might be biased as the impacts of the enterprise systems on innovation performance could be mitigated as these impacts might already be experienced much earlier. This potential caveat could be addressed with an appropriate panel analysis, however, the current dataset provides no perfectly utilizable panel structure due to high panel mortality paired with item non-response. Furthermore, as the zero-inflated model is not sufficiently tested and established for the panel use a different specification to picture the data generating might have to be chosen if a panel is used for inference. Nevertheless, future availability of new data may allow the exploration of enterprise software and legacy system age and cost levels, at best in a structured panel over several years enabling researchers to utilize and test the performance of the random effects zero-inflated model. Secondly, the data offers no information about implementation problems or costs of the enterprise systems installed. Accordingly, one has to use dummy proxy variables instead which might result in unobserved 
heterogeneity the estimation procedure cannot completely account for. Future availability of new data may offer the opportunity to control even for this very special case of firm heterogeneity.

\subsection{Appendix Chapter 3}

\section{Survey-Question for enterprise system usage:}

Which application or system do you use in your daily business routine? Please state if the application or system is used to minor degree, broadly or not at all.

software for planning and controlling, e.g. SAP/R3 (ERP system from SAP)

customer relationship management (CRM)

supply chain management (SCM)

Table 3.8: Distribution of enterprise systems usage

in initial survey

\begin{tabular}{l|ccc} 
& ERP & SCM & CRM \\
\hline no answer & 0.98 & 0.93 & 0.84 \\
no usage & 34.93 & 56.20 & 45.61 \\
minor usage & 18.06 & 24.81 & 32.85 \\
broad usage & 46.04 & 18.06 & 20.71 \\
\hline number of observa- & & & \\
tions & 4203 & 4308 & 4308 \\
\hline
\end{tabular}

Source: ZEW ICT survey 2004 and own calculations.

in end sample used for estimations (after controlling for item non-response and panel mortality):

\begin{tabular}{l|ccc} 
& ERP & SCM & CRM \\
\hline no usage & 39.00 & 59.83 & 47.80 \\
minor usage & 19.74 & 23.25 & 32.19 \\
broad usage & 41.27 & 16.92 & 20.01 \\
\hline number of observa- & & & \\
tions & 1454 & 1454 & 1454 \\
\hline
\end{tabular}

Source: ZEW ICT survey 2004 and own calculations. 



\title{
Chapter 4
}

\section{Does Enterprise Software Matter for Service Innovation? Standardization versus Customization ${ }^{\S}$}

\begin{abstract}
This paper analyzes the relationship between service innovation and different types of enterprise software systems, for example standardized enterprise software designed to fit one certain business sector and enterprise software specifically customized for a single firm. Using recent firm-level data of a survey among information and communication technology service providers as well as knowledge-intensive service providers in Germany, this is the first paper which empirically analyzes the question whether the use of sector specific or customized enterprise software triggers innovation. The results based on a knowledge production function suggest that customized enterprise software is related to the occurrence of service innovation. However, there is no relationship between sector specific enterprise software and innovation activity. These results stay robust to several different specifications and suggest that the causality runs from customized software usage to service innovation.
\end{abstract}

Keywords: enterprise systems, service innovation, customized enterprise software, sector specific enterprise software, service sector

JEL Classification: L10, M20, O31

\footnotetext{
$\S$ This chapter is co-written with Miruna Sarbu (ZEW, ICT Research Group) and currently under revise and resubmit at Economics of Innovation and New Technology.
} 


\subsection{Introduction}

A large range of enterprise software products nowadays supports day-to-day business operations, controls manufacturing plants, schedules services or facilitates decision-making. The purpose of these software applications is, in general, to automate operations reaching from supply management, inventory control or sales force automation to almost any other data-oriented management process. Especially in many fields like semiconductors, biotechnology, information and telecommunication or other knowledge-intensive industry branches, employees might be able to observe, measure or even envision certain phenomena only by using specific enterprise software applications. SAP, the largest global enterprise software vendor, estimates the adressable market for enterprise software applications to be roughly $\$ 110$ billion in 2010 (SAP 2010).

Overall, enterprise software can be categorized into three types, as users distinguish between generic applications such as an enterprise resource planning system purchased in standardized form from the vendor ${ }^{25}$, software systems or special modules specifically designed to fit one business sector ${ }^{26}$ or completely customized enterprise software packages developed for a single firm in particular and adopted to its specific needs ${ }^{27}$. Thus, customized enterprise software systems are usually unique.

Although the usage of information and communication technology (ICT) applications in general is suspected to enhance firms' innovative activity (Hempell and Zwick 2008; Engelstätter 2012a; Brynjolfsson and Saunders 2010), the potential impact of sector specific or completely customized enterprise software on innovation performance in particular is still not investigated. The literature in this field is scarce, offering only a few studies which examine the benefits of enterprise software for innovation activity, see e.g. Shang and Seddon (2002). Empirical evidence is even scarcer, provided only by Engelstätter (2012a) who outlines the impact of three common generic enterprise systems on firms' ability to realize process and product innovations. However, being more general based on the available sample, Engelstätter (2012a) does not picture the impacts of enterprise software on specific service innovations. Those service innovations might be driven by other characteristics such

\footnotetext{
${ }^{25}$ E.g. SAP Business One or Oracle E-Business Suite.

${ }^{26}$ Examples for sector specific enterprise software contain computer aided design or manufacturing programs, e.g., solutions offered from Sage.

${ }^{27}$ Examples here are completely designed software solutions like applications from firms as, for instance, Supremistic or Jay Technologies Inc. In addition, firms could also augment generic solutions like SAP packages with custom-made modules.
} 
as enhanced knowledge handling or contact to customers compared to mainly research driven innovations in manufacturing. However, to succeed in realizing innovations in dynamic, information-rich environments like the service sector a firm should engage in a combination of different practices like promoting information absorption and diffusion, knowledge handling or development of an extended intraand inter-organizational network (Mendelson and Pillai 1999). Engaging in these practices, however, is expected to be facilitated with advanced knowledge handling and storing capabilities of utilized enterprise software. In light of this research gap, the current study provides the first empirical evidence of the impact of business sector specific or customized enterprise software on firms' innovative performance for the specific case of service firms.

Our study relies on a unique database consisting of 335 German firms from ICT and knowledge-intensive service sectors. As analytical framework we employ a knowledge production function for our empirical analysis. Based on a probit approach, the results indicate that service firms relying on customized enterprise software have a higher probability of realizing service innovations compared to firms not using customized software packages. Concerning sector specific enterprise software we find no evidence of a positive impact on service firms' innovative activity. These results stay robust to many specifications controlling for different samples sizes and several sources of firm heterogeneity like size, age, workforce structure, competitive situation or prior innovative experience.

The paper proceeds as follows: Section 4.2 presents the methodological framework. Section 4.3 introduces the dataset. The estimation procedure is derived in section 4.4 and section 4.5 presents the estimation results. Section 4.6 concludes.

\subsection{Methodological and Theoretical Framework \\ 4.2.1 Background}

In brief, this study relates to the literature picturing the impacts on firm performance and innovation activity of ICT in general and of enterprise software in particular. Supporting the optimization of firms' business processes ICT is expected to enable productivity and performance gains, see e.g. Brynjolfsson and Hitt (2000). A crucial prerequisite for these productivity gains, however, is the firms' innovation activity (Crépon et al. 1998; Hall et al. 2009). In general, the link between ICT and innovation is not as extensively studied in the empirical literature as the relationship between ICT and productivity. Studies investigating the effects of ICT investments on innovative performance at the firm level usually report a positive and significant impact which may emerge directly, see e.g. Gera and Gu (2004), or indirectly via 
complementary assets as shown in Bresnahan et al. (2002) or Hempell and Zwick (2008).

For the literature focusing on enterprise software in particular the picture is similar to general ICT literature as there are many studies extensively examining the performance impacts of the software and nearly no analysis examining potential innovation impacts. In general, enterprise software can be roughly categorized in three types: generic applications, business sector specific software packages and lastly software specifically designed or customized for a single firm. Possible impacts of unspecific generic enterprise software systems, like, e.g., enterprise resource planning, on firm performance are extensively covered in the literature . In these performance analyses a wide range of performance measures is concerned, e.g. several return measures like return on equity, investment, assets or sales (Hunton et al. 2003; Hunton and Wier 2007; Hendricks et al. 2007) as well as labor productivity, net profit margin or value added (Hitt et al. 2002; Shin 2006; Wieder et al. 2006). Thereby, the reported positive performance impacts are linked to the benefits the enterprise software systems provide to a utilizing firm, e.g. enhancing operational and business planning capabilities, facilitating financial transaction handling or procurement. As for the impacts of generic enterprise software on innovation performance, Engelstätter (2012a) empirically shows that different types of enterprise software systems enhance the using firms' innovative activity resulting in more realized process respectively product innovations. However, analyses of potential innovative impacts of sector specific or customized enterprise software packages, are completely missing in the literature at the moment. Our study aims at filling this research gap starting out by picturing the impacts of these specific software packages on firms' innovation activity. For our analysis, we rely on firms from ICT and knowledge intensive service sectors as business sector specific software packages are incomparable between manufacturing and service firms.

\subsubsection{Service Innovations in General}

In general, the nature of services complicates the use of traditional economic measurements for innovations as this field is very heterogeneous due to features like intangibility, interactivity and coterminality (Gallouj and Weinstein 1997). In detail, services turn out to be intangible, because they are hard to store or transport and can sometimes not even be displayed to a customer in advance (Hipp and Grupp 2005). Interactivity is constituted in high communication and coordination needs between client and supplier as in most cases both have to be present for the transaction. Coterminality captures the fact that services are often produced and consumed at the same place and time. Accordingly, service innovation might focus 
exclusively on these three typical features (Miles 2005, 2008) blurring the lines between product, process and organizational innovations in service sectors.

For service innovation, key elements are, in particular, internal knowledge within the firm and its employees and the external network of the firm including customers and other businesses (Sundbo 1997). Human capital, especially personal skills like experience or extensive consumer contact, and knowledge about markets, consumer habits and tastes are important for realizing innovations in a service company (Meyer 2010). In addition, sources of information like consumers and suppliers of equipment can provide essential clues for service enhancement and advancement.

The analysis of the relationship between ICT and service innovations is, in general, structured in two different approaches. The first one interprets the introduction of technical equipment or ICT directly as a service innovation or at least as a starting point for it. The second group of studies, in turn, deals with non-technical, serviceoriented innovation (Meyer 2010). Analyzing the relationship between ICT-use, e.g. enterprise software, and service innovation, the current study takes on the second approach as ICT is not purely meant to provide already established services. In contrast, ICT is intended to improve and enhance knowledge processing as well as the connections of the information sources needed to realize service innovations positively impacting innovation performance.

\subsubsection{Enterprise Software and Service Innovations}

Each type of enterprise software may impact the firms' innovation activity through different channels, either directly on the benefits provided or indirectly if the software fosters the introduction of organizational enhancements improving the innovation process. Overall, all software types share enhanced information handling and processing thereby facilitating communication, knowledge transfer and contact maintenance between employees or consumers and partners. Sharing internal knowledge and connecting to the external network of firms the enterprise software packages can directly be expected to contribute to the realization of service innovations. Besides these basic features the examined types of enterprise software offer additional features potentially impacting innovative activity. Accordingly, the following section starts out highlighting the impacts of sector specific and customized enterprise software on firms' innovation performance and continues picturing indirect impacts on innovation performance both types of enterprise software share. 


\subsubsection{Sector Specific Enterprise Software}

Business sector specific enterprise software, whether employed as a module enhancing a generic system or a standalone package, is expected to facilitate the knowledge handling, storing and accumulation of a firm. Offering and presenting information in an adequate manner and providing frequently updated real-time databases, sector specific software might function as a "softer" source of innovation according to Tether (2005) and can be expected to improve innovative performance in service firms. Empirical evidence of these positive impacts of sector specific enterprise software is provided by Thomke (1998) who shows that the use of specific computer simulation software in the automotive industry is associated with overall better R \& D output. However, some industry branches like e.g. biotechnology, semiconductors or architects need sector specific enterprise software packages like computer aided architecture or manufacturing to complete even the simplest business tasks. In this case, sector specific software can be viewed as a necessary working tool which is not associated with innovation and not intended to shape the innovation process. Therefore, it may also be the case that this kind of software has no impact on firm's innovative performance at all as it is a standard working tool obtained and used as soon as possible mitigating any impact on innovative performance.

\subsubsection{Customized Enterprise Software}

If a firm instead or additionally employs enterprise software, which is specifically designed for the own company, all the potential benefits mentioned due to enhanced knowledge processing can even be expected to increase. Having influence on the development of this software, a firm can incorporate long-term experience and knowledge in the software application, making it perfectly suitable for fulfilling all requirements for their specific business resulting in shortened reaction times. Taking part in the software development may be particularly useful for firms in the dynamic service sector where firms face a high degree of heterogeneity. For this turbulent firm environment Pavlou and El Sawy (2006) show that the ability to effectively use IT functionalities is associated with competitive advantages in new product development. However, dynamic capabilities implying the ability to reconfigure the functionalities are needed to achieve these advantages. This necessary reconfiguration turns out to be more feasible if the employed software system is customized with regard to effective execution and reconfiguration of operational new product development processes.

Being able to directly construct and shape the employed enterprise software in a way that includes and reflects all needed business processes and tasks, a service firm might be able to quickly deliver information where it is needed. Besides en- 
hanced knowledge processing and strengthened connections between sources of information, customized enterprise software could equip the firm with forecasting and detection instruments enabling it to check for potential changes in its external operating environment or benefits and costs of innovations ahead of time. With shortened response times to such changes or cost and benefit analyses due to quick information delivery and enhanced communication structures utilizing firms exhibit an increased external focus which is hypothesized to increase the returns on information technology (Tambe et al. 2011). Tambe et al (2011) also show that in combination with decentralization and the use of sophisticated information technology like, e.g., enterprise software solutions the external focus leads to improved innovation performance. The necessary decentralization, however, is associated with customized enterprise software usage (Gronau 2010). In a case study Malhorta et al. (2001) offer first evidence of the positive impacts of customized enterprise software on firms' innovative performance as they show that virtual teaming yields crucial innovations at Boeing-Rocketdyne. The enterprise software the team needs for collaboration was explicitly developed and customized by a third party in response to a list of specified requirements offering the team a technology suited to their pre-defined needs.

\subsubsection{Enterprise Software in General}

Besides these direct effects, each type of enterprise software in general might also indirectly increase innovation activity as the software applications may help to realize some organizational enhancements which have been proven to facilitate the realization of more innovations. Thus, Tsai (2001) proclaims that business units become more innovative once they reach a more centralized network position that allows them to retrieve new knowledge generated by other units and also necessary information from them faster. Business sector specific enterprise software rightly fits into this context as the software applications advance the intern network and knowledge processing capabilities of the firm, e.g., by providing a centralized database with access for all employees and business units, fastening connections between them. Additionally, customized software can be expected to picture the adequate organizational structure of the utilizing firm thereby enhancing the firms' communication methods. With communication between employees and business units accelerated and broadened in this way the innovation activity of the firm might, according to Tsai (2001), also increase.

Criscuolo et al. (2005) argue that firms generate more innovations with established upstream/downstream contacts to suppliers and customers. This relation especially holds for service innovations as customers and suppliers can be providers of essential guidelines and ideas for enhancement and advancement of provided services. 
Roper et al. (2006) even support this argument as they stress the high value of backwards and horizontal knowledge linkages for innovations. Facilitating not only firms' internal communication, enterprise software also offers applications to enhance the communication structure outside the boundaries of the firm, making maintaining current and generating new contracts with suppliers and customers far easier, especially if the firms employ customized software with specifically developed components for communication, like customized or modified customer or supplier relationship management systems. Accordingly, firms with enterprise software in use have access to a large pool of knowledge, which can be expected to be helpful in creating more innovations.

Based on the literature and the expected benefits of enterprise software systems we carefully hypothesize that sector specific as well as customized enterprise software positively impact firms' innovative performance.

\subsection{Description of Data}

The data we use in this study are taken from the quarterly business survey among the "service providers of the information society" conducted by the Centre for European Economic Research (ZEW) in cooperation with the credit rating agency Creditreform. The sector "service providers of the information society" comprises nine sectors, three of information and communication services sectors and six knowledge-intensive services sectors ${ }^{28}$. Every quarter, a one-page questionnaire is sent to about 4.000 mostly small and medium-sized companies. The sample is stratified with respect to firm size, region (East/West Germany) and sector affiliation. The survey achieves a response rate of about $25 \%$ each wave and builds a representative sample of the German service sector. The interviewed candidates may choose between responding via pen and paper, fax or online. The questionnaire consists of two parts. In the first part of the questionnaire, companies complete questions on their current business situation with respect to the previous quarter as well as their expectations for the next quarter. The second part is dedicated to questions concerning diffusion and use of ICT and further firm characteristics like innovative activities or training behavior. The questions in the second part change every quarter but might be repeated annually or biyearly. Details on the survey design are presented in Vanberg (2003). The survey is constructed as a panel. The questions covering enterprise software usage were only included in the second quarter of 2007 . The questions about innovative activities were asked in the second quarter of 2009. Thus, a panel data analysis cannot be provided in this paper. Accordingly, we focus on a cross-section analysis by merging the second wave of the year 2007 to cover enterprise software usage and the second wave of the year 2009 to cover firms'

\footnotetext{
${ }^{28}$ The industry sectors are listed in Table 4.3 in the appendix.
} 
innovative activity thereby forming a well-defined temporal sequence. Considering item non-response for enterprise software and innovation, a sample consisting of 336 firms remains.

According to the OSLO Manual (2005) we define service innovations in our analysis as a completely new service or an essential improvement ${ }^{29}$ to an existing service that has been introduced between June 2008 and June 2009. Service innovation performance representing the dependent variable in our empirical analysis is accordingly measured as a dummy variable that takes the value one for firms realizing a service innovation and zero otherwise.

In the survey, the firms were asked about using two types of enterprise software, i.e. sector specific software and customized software. The variables capturing the use of enterprise software are dummy variables which take the value one if a firm uses the respective type of enterprise software in June 2007 and zero otherwise. Figure 3 shows that more than three quarters of the service firms use sector specific software and 38 percent of the firms use customized software. However, both software types are non exclusive. Hence, some firms also have customized as well as sector specific software systems running (27 percent, not reported).

Overall, 39 percent of the firms in our sample reported realizing a service innovation between June 2008 and June $2009^{30}$. For a first illustration Figure 3 also pictures the share of firms which realized a service innovation and also use enterprise software. Concerning sector specific enterprise software the according share amounts to 37 percent. In contrast, more than half of the firms using customized enterprise software realized service innovations in the covered time period. This relatively high share yields first descriptive evidence for our hypothesis that the use of customized enterprise software seems to foster the innovative activity in service firms. However, for sector specific enterprise software there is no descriptive evidence for a positive innovative impact.

\footnotetext{
${ }^{29}$ Based on such improvements firms might also realize productivity gains placing this study also in the literature of IT and productivity. However, as these improvements are determined as service innovations (Oslo Manual 2005) we refrain from the IT and productivity literature branch and focus only on the innovative impacts of IT.

${ }^{30}$ See the summary statistics pictured in Table 4.1.
} 
Figure 3: Usage of Enterprise Software and Service Innovation

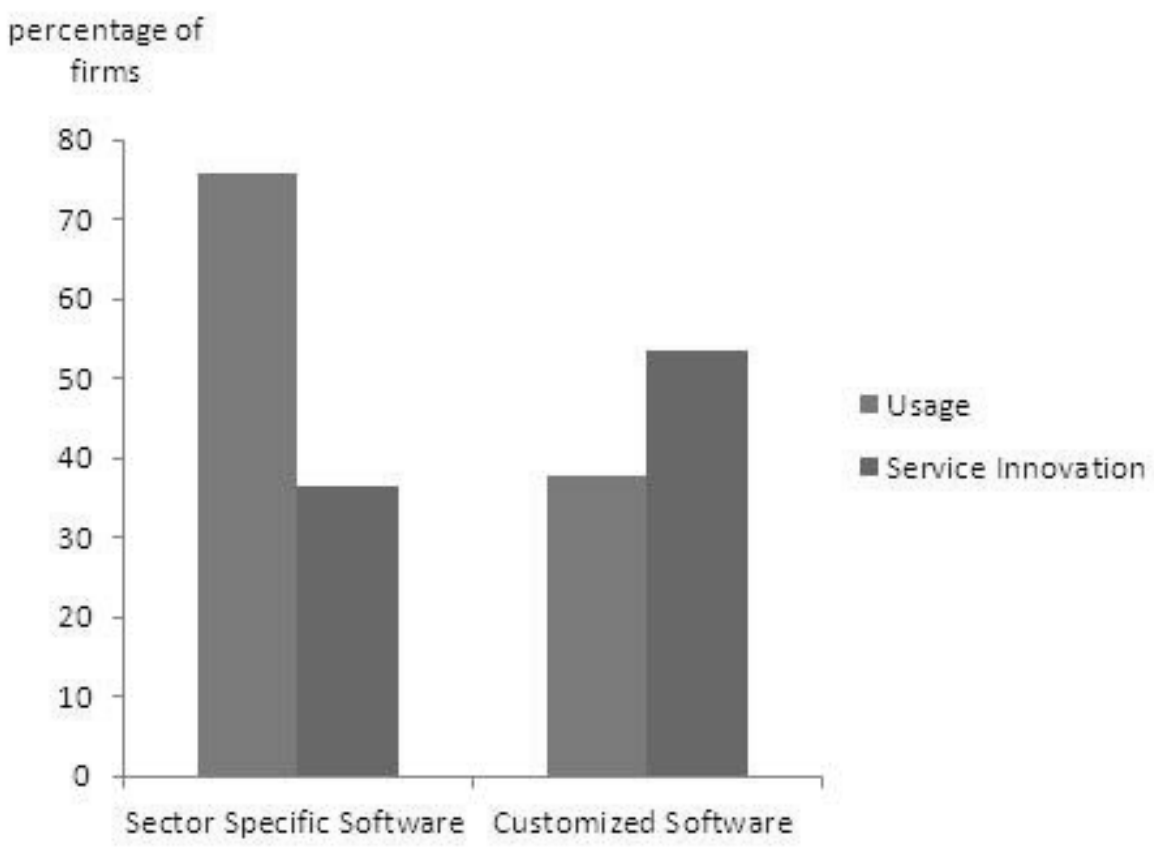

For a further overview, Table 4.1 provides summary statistics for our employed sample. We describe the construction of each variable and its relationship to service innovations in the next section in detail. However, it stands out that our representative sample of the German information service sector contains mostly small and medium sized enterprises with 38 employees at mean. Nevertheless, it seems like bigger firms are more eager to employ customized enterprise software solutions as the mean size amounts to 52 employees for firms using customized software (not reported). The appropriate mean in size for firms relying on sector specific software systems, in contrast, turns out to be smaller (36, not reported). Two different reasons might explain this issue. First, large firms generally tend to have the financial infrastructure to implement big and complicated customized software solutions. Secondly, the firm structure and business processes in large service firms might, in comparison to the situation in small firms, reach such a high level of complication and integration a simple generic enterprise software solution might be unable to handle. Accordingly, large firms may rely on customized software systems suited for their specific needs more frequently. As one might argue that those large firms could possibly drive the results of our empirical analysis we conduct appropriate robustness checks in the following. 


\begin{tabular}{|c|c|c|c|c|}
\hline Variable & Mean & Min. & Max. & $\mathbf{N}$ \\
\hline service innovation & 0.386 & 0 & 1 & 336 \\
\hline sector specific software & 0.758 & 0 & 1 & 336 \\
\hline customized software & 0.380 & 0 & 1 & 336 \\
\hline number of employees & 38 & 1 & 449 & 334 \\
\hline log (number of employees) & 2.718 & 0 & 6.107 & 334 \\
\hline firm age & 20 & 2 & 108 & 310 \\
\hline log (firm age) & 2.851 & 0.693 & 4.682 & 310 \\
\hline 0-5 competitors & 0.243 & 0 & 1 & 312 \\
\hline 6-20 competitors & 0.304 & 0 & 1 & 312 \\
\hline more than 20 competitors & 0.451 & 0 & 1 & 312 \\
\hline share of employees working with PC & 0.786 & 0.01 & 1 & 324 \\
\hline share of highly qualified employees & 0.435 & 0 & 1 & 316 \\
\hline share of medium qualified employees & 0.159 & 0 & 1 & 303 \\
\hline share of low qualified employees & 0.383 & 0 & 1 & 311 \\
\hline share of employees younger than 30 years & 0.194 & 0 & 1 & 308 \\
\hline share of employees between 30 and 55 & 0.656 & 0 & 1 & 318 \\
\hline \multicolumn{5}{|l|}{ years } \\
\hline share of employees older than 55 years & 0.160 & 0 & 1 & 307 \\
\hline prior service innovation & 0.414 & 0 & 1 & 258 \\
\hline prior process innovation & 0.437 & 0 & 1 & 265 \\
\hline East Germany & 0.405 & 0 & 1 & 335 \\
\hline
\end{tabular}

Source: ZEW Quarterly business survey among service providers of the information society, own calculations.

\subsection{Analytical Framework and Estimation Procedure}

Introduced by Griliches (1979), this study will be based on a knowledge production function, following the basic assumption that the output of the innovation process represents a result of several inputs linked to research and ongoing knowledge accumulation, such as, e.g., prior innovative experience or human capital (Vinding 2006). Taking the different routes through which knowledge might influence the firms' innovation activities into account, Roper et al. (2008) augment this function with even more inputs like enterprise characteristics, firm resources and organizational capabilities. In addition, we include enterprise software in the knowledge production function, providing first insights into the relationship between business sector specific or completely customized enterprise software usage and the firm's innovation activity. This yields the following innovation relation:

$S I_{\mathrm{i}}=f\left(E S_{\mathrm{i}}, L_{\mathrm{i}}, C_{\mathrm{i}}, F A_{\mathrm{i}}, F S_{\mathrm{i},-1}, F P_{\mathrm{i},-1}\right.$, controls $)$ 
with $S I_{i}$ covering service innovation for firm $i, E S_{i}$ enterprise software used by firm $i$, $L_{i}$ the labor input, $C_{i}$ the competitive environment and $F A_{i}$ the age of the firm. Prior service and process innovations $F S_{\mathrm{i},-1}$ and $F P_{\mathrm{i},-1}$ ) as well as controls like sector classifications and region dummy are also included. The employed explanatory variables and their temporal sequence are explained in detail below. The endogenous variable we use as measure for innovation contains the information whether the firms are service innovators or not. As this dependent variable is a dummy and we assume a normally distributed error term, the widely established probit model as, e.g., introduced in Greene (2003) is used for inference.

The labor input $L_{i}$ consists of firm size, qualification structure of employees, age structure of employees and IT-intensity. We control for firm size by the logarithm of the number of employees. Larger firms tend to have more lines of activity and therefore more areas in which they can innovate. This is valid for both the manufacturing and the service sector, see, e.g., Meyer (2010) or Leiponen (2005) for further information. Firm size is reported for the year 2008.

We also consider the qualification structure of the workforce by creating three control variables: the share of highly qualified (university or university of applied science degree), medium qualified (degree in technical college or vocational qualification) and low qualified (other) employees. All shares are measured in June 2009. The share of low qualified employees is taken as the reference category. In general, qualification pictures the suitable know-how and human capital which is essential for starting and enhancing innovations. Without suitable know-how, neither is successfully possible (Meyer 2010). Therefore, we assume that the higher the qualification of employees, the higher the innovative activity.

We control for the age structure of the employees with three variables. The first one represents the share of employees younger than 30 years and builds our reference category. The second variable captures the share of employees between 30 and 55 years whereas the third variable encompasses the share of employees over 55 years. Overall, the age structure of the employees is expected to drive the firms' innovative behavior. Börsch-Supan et al. (2006) point out that on the one hand, the process of aging leads to a cutback of fluid intelligence which is needed for new solutions and fast processing of information. Due to this fact an aging workforce could be more innovative. On the other hand, older workers may resist innovations as their "human capital" depreciates. Thus, the effect of the age structure of employees on innovative activity is an ambiguous issue. The age structure was measured in June 2009 in our survey. 
Following, e.g. Engelstätter (2012a), we proxy the IT-intensity of firms by the share of employees working with a computer in June 2007. Licht and Moch (1999) mention that IT can improve the quality of existing services, in particular customer service, timeliness and convenience. Moreover the productive use of IT is closely linked to complementary innovations (Hempell 2005).

The effect of firm age on innovation activity is still an ambiguous topic subjected to discussion. Koch and Strotmann (2006) mention that innovative output is higher in younger firms than in older ones. However, it is lowest in the middle-aged (18-20 years) firms and rises again with an age of over 25 years. On the one hand, firms could lose their adaptability to the environment with an increasing age or, on the other hand, organizational aging increases innovativeness due to learning processes. Firm age is also measured in the year 2008 in our sample.

The competitive situation is another relevant driver of innovative activity. We created three dummy variables representing the number of main competitors in June 2009 according to the firms' self assessment. The first one includes zero to five competitors, the second one six to twenty competitors which is our reference category and the last one more than 20 competitors. The relationship between innovation and competition is supposed to look like an inverted $U$ curve (Aghion et al. 2005). A monopolist has less incentives to innovate as he already enjoys a high flow of profit. In a competitive situation, there are less incentives to innovate if there is no possibility to fully reap the returns of the innovation (Gilbert 2006).

There are several reasons for taking prior innovation into account in our analysis. One of them is that innovative experience plays an important role in explaining innovations as successful innovations in the past lead to a higher probability for innovative success in the future (Flaig and Stadler 1994; Peters 2009). Another reason is a potential endogeneity bias our result might face, as it is not clear whether enterprise software leads to innovations or if innovative firms apply enterprise software merely as a diffusion channel for innovations. Both enterprise software variables were collected in June 2007 whereas the innovation variable was measured between June 2008 and June 2009. Accordingly, there is actually a time shift between the dependent and independent variable already forming a well-defined temporal sequence. Nevertheless, it is still possible that firms strategically purchased their enterprise systems in June 2007 or earlier simply for the diffusion of new innovated services starting out in June 2008 resulting in an upward bias of our estimated enterprise software coefficients. However, by controlling for prior innovative activity we capture the overall innovativeness of a firm to some extent, reducing the mentioned bias. If enterprise software shows no significant impact on today's innovation anymore than it does when controlling for prior innovation, we 
can expect that the software was employed only because the firm is already innovative. A significant impact of the enterprise software in this case, however, would point towards a causality running from the adoption of the software to the realization of new service innovations as the employed software still has an impact on recent innovations with firms' overall innovativeness controlled for. We use two dummy variables to control for prior innovations. The first one is prior service innovation that takes the value one if the firm realized at least one new or essentially improved service between March 2006 and March 2007. The second dummy variable is prior process innovation that takes the value one if the firm implemented new or essentially improved technologies during the same time period. We control for both types of prior innovations as service and process innovations are dynamically interrelated.

In addition, we use nine sector dummies to control for industry-specific fixed effects. A dummy variable for East Germany accounts for potential regional differences.

\subsection{Results}

\subsubsection{Main Results}

Table 4.2 shows the average marginal effects of the probit estimation of equation $(1)^{31}$. In the first model specification we estimate the raw effect of both enterprise software types on service innovation. The results indicate that sector specific software has no impact on service innovation. Firms using customized enterprise software instead seem more likely to innovate than firms which do not use this type of enterprise software. Based on a high significance level the probability to innovate is about $\mathbf{2 4 . 2}$ percentage points higher for firms using customized enterprise software.

In the second specification we include firm size, firm age and IT-intensity. The impact of sector specific and customized software on service innovation remains qualitatively unchanged in this specification suggesting that firms using customized software still face a probability of innovating that is 22.8 percentage points higher compared to firms not using this type of enterprise software. Furthermore, we observe that larger firms seem to have a higher probability of innovating as the marginal effect is significant at the five percent level. Firm age and IT-intensity appear to have no effect on service innovation. The insignificant impact of IT-intensity suggests that the significantly positive impact of customized enterprise software pictures not only an overall positive IT-effect but the real effect of this type of enterprise software.

\footnotetext{
${ }^{31}$ Sample averages of the changes in the quantities of interest evaluated for each observation. Table 4.4 in the appendix contains the coefficient estimates.
} 
In the third specification further variables capturing competitive situation, qualification structure and age structure of employees are added. The impacts of both enterprise software systems do again not change compared to former specifications indicating that the probability of realizing service innovations is higher for firms utilizing customized software. Older firms seem less likely to innovate, based on an estimated marginal effect significant at the five percent level. The age structure of the workforce reveals some interesting results. Firms with a higher share of employees between 30 and 55 years as well as employees over 55 years are less likely to innovate compared to firms with a higher share of younger employees. The impact of employees between 30 and 55 years is significant at one percent while the impact of employees over 55 years is only significant at ten percent.

In the fourth specification, we include dummy variables measuring prio service and process innovations in our analysis. Based on a high significance level the average marginal effect suggests that the probability to innovate is larger for firms which have already realized service innovations in the past. The average marginal effect of customized software remains positive and significant proposing that customized software could indeed lead to service innovation instead of being employed simply because utilizing firms are already innovative as argued in section 4.4. However, the incorporation of prior service innovation weakens the impact of customized software by reducing its significance level from one to five percent. In contrast to prior service innovations, prior process innovations seem to have no impact on current service innovations. The impact of firm age and employees between 30 and 55 years and employees over 55 years turns insignificant once we include prior innovations into the estimation specification.

In summary, our results suggest that firms using customized enterprise software experience a higher probability of innovating compared to firms without this type of enterprise software or sector specific enterprise software. This result stays robust across all specifications and supports our hypothesis that customized enterprise software applications tailored to specific firms' needs helps to enhance service innovation activity. Additionally, our results also indicate that sector specific enterprise software solutions seem to have no impact on service firms' innovative performance. 
Table 4.2: Probit Estimation Results: Average Marginal Effects

dependent variable: dummy for service innovation

\begin{tabular}{|c|c|c|c|c|}
\hline & (1) & (2) & (3) & (4) \\
\hline \multirow[t]{2}{*}{ sector specific software } & -0.055 & 0.026 & -0.011 & -0.003 \\
\hline & $(0.060)$ & $(0.064)$ & $(0.073)$ & $(0.081)$ \\
\hline \multirow[t]{2}{*}{ customized software } & $0.242 * * *$ & $0.228 * * *$ & $0.264 * * *$ & $0.182 * *$ \\
\hline & $(0.054)$ & $(0.060)$ & $(0.065)$ & $(0.075)$ \\
\hline \multirow[t]{2}{*}{ log. firm size } & & $0.047^{* *}$ & 0.026 & 0.020 \\
\hline & & $(0.020)$ & $(0.023)$ & $(0.025)$ \\
\hline \multirow[t]{2}{*}{ log. firm age } & & -0.065 & $-0.150 * *$ & -0.098 \\
\hline & & $(0.055)$ & $(0.063)$ & $(0.072)$ \\
\hline \multirow[t]{2}{*}{ IT-intensity } & & 0.056 & -0.065 & 0.063 \\
\hline & & $(0.110)$ & $(0.131)$ & $(0.155)$ \\
\hline \multirow[t]{2}{*}{ competitors 0 - 5} & & & -0.028 & 0.018 \\
\hline & & & $(0.078)$ & $(0.089)$ \\
\hline \multirow[t]{2}{*}{ competitors > 20} & & & -0.055 & -0.040 \\
\hline & & & $(0.071)$ & $(0.077)$ \\
\hline highly qualified & & & 0.026 & -0.002 \\
\hline employees & & & $(0.124)$ & $(0.137)$ \\
\hline medium qualified & & & 0.018 & -0.128 \\
\hline employees & & & $(0.165)$ & $(0.178)$ \\
\hline \multirow[t]{2}{*}{ employees $30-55$ years } & & & $-0.468 * * *$ & -0.184 \\
\hline & & & $(0.172)$ & (0.194) \\
\hline \multirow[t]{2}{*}{ employees $>55$ years } & & & $-0.368^{*}$ & -0.189 \\
\hline & & & $(0.221)$ & $(0.244)$ \\
\hline \multirow[t]{2}{*}{ prior service innovation } & & & & $0.259 * * *$ \\
\hline & & & & $(0.080)$ \\
\hline \multirow[t]{2}{*}{ prior process innovation } & & & & -0.033 \\
\hline & & & & $(0.074)$ \\
\hline \multirow[t]{2}{*}{ dummies } & & Sector & Sector & Sector \\
\hline & & East & East & East \\
\hline observations & 336 & 298 & 240 & 179 \\
\hline Pseudo $\mathrm{R}^{2}$ & 0.046 & 0.103 & 0.147 & 0.206 \\
\hline
\end{tabular}

Significance levels: $*: 10 \%, * *: 5 \%, * * *: 1 \%$.

Reference categories: competitors 6-20, unqualified employees, employees $<30$ years. 


\subsubsection{Robustness Check}

To ensure the validity of our results obtained we also conduct several robustness checks $^{32}$. First, as firms could adopt sector specific in conjunction with customized enterprise software, we also estimate the model with an interaction term of the two enterprise software systems added. However, the interaction effect is not significant in all specifications and does not change the other results qualitatively.

The consideration of prior innovations reduces our sample to the very low size of 179 observations. Due to the insufficient panel structure, we decide to estimate all specifications with this reduced sample size as another robustness check to ensure that our results are not driven by observation loss ${ }^{33}$. As a further robustness check, we also estimate all specifications without the industry and regional fixed effects. The results regarding the use of sector specific and customized enterprise software do not change qualitatively in all these robustness checks.

Our last robustness check covers the firm size in our sample. As it could be the case that especially some big enterprises drive the results we decide to restrict our sample to those enterprises with a number of employees at or below the mean in size for the complete sample, i.e. 37 employees or less. As this robustness check reduces our sample to 262 small and mediumsized enterprises (SMEs) we estimate all specifications as before except the last one controlling for prior innovations. Adding prior innovations to this reduced sample results in a number of observations too small for the model to achieve convergence. The results generated from analyzing our SMEs sample do not change qualitatively compared to the results obtained before. Accordingly, we suspect that big enterprises do not drive our empirical results indicating that customized enterprise software is useful for innovative activity in firms of any sizeclass.

\subsection{Conclusion}

This paper analyzes the relationship between different types of enterprise software systems and innovation in services. In the service sector, enterprise software is an essential tool for providing services. Therefore, it may represent a crucial contribution to a firm's innovation performance. We analyze the innovative impact of two different kinds of enterprise software, i.e. business sector specific and completely customized enterprise software. In essence, sector specific enterprise software is

\footnotetext{
${ }^{32}$ All tables of the regressions performed as robustness checks are available from the authors upon request.

33
}

Table 4.5 in the appendix pictures the results of this robustness check. 
off-the-shelf software designed and standardized for certain industries whereas customized software is designed and adopted to the needs of a single firm thereby implying unique features. The analysis is based on a knowledge production function constituted by an innovation equation with data of German firms in ICT- and knowledge-intensive service sectors.

Our results suggest that ICT- and knowledge-intensive service firms using customized enterprise software that fulfills their specific requirements realize positive impacts in innovative activity. The results stay robust to several specifications and robustness checks proposing that not only big enterprises drive this positive impact but SMEs may also realize gains in innovative performance. However, it is important to mention here that customized enterprise software can only support service innovation if it is developed and applied properly, if the firm has complete knowledge of its organizational structure and processes and is aware of the goals it wants to achieve by using customized enterprise software. These facts ensure an enterprise software system that is perfectly suitable for all business requirements. Only given these circumstances, service firms are able to profit from the quick delivery of information, enhanced knowledge processing, the strengthened connections of information sources or reflection of all needed business processes customized enterprise software is linked to. Another benefit that arises for firms using customized enterprise software is the increased IT know-how, especially when developing the software themselves. This know-how is an essential tool for innovation which is especially useful to ICT-intensive service providers as these firms could generate benefits out of it given that software development, for instance, is a major task in these industries.

In contrast, firms that use sector specific enterprise software cannot exploit the benefits outlined. Although this type of enterprise software is very supportive by providing frequently updated databases or presenting information in an adequate manner, these advantages by themselves seem, based on our results, insufficient to support service innovation. Accordingly, relying on off-the-shelf software applications seems to be no adequate strategy when aiming for innovations. Hence, managers should consider investing in developing and customizing the needed software systems to realize service innovations.

However, the current study is not without limitations, one of these being the establishment of a causality relationship as already mentioned above. Restrained to the available data, we also have no information about other unobserved factors potentially influencing the software adoption decision like management quality or implementation problems and costs of the enterprise systems installed. Accordingly, we have to use dummy proxy variables instead, possibly resulting in unobserved heter- 
ogeneity the estimation procedure cannot completely account for. Future availability of new data might offer the opportunity to control even for these special cases of firm heterogeneity and allow for further research exploiting in detail the determinants driving the adoption of different types of enterprise software.

\subsection{Appendix Chapter 4}

Table 4.3: Distribution of Industries in the Sample

\begin{tabular}{rcc} 
Industry & Observations & Percentage \\
\hline software and IT services & 43 & 12.80 \\
ICT-specialized trade & 33 & 9.82 \\
telecommunication services & 13 & 3.87 \\
tax consultancy and accounting & 56 & 16.67 \\
management consultancy & 37 & 11.01 \\
architecture & 54 & 16.07 \\
technical consultancy and planning & 34 & 10.12 \\
research and development & 38 & 11.31 \\
advertising & 28 & 8.33 \\
\hline sum & 336 & 100
\end{tabular}

Source: ZEW Quarterly business survey among service providers of the information society, own calculations. 
Table 4.4: Probit Estimation Results: Coefficient Estimates

dependent variable: dummy for service innovation

\begin{tabular}{|c|c|c|c|c|}
\hline & (1) & (2) & (3) & (5) \\
\hline \multirow[t]{2}{*}{ sector specific software } & -0.151 & 0.078 & -0.036 & -0.022 \\
\hline & $(0.164)$ & (0.191) & $(0.226)$ & $(0.277)$ \\
\hline \multirow[t]{2}{*}{ customized software } & $0.633 * * *$ & $0.630 * * *$ & $0.767^{* * *}$ & $0.586 * *$ \\
\hline & $(0.144)$ & $(0.166)$ & $(0.194)$ & $(0.234)$ \\
\hline \multirow[t]{2}{*}{ log. firm size } & & $0.139 * *$ & 0.082 & 0.071 \\
\hline & & $(0.060)$ & $(0.072)$ & $(0.087)$ \\
\hline \multirow[t]{2}{*}{ log. firm age } & & -0.192 & $-0.463 * *$ & -0.337 \\
\hline & & $(0.164)$ & $(0.201)$ & $(0.251)$ \\
\hline \multirow[t]{2}{*}{ IT-intensity } & & 0.166 & -0.203 & 0.216 \\
\hline & & $(0.325)$ & $(0.405)$ & $(0.531)$ \\
\hline \multirow[t]{2}{*}{ competitors 0 - 5} & & & -0.088 & 0.063 \\
\hline & & & $(0.245)$ & $(0.300)$ \\
\hline \multirow[t]{2}{*}{ competitors $>20$} & & & -0.170 & -0.136 \\
\hline & & & $(0.219)$ & $(0.263)$ \\
\hline highly qualified & & & 0.082 & -0.008 \\
\hline employees & & & $(0.383)$ & $(0.468)$ \\
\hline medium qualified & & & 0.058 & -0.438 \\
\hline employees & & & $(0.512)$ & $(0.610)$ \\
\hline \multirow[t]{2}{*}{ employees $30-55$ years } & & & $-1.445 * * *$ & -0.629 \\
\hline & & & $(0.554)$ & $(0.667)$ \\
\hline \multirow[t]{2}{*}{ employees $>55$ years } & & & -1.136 & -0.646 \\
\hline & & & $(0.692)$ & $(0.839)$ \\
\hline \multirow[t]{2}{*}{ prior service innovation } & & & & $0.816 * * *$ \\
\hline & & & & $(0.250)$ \\
\hline \multirow[t]{2}{*}{ prior process innovation } & & & & -0.114 \\
\hline & & & & $(0.259)$ \\
\hline \multirow[t]{3}{*}{ constant term } & - & -0.410 & $1.794 *$ & 0.520 \\
\hline & $0.426 * * *$ & $(0.667)$ & (0.929) & (1.119) \\
\hline & $(0.156)$ & & & \\
\hline observations & 336 & 298 & 240 & 197 \\
\hline pseudo $\mathrm{R}^{2}$ & 0.046 & 0.103 & 0.147 & 0.206 \\
\hline
\end{tabular}

Significance levels: ${ }^{*}: 10 \%, * *: 5 \%, * * *: 1 \%$.

Reference categories: competitors 6-20, unqualified employees, employees <30 years. 
Table 4.5: Probit Estimation Results: Average Marginal Effects, Reduced Sample dependent variable: dummy for service innovation

\begin{tabular}{|c|c|c|c|c|}
\hline & (1) & (2) & (3) & (4) \\
\hline \multirow[t]{2}{*}{ sector specific software } & -0.040 & 0.007 & -0.001 & 0.003 \\
\hline & $(0.079)$ & $(0.083)$ & $(0.084)$ & $(0.081)$ \\
\hline \multirow[t]{2}{*}{ customized software } & $0.290 * * *$ & $0.250 * * *$ & $0.239 * * *$ & $0.182 * *$ \\
\hline & $(0.071)$ & $(0.074)$ & $(0.074)$ & $(0.075)$ \\
\hline \multirow[t]{2}{*}{ log. firm size } & & 0.030 & 0.026 & 0.020 \\
\hline & & $(0.025)$ & $(0.026)$ & $(0.025)$ \\
\hline \multirow[t]{2}{*}{ log. firm age } & & $-0.167^{* *}$ & $-0.158 * *$ & -0.098 \\
\hline & & $(0.069)$ & $(0.072)$ & $(0.072)$ \\
\hline \multirow[t]{2}{*}{ IT-intensity } & & 0.108 & -0.096 & 0.063 \\
\hline & & (0.139) & $(0.157)$ & $(0.155)$ \\
\hline \multirow[t]{2}{*}{ competitors 0 - 5} & & & -0.048 & 0.018 \\
\hline & & & $(0.094)$ & $(0.089)$ \\
\hline \multirow[t]{2}{*}{ competitors $>20$} & & & -0.014 & -0.040 \\
\hline & & & $(0.078)$ & $(0.077)$ \\
\hline highly qualified & & & 0.007 & -0.002 \\
\hline employees & & & $(0.142)$ & $(0.137)$ \\
\hline medium qualified & & & 0.065 & -0.128 \\
\hline employees & & & (0.181) & (0.178) \\
\hline \multirow[t]{2}{*}{ employees $30-55$ years } & & & -0.285 & -0.184 \\
\hline & & & (0.199) & (0.194) \\
\hline \multirow[t]{2}{*}{ employees $>55$ years } & & & -0.279 & -0.189 \\
\hline & & & $(0.251)$ & $(0.244)$ \\
\hline \multirow[t]{2}{*}{ prior service innovation } & & & & $0.259 * * *$ \\
\hline & & & & $(0.080)$ \\
\hline \multirow[t]{2}{*}{ prior process innovation } & & & & -0.033 \\
\hline & & & & $(0.074)$ \\
\hline \multirow[t]{2}{*}{ dummies } & & Sector & Sector & Sector \\
\hline & & East & East & East \\
\hline observations & 179 & 179 & 179 & 179 \\
\hline pseudo $\mathrm{R}^{2}$ & 0.071 & 0.145 & 0.157 & 0.206 \\
\hline
\end{tabular}

Significance levels: $*: 10 \%, * *: 5 \%, * * *: 1 \%$.

Reference categories: competitors 6-20, unqualified employees, employees $<30$ years. 
Table 4.5: Probit Estimation Results: Average Marginal Effects, Reduced Sample dependent variable: dummy for service innovation

\begin{tabular}{|c|c|c|c|c|}
\hline & (1) & (2) & (3) & (4) \\
\hline \multirow[t]{2}{*}{ sector specific software } & -0.040 & 0.007 & -0.001 & 0.003 \\
\hline & $(0.079)$ & $(0.083)$ & $(0.084)$ & $(0.081)$ \\
\hline \multirow[t]{2}{*}{ customized software } & $0.290 * * *$ & $0.250 * * *$ & $0.239 * * *$ & $0.182 * *$ \\
\hline & $(0.071)$ & $(0.074)$ & $(0.074)$ & $(0.075)$ \\
\hline \multirow[t]{2}{*}{ log. firm size } & & 0.030 & 0.026 & 0.020 \\
\hline & & $(0.025)$ & $(0.026)$ & $(0.025)$ \\
\hline \multirow[t]{2}{*}{ log. firm age } & & $-0.167 * *$ & $-0.158 * *$ & -0.098 \\
\hline & & $(0.069)$ & $(0.072)$ & $(0.072)$ \\
\hline \multirow[t]{2}{*}{ IT-intensity } & & 0.108 & -0.096 & 0.063 \\
\hline & & (0.139) & $(0.157)$ & $(0.155)$ \\
\hline \multirow[t]{2}{*}{ competitors 0 - 5} & & & -0.048 & 0.018 \\
\hline & & & $(0.094)$ & $(0.089)$ \\
\hline \multirow[t]{2}{*}{ competitors $>20$} & & & -0.014 & -0.040 \\
\hline & & & $(0.078)$ & $(0.077)$ \\
\hline highly qualified & & & 0.007 & -0.002 \\
\hline employees & & & $(0.142)$ & $(0.137)$ \\
\hline medium qualified & & & 0.065 & -0.128 \\
\hline employees & & & $(0.181)$ & $(0.178)$ \\
\hline \multirow[t]{2}{*}{ employees $30-55$ years } & & & -0.285 & -0.184 \\
\hline & & & (0.199) & (0.194) \\
\hline \multirow[t]{2}{*}{ employees $>55$ years } & & & -0.279 & -0.189 \\
\hline & & & $(0.251)$ & $(0.244)$ \\
\hline \multirow[t]{2}{*}{ prior service innovation } & & & & $0.259 * * *$ \\
\hline & & & & $(0.080)$ \\
\hline \multirow[t]{2}{*}{ prior process innovation } & & & & -0.033 \\
\hline & & & & $(0.074)$ \\
\hline \multirow[t]{2}{*}{ dummies } & & Sector & Sector & Sector \\
\hline & & East & East & East \\
\hline observations & 179 & 179 & 179 & 179 \\
\hline pseudo $\mathrm{R}^{2}$ & 0.071 & 0.145 & 0.157 & 0.206 \\
\hline
\end{tabular}

Significance levels: $*: 10 \%, * *: 5 \%, * * *: 1 \%$.

Reference categories: competitors 6-20, unqualified employees, employees $<30$ years. 


\title{
5 Chapter 5
}

\section{Persistence and Complementarity in ICT Innovations - The Case of Social Enterprise Software ${ }^{\S}$}

\begin{abstract}
This paper studies persistence in ICT innovations using German firm-level data. Our measure of ICT innovation is the adoption of recent social enterprise software (SES). SES is a nested innovation as its adoption requires an established ICT infrastructure. To control for induced sample selection in that case we use a two-step estimation procedure. Our results confirm persistence in ICT innovations along two channels, i.e., via the adoption of prior ICT innovations and prior process innovation success. The estimated correlations also provide weak evidence for complementarity between prior ICT innovations, prior process innovations and SES.
\end{abstract}

Keywords: persistence, ICT innovation, adoption of innovations, social enterprise software, nested innovation, complementarity

JEL Classification: D00, L10, O31

\footnotetext{
$\S$ This chapter is co-written with Miruna Sarbu (ZEW, ICT Research Group) and currently under revise and resubmit at Information Economics and Policy.
} 


\subsection{Introduction}

Whether success breeds success in innovations is a long-standing question in economics. This persistence of innovations is important for endogenous growth and industrial dynamics as it helps us to understand ongoing growth even in the absence of knowledge externalities (Raymond et al. 2010). A lively debate on this topic has mostly focused on general innovations using generic measures like the number of realized innovations or established patents. However, these measures do not apply as well to some innovations, particularly innovations in Information and Communication Technology (ICT). According to the Oslo Manual (OECD, 2005) these innovations fall into several innovation categories as they could offer enhanced process handling together with organizational improvements and improvements in marketing or even product designing. Thus, persistence in ICT innovations most likely depends on prior success in several innovation categories. Checking for persistence based on lagged undetailed general innovation measures might not be sufficient to reveal useful results. We measure persistence based on detailed prior innovation measures in the adoption of ICT innovations viewing the adopting firms as the users of innovations. Adoption of innovations has not been explored for persistence at all as most existing studies pay little attention to the users of an innovation (Kretschmer et al., 2012).

Our paper contributes to this debate with insights into the persistence of ICT innovations based on recent German firm-level data. We measure ICT innovation as the adoption of a current innovative ICT, so-called social enterprise software (SES), to explore persistence in technology adoption. SES is an upgrade for enterprise software and social software that links both software types ${ }^{34}$. Thereby, SES is an innovation which is hard to classify as its real-time data availability and enhancements in communications fall into the category of process as well as organizational innovations. SES might be categorized as a marketing innovation as it provides hypertargeting functions and structures for two-way interaction with customers. In addition, since SES requires a firm first to adopt particular ICTs before it can upgrade them to SES, it represents a so-called "nested innovation" (Greenstein and Prince 2007).

Our study adds to the empirical literature on innovation in a number of ways. First, to our knowledge we are the first to analyze persistence in the adoption of most recent ICT innovations. Second, our paper presents a valid empirical method with which to model the data generating process in the case of a "nested innovation", i.e. the probit with sample selection (Berinsky, 2004; Gourieroux and Jasiak, 2007).

\footnotetext{
34 For a comprehensive tutorial on social software and SES executed at Stanford University see http://www.youtube.com/watch?v=9fiEws22b3M, last visited June 29th, 2012.
} 
The model is based on an exclusion restriction that addresses likely sample selection. Third, considering that ICTs might act as complements (Aral et al., 2012) or even substitutes (Kretschmer at al., 2012) in their impact on performance our results offer a weak test for complementarity based on correlations between prior ICT innovations and ongoing ICT innovation activity.

Our results show that persistence in ICT innovations is realized over two channels, i.e., via the adoption of prior ICT and prior process innovations. Furthermore, the estimated positive correlations in the main model also provide first evidence for a complementary relationship between e-commerce usage, previous process innovations and SES.

The paper proceeds as follows: Section 5.2 summarizes the empirical literature of persistence in innovations and explains potential complementarities in innovations. Section 3 explains SES and its classification as a "nested" ICT innovation. Section 5.4 presents the dataset whereas section 5.5 highlights the empirical model. Section 6 explains in detail the selected exogenous variables and the necessary exclusion restriction. The estimation results and additional robustness checks to clarify the validity of the results are presented in section 5.7. Finally, section 5.8 concludes.

\subsection{Persistence and Complementarities in Innovations}

To explain whether success breeds success in innovations, researchers commonly introduce lagged innovation as an explanatory variable. Two different streams of studies can be identified in this literature, studies based on patent data and those that rely on other data sources. Raymond et al. (2010) and Mairesse and Mohnen (2010) provide comprehensive overviews of the literature.

Most studies based on patent data, e.g. Geroski et al. (1997) or Cefis (2003), conclude that there exists no clear evidence for strong persistence in innovation. This is true for multiple methodologies. However, these studies all share the common drawback in terms of data used as the firms need to be the first to apply for a patent which might be even harder than presenting a new innovative product (Raymond et al. 2010).

In studies using data at the firm-level persistence in innovation activities is found to be high. This result holds for both input measures (Peters 2009) and output measures (Flaig and Stadler 1994) of innovations. In contrast, some studies exploring the persistence in a particular type of innovation show different results. Geroski et al. (1997) confirm that there is low persistence for major innovations and Parisi et al. (2006) find persistence in product but not for process innovations. Hempell 
(2005) shows persistence to some extent as his results confirm that previously realized innovations increase the productivity of ICT capital linked to complementary innovations.

However, innovation activities have other determinants besides persistence. Other suspected important drivers of innovations are complementarities among different kinds of innovations (Miravete and Pernías 2006) or innovation strategies (Cassiman and Veugelers 2006). Complementary innovations are also argued to be crucial to realize gains out of used and adopted ICT as ICT serves often as "enabling technology" for innovative activity (Brynjolfsson and Hitt 2000). Also, ICT innovations like current enterprise software packages are argued to increase innovation activity (Engelstätter 2012a) and show complementarities in their performance impact (Aral et al. 2012). However, in other circumstances software applications might as well function as substitutes to each other in respect to impact performance (Kretschmer et al. 2012).

Using most recent German firm-level data our study explores persistence in a particular type of innovation not been studied so far, i.e. ICT innovation. We measure ICT innovation as the adoption of SES. Our estimation approach allows for modeling SES as a "nested innovation" (Greenstein and Prince 2007) which requires prerequisite software applications running before upgrading to SES is possible. Our study also attempts to identify potential complementarities between earlier innovation success and eagerness to stay innovative by adopting innovative SES.

\subsection{Adoption of Social Enterprise Software}

Our measure of innovation does not simply model a reported general innovation but it fills a gap by capturing whether a firm has adopted a recent ICT innovation in form of an innovative software application. This software, so called SES, links and combines the firms' established enterprise software systems with its social software applications in use. Enterprise software systems, like enterprise resource planning (ERP) and customer relationship management (CRM), are company-wide suites of business software devoted to particular process integration across the value chain serving many industries in numerous areas. They encompass a wide range of software products supporting day-to-day business operations and decision-making. Social software applications are wikis, blogs, web forums, instant messaging services, and social networks sites like, e.g. Facebook. In a firm, social software is used to strengthen external communication with other firms and partners or enhance CRM marketing and market research but can also be utilized as a knowledge management tool to facilitate internal communication like knowledge and project management. 
Once enterprise and social software are connected by of SES they allow sharing of data in real-time with employees participating in a fast information transfer. All available data needed is sourced directly from the enterprise systems and distributed rapidly via the communication tools of social software. SES seems particularly useful for managing customer relations as a so-called social CRM can directly implement and exploit data and information from customer surveys, commentaries, reviews or user profiles on social networks or blogs. If these data are processed via social CRM, the utilizing firm can monitor recent trends and customer demands quickly, helping with the elaboration of sales forecasts, market development expectations or the development of new products. Appropriate targeting of customers based on their interests, so-called hyper-targeting (Shih 2010), also becomes feasible. Social CRM systems can add value back to the customer as they offer different channels like email, several instant messaging or chat applications for him to interact with the firm. Direct customer feedback on their ideas, needs, and wants may also contribute to the development of new or improved products and services or the observation of new trends and purchase intentions (Gartner 2012). In addition, the established two-way interaction between the customer and the firm via social CRM might allow engaging with non-traditional industry influencers like bloggers, independent analysts and customers passionate about brands (Chess Media Group 2010) resulting in a positive attitude of the firm's products potentially attracting more customers. Up till today, 15 percent of companies engaged in business to business e-commerce already implemented SES. This number is expected to grow up to 70 percent by 2014 (Gartner 2012).

Based on its characteristics as an ICT innovation, SES does not fit into just one category of innovation as distinguished by the Oslo Manual (OECD 2005). With its realtime data availability and processing as well as its enhancements in communication SES falls into the category of process (changes in production, delivery methods) or organizational innovations (changes in workplace organization or the firm's external relations). Hyper-targeting and two-way interaction with customers put SES in the category of marketing innovations (changes in product placement or promotion). Exploring persistence by introducing lagged innovation activity is difficult with several types of innovations needed to be reported in the data. Accordingly, we measure persistence in ICT innovations as accurate as possible by introducing several persistence measures which we explain in detail in section 6 .

A firm can implement SES in two ways by either linking its enterprise and social software already in use with the appropriate SES upgrade or via installing a full SES solution providing the complete software without prior experience with enterprise or social software. Chronologically, the possibility of linking via the appropriate software upgrade occurred first. Installing a complete solution was offered later for 
firms starting out completely new in the adoption of ICT infrastructure or for firms wanting to change their service provider or vendor. With upgrades, enterprise and social software must already exist before SES can be used making SES a "nested innovation". With "nested innovations", one needs first to adopt a prerequisite tool, like e.g. a personal computer, and build the more advanced tool, like e.g. internet usage, upon the existing infrastructure (Greenstein and Prince 2007). As explained in section 5.5, we model this nested structure empirically via a Heckit model.

Although potentially profitable, the adopting firm bears some costs of enhancing its current ICT infrastructure with SES. In general, costs occur per user ${ }^{35}$ making it possible for even smaller firms to adopt SES. However, researchers still have to have the costs in mind when focusing on the adoption of SES and should adequately control for each firm's ICT budget situation.

\subsection{Description of Data}

The dataset used in this study stems from two computer-aided telephone surveys conducted in 2007 and 2010 by the Centre for European Economic Research (ZEW). These ZEW ICT surveys lay a specific focus on the diffusion and use of ICT in German companies. In addition, the surveys contain detailed information about the firms' economic characteristics and performance, e.g. qualification or age structure of the workforce, competitive situation, innovation performance, exports and ecommerce. Usually, the interviewee was the chief executive officer of the firm, but he could also decide to pass on questions to a corresponding employee, e.g., the head of the ICT department. Each wave of this dataset originally contains information of about 4,400 firms with five or more employees, representatively chosen from service and manufacturing sectors in Germany.

The ZEW ICT surveys are organized as a panel dataset. However, as the question on the usage of SES was first included in the survey in 2010, a panel data analysis cannot be provided in this paper. Thus, we employ a cross-section which consists of a combination of the survey waves conducted in 2007 and 2010 for inference. Combining these two surveys is necessary as we need a well-defined temporal sequence between the usage of SES and appropriate prior experience. We explain the selection of these variables in detail in the following section.

For this study, we construct a dummy variable measuring the adoption of SES which takes the value one if a firm establishes a link between its enterprise systems in use

\footnotetext{
35 See http://www.infoworld.com/d/applications/enterprise-social-software-spurs-connections-804 for an overview about pricing schemes and costs levels of some SES providers.
} 
and its employed social software applications via the appropriate software upgrade in the year 2010 and zero otherwise. This dummy variable represents the dependent variable in our analysis. The questionnaire was structured in a way that only firms who already use both social software and enterprise software were asked if they link both software types. Accordingly, we have to presume that the firms adopt SES in the form of an upgrade of their existing software infrastructure and not as a completely new solution. This presumption is strengthened as $92 \%$ of the firms that reported using enterprise software in $\mathbf{2 0 1 0}$ had already used enterprise software in 2007. If these firms adopt SES they most likely use the appropriate upgrade.

In order to analyze the adoption of SES, we built three dummy variables for the usage of social software applications, the usage of enterprise software systems and the usage of both social software and enterprise software in the year 2010. The dummy variable representing the use of social software applications takes the value one if at least one social software application such as a blog, wiki, social network, collaboration platform, podcast, RSS-feed or tagging is used in the year 2010. Figure 4 shows that at least one social software application is employed by about 40 percent of the firms. The dummy variable for the usage of enterprise software systems, on the other hand, takes the value one if a firm uses at least one of the enterprise software systems ERP, CRM or Supply Chain Management and zero otherwise. Nearly 80 percent of the firms use at least one of the mentioned enterprise software applications, see figure $4^{36}$. Furthermore, figure 4 indicates that about one third of the firms employ social software and enterprise software applications. About 59 percent (not reported) of the firms using both software types, which represent about 22 percent of all firms, adopt $\mathrm{SES}^{37}$ as pictured in figure 4.

\footnotetext{
${ }^{36}$ Overall, a share of 80 percent of the surveyed firms using enterprise software seems quite high. However, one has to keep in mind that enterprise software is available for more than thirty years now resulting in a vast reduction of complexity and making recent applications useful even for smaller firms. Also, there are nowadays cheap applications available like open source or freeware solutions and software as service applications in the cloud. Hence, even small firms with a restricted budget can adopt enterprise software.

${ }^{37}$ Given these adoption rates we cannot exclude the possibility that our analysis only focuses early adopters with SES being widely diffused and perhaps used by nearly every firm in several years. However, in modelling persistence we exactly need this period of early adoption as SES could not be considered a most recent innovative technology anymore if it is already established on the market for several years.
} 
Figure 4: Usage of Software Applications

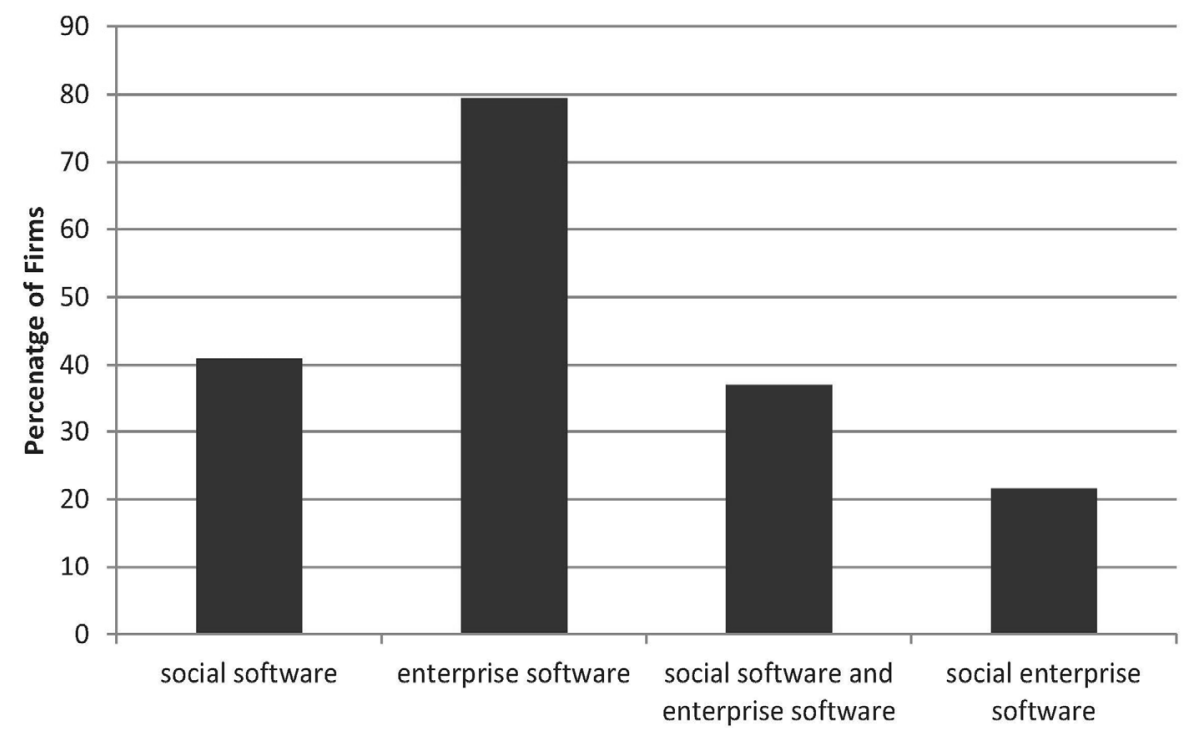

Source: ZEW ICT Survey 2010, own calculations, 1523 observations, descriptive statistics

\subsection{Analytical Framework and Estimation Procedure}

As our dataset only contains firms suspected to upgrade their existing ICT infrastructure to SES we face sample selection in our analysis. First, firms have to decide about using both social software and enterprise software applications. In a second step firms then decide to link both software types, i.e. upgrading them to SES. This "nested innovation" structure with one prerequisite innovation needed to be adopted before the next innovation can be used results in a two stage decision process. We model this structure adequately as we employ the Heckman selection model (Heckman 1979) for inference in our empirical analysis. The first part of the decision process is modeled by the selection equation

$$
E S_{\mathrm{i}}^{*}=X_{\mathrm{i}} B_{1}+I D_{\mathrm{i}} B_{2}+Z_{\mathrm{i}} B_{3}+\epsilon_{\mathrm{i}} \quad E S_{\mathrm{i}}=1 \text { if } E S_{\mathrm{i}}^{*} \geq 0 ; E S_{\mathrm{i}}=0 \text { otherwise }
$$

with $E S_{i}^{*}$ being a latent variable reflecting both the use of social software applications and enterprise software for firm i. Both types of software applications are used by firm i but not linked with each other at this point in time. $X_{i}$ contains firm characteristics expected to influence the decision of firm $i$ to use social software and enterprise software, e.g. lagged innovation activity, firm size, characteristics of the 
workforce or ICT intensity. $I D_{\mathrm{i}}$ includes common control dummies for business sector and East Germany. $Z_{\mathrm{i}}$ reflects the necessary exclusion restriction needed to identify the model. We assume a standard identically distributed error term.

As the selection equation (1) shows which firm characteristics foster the unlinked use of social software applications and enterprise software, the next consecutive step will be to explain the firms' decision to link both software types via SES. We model the second part of the decision process being the outcome equation as

$$
S E S_{\mathrm{i}}^{*}=X_{\mathrm{i}} Y_{1}+I D_{\mathrm{i}} Y_{2}+u_{\mathrm{i}} \quad S E S_{\mathrm{i}}=1 \text { if } S E S_{\mathrm{i}}^{*} \geq 0 ; S E S_{\mathrm{i}}=0 \text { otherwise }
$$

where $S E S_{i}^{*}$ is the unobserved latent variable accounting for the usage of social enterprise software for firm i. In the outcome equation, we use the same explanatory variables $X_{i}$ as in the selection equation without the mentioned exclusion restriction. $u_{\mathrm{i}}$ is again a standard identically distributed error term.

Equations (1) and (2) are estimated via maximum likelihood. As $E S_{i}$ and $S E S_{i}$ are both dummy variables we use a probit with sample selection (Berinsky 2004, Gourieroux and Jasiak 2007), the so called heck-probit, as estimation procedure for the Heckman selection model. The probit structure of our employed model also provides a weak test for complementarity based on its observed correlations (Aral et al. 2012). The employed explanatory variables as well as the exclusion restriction and their temporal sequence are explained in detail in the following section.

\subsection{Selection of exogenous variables and exclusion restriction}

Attempting to explore persistence in ICT innovations we model potential persistence using different parameters. However, as described before, SES does not perfectly fit into one category of innovation but is related to process, organizational and marketing innovations. Measuring prior innovation activities becomes difficult in this setting as our dataset only contains product and process but not organizational or marketing innovations. Nevertheless, lagged process innovation represents one adequate proxy of prior innovation success in this case. Additionally, we control for prior product innovations as process and product innovations are often interrelated (Hall et al. 2009). We capture success in both innovations in form of a dummy variable. Each dummy variable takes the value one if a firm realized at least either one product or a process innovation during 2004 to 2007 and zero if no type of innovation was realized. As an additional persistence parameter we use the adoption of e-commerce practices which we measure by a dummy variable taking the value one if a firm applies either business-to-business or business-to-consumer ecommerce practices in the year 2010. Although nowadays widely diffused and es- 
tablished, e-commerce applications serve to proxy prior ICT innovation activity representing another persistence parameter in our analysis.

Additionally, we control for typical firm characteristics expected to drive innovation activity, e.g., firm size (Mairesse and Mohnen 2010). However, with SES being a rather new technology, its adoption and usefulness might also depend on the availability of appropriate human capital (Lo and Sutthiphisal 2010) or a younger workforce (Meyer 2010). We measure firm size by the logarithm of the number of employees in the year 2009. As for the availability of human capital we consider the qualification structure of the workforce by creating three control variables: the share of highly qualified (university or university of applied science degree), medium qualified (technical college or vocational qualification) and low qualified (other) employees measured in the year 2009. The share of low qualified employees is taken as the reference category. We also control for the age structure of the work force with three different variables. The first one represents the share of employees younger than 30 years, the second one the share of employees between 30 and 50 years (reference category) and the third one the share of employees over 50 years. The age structure of employees refers to the year 2009. We also control for an additional workforce characteristic, i.e. the establishment of a works council, which is common in German firms. Such a council enables employees to participate in decision making (Zwick 2003) like, for example, the decision to adopt huge sophisticated software applications and presents a proxy for firm strategy and aims.

Competitive pressure is also expected to impact innovation activity (Aghion et al. 2002, Kretschmer et al. 2012). We employ three dummy variables capturing the number of main competitors in the year 2009 according to the firms' selfassessment as additional controls. The first variable indicates 0 to 5 competitors, the second one 6 to 50 competitors (reference category) and the last one more than 50 competitors. We control for international competition and business activity as a driver of innovation activity and technology adoption (see, e.g., Bertschek 1995). We measure the export activity of firms by a dummy variable that takes the value one if the firms exported goods or services during the year 2009. The firms' import activity is measured analogously as a dummy variable taking the value one if the firms imported goods or services during the year 2009 and zero otherwise.

We also include some general controls that might affect the adoption of SES, e.g., ICT budget constraints or business sector classification. Since the adoption of SES might induce substantial costs the firm has to bear, we control for the firms' ICT budget by taking the expenditures for both ICT components and staff per employee in the year 2009 into account in our analysis. Another part of the firms' ICT budget is captured in ICT outsourcing measured as the share of ICT expenditures allotted to 
external service providers during the year 2009. We employ the logarithm of the expenditure measures to make this measure comparable to the number of employees measure. In addition, we use a dummy variable to control for business sector specific effects. This dummy variable takes the value one if a firm belongs to the service sector and zero for manufacturing firms. A dummy variable for East Germany accounts for potential regional differences.

An appropriate exclusion restriction requires an explanatory variable which is highly correlated with the selection variable but is not correlated to SES adoption. The exclusion restriction we use is ICT training measured as the share of employees who received specific ICT-related training in the year 2006. We expect this exclusion restriction to be correlated with the common use of social software and enterprise software but showing no correlation with the linkage of both software types. Firms engaging in ICT training in the year 2006 might do so to get first insights into the use of social software applications and possibly prepare the use of these software applications at a later point in time. Social software applications were a new technology in the year 2006, especially for private users, and not yet broadly adopted by firms. Thus, ICT training would have been necessary for firms' adoption of social software applications. Firms' adoption of new enterprise software systems usually also requires ICT training as these systems are sophisticated and it is hardly possible to adopt and use them properly without appropriate training. SES applications, however, arose in $\mathbf{2 0 0 8}$ for the first time. Accordingly we can exclude the possibility that SES may be part of the ICT training measures conducted by the firms in 2006. This timing argument allows us to conclude that our ICT training measure is not correlated to the adoption decision and represents a suitable exclusion restriction in our empirical setup. For an overview, Table 5.1 pictures the summary statistics for all variables, including endogenous and exogenous variables as well as the exclusion restriction. 


\begin{tabular}{|c|c|c|c|c|}
\hline Variable & Mean & Min. & Max. & $\mathbf{N}$ \\
\hline social enterprise software & 0.216 & 0 & 1 & 1523 \\
\hline enterprise software & & 0 & 1 & 1516 \\
\hline social software & & 0 & 1 & 1458 \\
\hline social software and enterprise software & & 0 & 1 & 1521 \\
\hline number of employees & & 1 & 45000 & 1523 \\
\hline log (number of employees) & & 0 & 10.714 & 1523 \\
\hline share of highly qualified employees & & 0 & 1 & 1408 \\
\hline share of medium qualified employees & & 0 & 1 & 1406 \\
\hline share of low qualified employees & & 0 & 1 & 1413 \\
\hline share of employees younger than 30 years & & 0 & 1 & 1415 \\
\hline share of employees between than 30 and 50 & & 0 & 1 & 1420 \\
\hline years & & & & \\
\hline share of employees older than 50 years & & 0 & 1 & 1425 \\
\hline $0-5$ competitors & & 0 & 1 & 1523 \\
\hline $6-50$ competitors & & 0 & 1 & 1523 \\
\hline more than 50 competitors & & 0 & 1 & 1523 \\
\hline exports & & 0 & 1 & 1519 \\
\hline imports & & 0 & 1 & 1514 \\
\hline prior product innovation & 0.557 & 0 & 1 & 1505 \\
\hline prior process innovation & 0.632 & 0 & 1 & 1510 \\
\hline ICT outsourcing & & 0 & 1 & 1183 \\
\hline ICT expenditures per employee & & 1 & 300000 & 1195 \\
\hline log (ICT expenditures per employee) & & -5.480 & 12.611 & 1195 \\
\hline works council & 0.313 & 0 & 1 & 1523 \\
\hline service sector & & 0 & 1 & 1523 \\
\hline East Germany & & 0 & 1 & 1523 \\
\hline ICT training 2006 & & 0 & 1 & 1458 \\
\hline
\end{tabular}

Source: ZEW ICT Survey 2007, 2010 and own calculations.

\subsection{Results}

\subsubsection{Main Results}

Table 5.2 contains our main estimation results for the selection equation (1) and the outcome equation (2) in two different specifications. In the first specification, we estimate the model with a parsimonious set of baseline variables representing firm characteristics like firm size, qualification and age structure of the workforce, the competitive situation, an established works council and the application of ecommerce as a first indicator of persistence. In the second specification of Table 5.2, we augment the baseline specification with additional controls like international 
business activity (exports and imports), ICT budget as well as business sector and regional dummies. In this second specification we also complete our set of persistence parameters by adding previous process and product innovation activity. In general, the model is precisely estimated as the selection parameter Rho is significant in both specifications. Concerning the exclusion restriction, the coefficient estimate of ICT training is positive and also highly significant in both specifications.

Overall, the estimation results show that the persistence parameters e-commerce adoption and lagged process innovation success positively and significantly affect the probability of SES adoption. The same pattern holds for the selection equation. As for other controls, significant drivers of the adoption of SES are import activity, a high share of young and highly qualified workers ${ }^{38}$, import activity as well as business activity in the service sector. Overall, similar firm characteristics drive the adoption of social and enterprise software in the selection equation. The most prominent differences between the selection and the adoption equation emerge in the positive and significant effect of ICT budget and firm size on the selection probability. This may indicate that, despite available low cost solutions, the adoption of enterprise software might still be subject to budget constraints with larger firms being potentially more easily able to tolerate the first fixed costs of adoption ${ }^{39}$.

All significant coefficients in the outcome equation of the main regression translate to significant marginal effects as shown in Table 5.3. Concerning the persistence parameters, firms that use e-commerce practices face a probability of adopting SES which is about 13 percentage points higher compared to firms not employing ecommerce applications. Prior process innovators face a probability to adopt SES which is about 7 percentage points higher than for non-innovative firms.

In sum, our results show that persistence in the adoption of SES occurs via two separate channels, i.e. the adoption of prior innovative ICT applications and prior process innovation success, but it is not related to prior product innovation success. In our probit approach, the estimated coefficients generate pairwise correlations and provide, if positive, weak evidence for complementarity between the drivers of the adoption and the adoption itself. Accordingly, the results suggest that e-commerce adoption and prior process innovation success each form a complementarity system with SES adoption. However, without sufficient firm performance measures availa-

\footnotetext{
38 The share of highly qualified workers only shows a significant impact in specification 2 . We diagnose and explain this issue in more detail in section 7.2 providing robustness checks.

${ }^{39}$ A simple probit checking for a positive correlation between the probability to adopt enterprise software and ICT budget as well as firm size shows highly significant positive coefficient estimates confirming this presumption. These estimations are available from the authors upon request.
} 
ble in our data we cannot stress our conjecture of potential complementarities further.

Table 5.2: Bivariate Probit with Sample Selection: Coefficients Estimates

\begin{tabular}{|c|c|c|c|c|}
\hline & \multicolumn{2}{|c|}{ Specification 1} & \multicolumn{2}{|c|}{ Specification 2} \\
\hline & $\begin{array}{l}\text { Selection } \\
\text { Equation }\end{array}$ & $\begin{array}{l}\text { Outcome } \\
\text { Equation }\end{array}$ & $\begin{array}{l}\text { Selection } \\
\text { Equation }\end{array}$ & $\begin{array}{l}\text { Outcome } \\
\text { Equation }\end{array}$ \\
\hline In firm size & $\begin{array}{l}0.294 * * * \\
(0.035)\end{array}$ & $\begin{array}{c}0.061 \\
(0.073)\end{array}$ & $\begin{array}{c}0.274 * * * \\
(0.041)\end{array}$ & $\begin{array}{c}0.076 \\
(0.087)\end{array}$ \\
\hline $\begin{array}{l}\text { share of highly qualified em- } \\
\text { ployees }\end{array}$ & $\begin{array}{l}1.314^{* * *} \\
(0.224)\end{array}$ & $\begin{array}{c}0.552 \\
(0.440)\end{array}$ & $\begin{array}{c}1.290 * * * \\
(0.267)\end{array}$ & $\begin{array}{l}0.817^{*} \\
(0.427)\end{array}$ \\
\hline $\begin{array}{l}\text { share of medium qualified } \\
\text { employees }\end{array}$ & $\begin{array}{c}0.156 \\
(0.219)\end{array}$ & $\begin{array}{l}-0.084 \\
(0.371)\end{array}$ & $\begin{array}{c}0.265 \\
(0.251)\end{array}$ & $\begin{array}{c}0.137 \\
(0.373)\end{array}$ \\
\hline employees $<30$ years & $\begin{array}{c}0.256 \\
(0.234)\end{array}$ & $\begin{array}{l}0.801^{*} \\
(0.341)\end{array}$ & $\begin{array}{c}0.244 \\
(0.271)\end{array}$ & $\begin{array}{l}0.918 * * \\
(0.413)\end{array}$ \\
\hline employees $>50$ years & $\begin{array}{l}-0.146 \\
(0.223)\end{array}$ & $\begin{array}{c}0.106 \\
(0.352)\end{array}$ & $\begin{array}{c}0.015 \\
(0.256)\end{array}$ & $\begin{array}{c}0.140 \\
(0.354)\end{array}$ \\
\hline e-commerce & $\begin{array}{c}0.571 * * * \\
(0.079)\end{array}$ & $\begin{array}{c}0.552 * * * \\
(0.125)\end{array}$ & $\begin{array}{c}0.515^{* * *} \\
(0.091)\end{array}$ & $\begin{array}{c}0.446 * * * \\
(0.127)\end{array}$ \\
\hline competitors 0-5 & $\begin{array}{l}-0.115 \\
(0.091)\end{array}$ & $\begin{array}{c}0.076 \\
(0.129)\end{array}$ & $\begin{array}{l}-0.200 * \\
(0.103)\end{array}$ & $\begin{array}{c}0.074 \\
(0.155)\end{array}$ \\
\hline competitors $>50$ & $\begin{array}{l}-0.043 \\
(0.106)\end{array}$ & $\begin{array}{l}-0.001 \\
(0.154)\end{array}$ & $\begin{array}{c}0.031 \\
(0.120)\end{array}$ & $\begin{array}{l}-0.028 \\
(0.161)\end{array}$ \\
\hline works Council & $\begin{array}{l}-0.065 \\
(0.109)\end{array}$ & $\begin{array}{c}0.259 \\
(0.158) \\
\end{array}$ & $\begin{array}{l}-0.177 \\
(0.123)\end{array}$ & $\begin{array}{c}0.219 \\
(0.207) \\
\end{array}$ \\
\hline exports & - & - & $\begin{array}{c}0.119 \\
(0.109)\end{array}$ & $\begin{array}{c}0.056 \\
(0.140)\end{array}$ \\
\hline imports & - & - & $\begin{array}{l}0.198 * \\
(0.103)\end{array}$ & $\begin{array}{l}0.247^{*} \\
(0.127)\end{array}$ \\
\hline prior product innovations & - & - & $\begin{array}{c}0.143 \\
(0.099)\end{array}$ & $\begin{array}{l}-0.011 \\
(0.147)\end{array}$ \\
\hline prior process innovations & - & - & $\begin{array}{c}0.355^{* * *} \\
(0.098)\end{array}$ & $\begin{array}{l}0.256^{*} \\
(0.145)\end{array}$ \\
\hline ICT outsourcing & - & - & $\begin{array}{l}-0.271^{*} \\
(0.149)\end{array}$ & $\begin{array}{l}-0.005 \\
(0.228)\end{array}$ \\
\hline $\begin{array}{l}\text { ICT expenditures per employ- } \\
\text { ee }\end{array}$ & - & - & $\begin{array}{c}0.077 * * * \\
(0.023)\end{array}$ & $\begin{array}{c}0.036 \\
(0.035)\end{array}$ \\
\hline service sector dummy & & & $\begin{array}{l}0.190 * \\
(0.109)\end{array}$ & $\begin{array}{c}0.328 * * \\
(0.149)\end{array}$ \\
\hline
\end{tabular}




\begin{tabular}{|c|c|c|c|c|}
\hline & \multicolumn{2}{|c|}{ Specification 1} & \multicolumn{2}{|c|}{ Specification 2} \\
\hline & $\begin{array}{l}\text { Selection } \\
\text { Equation }\end{array}$ & $\begin{array}{l}\text { Outcome } \\
\text { Equation }\end{array}$ & $\begin{array}{l}\text { Selection } \\
\text { Equation }\end{array}$ & $\begin{array}{l}\text { Outcome } \\
\text { Equation }\end{array}$ \\
\hline region dummy & & & $\begin{array}{l}-0.088 \\
(0.096)\end{array}$ & $\begin{array}{l}-0.085 \\
(0.127)\end{array}$ \\
\hline constant & $\begin{array}{c}-2.203^{* * *} \\
(0.248)\end{array}$ & $\begin{array}{l}-1.342 * \\
(0.694)\end{array}$ & $\begin{array}{c}-2.597 * * * \\
(0.312)\end{array}$ & $\begin{array}{c}- \\
2.281^{* * *} \\
(0.729)\end{array}$ \\
\hline $\begin{array}{l}\text { exclusion restriction: } \\
\text { ICT Training } 2006\end{array}$ & $\begin{array}{c}0.847^{* * *} \\
(0.174)\end{array}$ & - & $\begin{array}{c}0.502 * * \\
(0.220)\end{array}$ & - \\
\hline Rho & $0.60 €$ & 274) & $0.803(0$ & $.294)$ \\
\hline LR-Test $($ Rho $=0)$ & & & 3.05 & \\
\hline \# of obs. (cens/uncensored) & 1306 & /456) & $1047(67$ & $5 / 372)$ \\
\hline
\end{tabular}

Notes: ${ }^{* *} \mathrm{p}<0.01,{ }^{* *} \mathrm{p}<0.05, * \mathrm{p}<0.1$; standard errors in parentheses.

Reference categories: competitors 6-20, least qualified employees, Employees 3050 years.

Source: ZEW ICT survey 2007, 2010 and own calculations. 
Table 5.3: Bivariate Probit with Sample Selection: Average Marginal Effects

dependent variable: dummy for social enterprise software

(1)

(2)

\begin{tabular}{|c|c|c|}
\hline log. firm size & 0.020 & 0.021 \\
\hline & $(0.021)$ & $(0.020)$ \\
\hline \multirow[t]{2}{*}{ highly qualified employees } & 0.179 & $0.226 * *$ \\
\hline & $(0.125)$ & $(0.100)$ \\
\hline \multirow[t]{2}{*}{ medium qualified employees } & -0.027 & 0.038 \\
\hline & $(0.121)$ & $(0.103)$ \\
\hline \multirow[t]{2}{*}{ employees < 30} & $0.260 * *$ & $0.254^{*}$ \\
\hline & $(0.122)$ & $(0.150)$ \\
\hline \multirow[t]{2}{*}{ employees > 50} & 0.035 & 0.039 \\
\hline & $(0.116)$ & $(0.100)$ \\
\hline \multirow[t]{2}{*}{ e-commerce } & $0.188^{* * *}$ & $0.128 * * *$ \\
\hline & $(0.039)$ & $(0.036)$ \\
\hline \multirow[t]{2}{*}{ competitors 0 - 5} & 0.025 & 0.021 \\
\hline & $(0.043)$ & $(0.046)$ \\
\hline \multirow[t]{2}{*}{ competitors $>50$} & -0.000 & -0.008 \\
\hline & $(0.050)$ & $(0.044)$ \\
\hline \multirow[t]{2}{*}{ works council } & 0.087 & 0.063 \\
\hline & $(0.060)$ & $(0.071)$ \\
\hline \multirow[t]{2}{*}{ exports } & & 0.015 \\
\hline & & $(0.039)$ \\
\hline \multirow[t]{2}{*}{ imports } & & $0.070^{*}$ \\
\hline & & $(0.038)$ \\
\hline \multirow[t]{2}{*}{ prior product innovation } & & -0.003 \\
\hline & & $(0.041)$ \\
\hline \multirow[t]{2}{*}{ prior process innovation } & & $0.070 * *$ \\
\hline & & $(0.035)$ \\
\hline \multirow[t]{2}{*}{ ICT outsourcing } & & -0.002 \\
\hline & & $(0.063)$ \\
\hline ICT expenditures per & & 0.020 \\
\hline employee & & $(0.009)$ \\
\hline \multirow[t]{2}{*}{ service sector dummy } & & $0.091^{*}$ \\
\hline & & $(0.049)$ \\
\hline \multirow[t]{2}{*}{ region dummy } & & -0.023 \\
\hline & & $(0.035)$ \\
\hline observations & 1306 & 1047 \\
\hline
\end{tabular}

Significance levels: ${ }^{*}: 10 \%,{ }^{* *}: 5 \%,{ }^{* * *}: 1 \%$. Reference categories: competitors 6-50, unqualified employees, employees $30-50$ years. Source: ZEW ICT survey 2007, 2010 and own calculations. 


\subsubsection{Robustness Checks}

To validate the robustness of our result we conduct different checks. First, we estimate specification (1) based on the sample of specification (2) which is smaller due to missing values in some of the additional variables. The results (not reported) ${ }^{40}$ indicate that the control capturing the share of highly skilled workers seems to react to the loss in observations as it becomes nearly significant ( $p$-value 0.16 ) in this estimation. All others coefficients are qualitatively unchanged in this case. However, as we take the share of highly skilled workers merely as a control we do not consider this as a contradiction of our main results.

For another robustness check we address industry fixed effects. In addition to our main specification (2) where we simply control for manufacturing and services we also run the regressions introducing all seventeen industry classifications available in our sample separately in the estimation ${ }^{41}$. In general, all industry coefficients turned out to be insignificant in the outcome equation with the overall model being slightly less precisely estimated. Additionally, we could not reject the hypothesis that all industry dummies have the same coefficient, i.e. zero. By conducting a likelihood ratio test comparing the models with and without additional industry dummies, we are also unable to reject the null hypothesis in favor of the more parsimonious model with only one business sector dummy expressing the data generating process. Accordingly, with the little additional information gained from industry classifications, we decided to refrain from including all industry dummies in our regression and aggregated them to a business sector dummy.

To control for additional unobserved heterogeneity we also add additional explanatory variables to our estimations which might impact the adoption of SES. Specifically, we control for a subsidiary of firms in foreign countries and firms being part of a corporation. In both cases, the adoption of social enterprise software could facilitate and enhance the communication and knowledge transfer between subsidiaries. Both variables were collected in the survey wave of 2007 . However, both coefficients turn out be insignificant and including both variables does not change the results obtained. Based on a likelihood ratio test, they do not add exploration power to the model either as the null hypothesis favoring the model without both variables cannot be rejected. Since adding both variables also results in observation loss due to item non-response we decided against including them in our main estimation.

\footnotetext{
40 These results are available from the authors upon request.

${ }^{41}$ For convenience we include the results of the model with industry dummies in Table 5.4Fout! Verwijzingsbron niet gevonden. located in the appendix of this chapter.
} 
Two additional robustness checks focus on different estimation techniques. We estimated both specifications also using the classical two-stage heckman selection model. As expected, the results remain qualitatively similar with only marginal changes in coefficients and standard errors. Ignoring a possible selection, we also estimated a simple probit model to explain SES adoption and take only those firms into account that use enterprise software and social software together. Overall, the results remain mostly the same compared to the heck-probit although the coefficients are less precisely estimated. However, some coefficients that are based on a weak significance level in our main estimation, specifically imports and prior process innovation success, fail to reach significance in this robustness check. All other coefficients keep their level of significance and sizes. Being appropriately careful in case of a potential bias we repeat our estimations, i.e. the heck-probit and the simple probit, using standard errors obtained via bootstrap (50 replications) as well as jackknife. In each case, there were no appreciable coefficient changes. We also conduct a likelihood ratio test comparing the models with and without selection. As expected, we reject the null hypothesis of the simple probit model ( $p$-value less than 0.01 ) in favor of the heck-probit. Thus, we conjecture based on these checks that a simple probit model seems to produce biased results as it does not appropriately model the data generating process in the case of a selection based on a "nested innovation".

\subsection{Conclusion}

Based on most recent German firm-level data, our study provides insight into persistence of ICT innovations. As a measure for ICT innovation we use the adoption of a current new innovative ICT, i.e. SES. We estimate a heck-probit using ICT training as an exclusion restriction to model a "nested innovation". We find that persistence in ICT innovations occurs through two channels as the adoption of prior ICT innovations, i.e. e-commerce, and prior process innovation success lead to the adoption of SES. The estimated correlations in the probit model also provide weak evidence for a complementary relationship between e-commerce usage, prior process innovations and SES. The results remain robust to several model specifications and estimation procedures.

Overall, our results have three implications. First, we confirm that persistence in innovation activity also holds when dealing with particular innovations, i.e. the adoption of SES. Second, modeling the data generating process as case of "nested innovations" adequately takes the selection process into account as otherwise the results are biased. Third, there is evidence for complementarity between prior and most recent innovations. This should be stressed and confirmed with new data in 
further research. Based on the tools offered by SES to enhance communications, marketing and production processes, we conjecture that potential complementarities will most likely occur in the impact of SES and previous innovation success on labor productivity or ongoing innovation activity.

Our analysis faces a few potential short-comings which are primarily related to data constraints and unobserved heterogeneity. Besides the proxy of an established works council, we do not observe management decisions of the surveyed firms. It may be the case that some firms simply adopt new technologies because they want to be on the fast lane in terms of technology, sending out a positive signal. A part of this phenomenon may be captured in the ICT expenditures we control for as those firms can be expected to spend more money on ICT compared to firms which are not as oriented towards the technology frontier. Availability of new data might take care of this potential drawback. Also, our exclusion restriction is not without concern about its exogeneity. It may be the case that ICT intensive firms invest more in ICT training and expect their trained employees to adopt and utilize SES more eagerly. As SES solutions are sophisticated software tools, even more eager employees might not be able to utilize the software to its full potential without specific training. However, as such additional training and further education is definitely not captured in our exclusion restriction general ICT training, we expect the mentioned eagerness to produce a bias of negligible size. 


\subsection{Appendix Chapter 5}

Table 5.4: Probit with Sample Selection: Coefficient estimates, ID robustnesscheck, Specification 2

Selection Equation Outcome Equation

\begin{tabular}{|c|c|c|}
\hline log. firm size & $0.295^{* * *}$ & 0.055 \\
\hline & $(0.042)$ & $(0.125)$ \\
\hline \multirow[t]{2}{*}{ highly qualified employees } & $1.070 * * *$ & $0.782 *$ \\
\hline & $(0.287)$ & $(0.471)$ \\
\hline \multirow[t]{2}{*}{ medium qualified employees } & 0.244 & 0.110 \\
\hline & $(0.256)$ & $(0.410)$ \\
\hline \multirow[t]{2}{*}{ employees $<30$} & 0.208 & $1.011 * *$ \\
\hline & $(0.280)$ & $(0.496)$ \\
\hline \multirow[t]{2}{*}{ employees > 50} & 0.082 & 0.340 \\
\hline & $(0.260)$ & $(0.402)$ \\
\hline \multirow[t]{2}{*}{ e-commerce } & $0.533 * * *$ & $0.453 * * *$ \\
\hline & $(0.093)$ & $(0.150)$ \\
\hline \multirow[t]{2}{*}{ competitors 0 - 5} & $-0.215^{* *}$ & 0.095 \\
\hline & $(0.105)$ & $(0.188)$ \\
\hline \multirow[t]{2}{*}{ competitors $>50$} & -0.024 & -0.051 \\
\hline & $(0.125)$ & $(0.170)$ \\
\hline \multirow[t]{2}{*}{ works council } & -0.193 & 0.244 \\
\hline & $(0.126)$ & $(0.243)$ \\
\hline \multirow[t]{2}{*}{ exports } & 0.100 & 0.103 \\
\hline & $(0.114)$ & $(0.154)$ \\
\hline \multirow[t]{2}{*}{ imports } & $0.232 * *$ & 0.228 \\
\hline & $(0.108)$ & $(0.140)$ \\
\hline \multirow[t]{2}{*}{ prior product innovation } & 0.076 & -0.042 \\
\hline & $(0.102)$ & $(0.148)$ \\
\hline \multirow[t]{2}{*}{ prior process innovation } & $0.336 * * *$ & 0.241 \\
\hline & $(0.100)$ & $(0.169)$ \\
\hline \multirow[t]{2}{*}{ ICT outsourcing } & -0.228 & 0.014 \\
\hline & $(0.155)$ & $(0.244)$ \\
\hline \multirow[t]{2}{*}{ ICT expenditures per employee } & 0.062 & 0.027 \\
\hline & $(0.024)$ & $(0.038)$ \\
\hline \multirow[t]{2}{*}{ region dummy } & -0.053 & -0.110 \\
\hline & $(0.099)$ & $(0.138)$ \\
\hline \multirow[t]{2}{*}{ chemical Industry } & -0.011 & -0.138 \\
\hline & $(0.261)$ & $(0.374)$ \\
\hline other raw materials & -0.238 & -0.187 \\
\hline
\end{tabular}




\begin{tabular}{|c|c|c|}
\hline & $(0.260)$ & $(0.372)$ \\
\hline metal and machine & 0.051 & -0.086 \\
\hline construction & $(0.234)$ & (0.349) \\
\hline \multirow[t]{2}{*}{ electrical engineering } & 0.103 & -0.191 \\
\hline & $(0.216)$ & $(0.347)$ \\
\hline \multirow[t]{2}{*}{ precision instruments } & -0.197 & -0.436 \\
\hline & $(0.242)$ & $(0.361)$ \\
\hline \multirow[t]{2}{*}{ automobile } & -0.120 & 0.120 \\
\hline & $(0.272)$ & $(0.374)$ \\
\hline \multirow[t]{2}{*}{ wholesale trade } & -0.286 & -0.300 \\
\hline & $(0.271)$ & $(0.402)$ \\
\hline \multirow[t]{2}{*}{ retail trade } & -0.161 & 0.696 \\
\hline & $(0.264)$ & $(0.617)$ \\
\hline transportation and postal & -0.050 & 0.185 \\
\hline services & $(0.251)$ & $(0.379)$ \\
\hline \multirow[t]{2}{*}{ banks and insurances } & 0.454 & 0.510 \\
\hline & $(0.305)$ & $(0.423)$ \\
\hline computer and telecomm. & $0.634^{* *}$ & 0.320 \\
\hline services & $(0.245)$ & $(0.387)$ \\
\hline technical services & 0.209 & 0.165 \\
\hline & $(0.261)$ & $(0.379)$ \\
\hline \multirow[t]{2}{*}{ real estate and leasing services } & 0.136 & 0.380 \\
\hline & $(0.343)$ & $(0.528)$ \\
\hline management consult. and & $0.624 * *$ & -0.060 \\
\hline advertising & $(0.317)$ & $(0.500)$ \\
\hline \multirow[t]{2}{*}{ media services } & 0.218 & 0.178 \\
\hline & $(0.247)$ & $(0.325)$ \\
\hline \multirow[t]{2}{*}{ services for enterprises } & 0.138 & 0.026 \\
\hline & $(0.353)$ & $(0.482)$ \\
\hline \multirow[t]{2}{*}{ constant } & $-2.539 * * *$ & $-2.048^{*}$ \\
\hline & $(0.353)$ & (1.099) \\
\hline Exclusion restriction: & $0.438 * *$ & - \\
\hline ICT Training 2006 & $(0.219)$ & \\
\hline Rho & \multicolumn{2}{|c|}{$0.759(0.456)$} \\
\hline LR-test $($ Rho $=0)$ & \multicolumn{2}{|c|}{1.94} \\
\hline \# of obs. (cens/uncensored) & \multicolumn{2}{|c|}{$1047(675 / 372)$} \\
\hline $\begin{array}{l}\text { Notes: } * * * \mathrm{p}<0.01, * * \mathrm{p}<0.05,{ }^{*} \\
\text { Reference categories: competitor } \\
30-50 \text { years, consumer goods. }\end{array}$ & $\begin{array}{l}\text { 1; standard e } \\
0 \text {, least quali }\end{array}$ & $\begin{array}{l}\text { ntheses. } \\
\text { ees, Employees }\end{array}$ \\
\hline \multicolumn{3}{|c|}{ Source: ZEW ICT survey 2007, 2010 and own calculations. } \\
\hline
\end{tabular}





\title{
6 Chapter 6
}

\section{Understanding the effects of violent video games on violent crime $^{\S}$}

\begin{abstract}
Video games are a popular, time-intensive leisure activity. As many of best-selling games contain hyper-realistic violence, many researchers and policymakers have suggested violent games cause violent behaviors. Evidence on a causal effect of violent games on violence is usually based on laboratory experiments finding violent games increase aggression. Previous experimental studies, though, do not incorporate time use into the research design, and therefore lack external validity for drawing inference about the effect of violent games on actual behavior. Our study uses a quasi-experimental methodology to identify the short and medium run effects of violent game sales on violent crime using within-month variation in retail unit sales data of the top 50 selling video games and violent criminal offenses from the National Incident Based Reporting System (NIBRS) for each week of 2005 to 2008. We instrument for game sales with professional video game reviewers and estimate that, while a one percent increase in non-violent games is associated with a $0.1 \%$ decrease in violent crime, intensely violent games appear to have no effect on violent crime rates. While violent video games may increase aggression, the intensity of time use associated with popular video games appears to disrupt the social determinants of crime, at least in the short to medium run. Future studies of violent video games effects on society should focus on the games' time usage.
\end{abstract}

JEL Codes: D08, K14, L86

Keywords: Video Games, Violence, Crime

\footnotetext{
$\S$ This chapter is co-written with A. Scott Cunningham (Baylor University) and Michael R. Ward (University of Texas at Arlington). The paper is still in a state of editing and the recent version may vary from the one presented here.
} 


\subsection{Introduction}

Violence in video games has become a growing policy concern. The issue has generated six reports to the US Congress by the Federal Trade Commission (FTC, 2009) and was the subject of a US Supreme Court decision. ${ }^{42}$ The concern centers on two aspects of video games: there is evidence that continued exposure to violent virtual depictions desensitizes gamers to actual violence and children represent a disproportionate share of gamers. The first effect, summarized in literature reviews such as Anderson, Gentile and Buckley (2007), has been documented extensively in experimental trials and largely support the conclusion that exposure to violent video games increases the viewer's measured aggression. The evidence is so strong that some researchers have speculated that the rise in violent video games has caused acts of even extreme aggression, such as crimes and homicide. Craig Anderson, a prominent researcher in these studies, has suggested that violent video games were responsible for the Columbine High School shootings (Anderson 2004). ${ }^{43}$

Our analysis of video game violence does not address the psychological aspects of violent video games as a means to change the behaviors of gamers. Instead, we focus on the time use effects of typical video game play. Video game play typically involves hours of attention. Since time is rival in consumption, video games have an incapacitation effect that tends to crowd out other activities, including those linked to aggression. Because of this, the net effect of violent games on crime is ambiguous. For instance, if players substitute from outdoor leisure into indoor leisure, then the opportunities for crime may diminish simply by disrupting the social interactions which determine crime, such as chance public encounters (Glaeser, Sacerdote and Scheinkman 1996; 2003). Time use associated with incapacitating gamers while playing violent games may reduce violent crime in ways that laboratory experiments are not designed to reveal. The "control group" in experimental designs of violent media may lose interest in the activity assigned to them but do not have the option of using this idle time to commit crimes. Since laboratory experiments do not incorporate time use into the research design, they may lack external validity for inferring the effects of violent games on crime.

We answer this question by estimating the effect of violent video game retail unit sales on the criminal offenses using two-stage least squares. We relate the weekly aggregate number of violent crimes from the National Incident Based Reporting

\footnotetext{
${ }^{42}$ In 2010, California passed a law making it a punishable offense for a distributor to sell a banned violent video to a minor. The US Supreme Court struck down this law in June, 2011.

${ }^{43}$ There is disagreement within the psychological literature about the interpretation of psychological laboratory studies of video game violence (Ferguson \& Kilburn, 2008).
} 
System (NIBRS) to weekly retail unit sales for the top 50 selling games from VGChartz ${ }^{44}$ and descriptions of each game's violence content provided by the Entertainment Software Rating Board (ESRB). ${ }^{45}$ To address possible endogeneity of game releases with unobserved determinants of crime, such as economic indicators driving income, purchasing and opportunity cost of time, we instrument for weekly game sales with experts' reviews of each game in our sample using Gamespot, a video game review aggregation website. ${ }^{46}$ For our strategy to be valid, the instrumental variable measuring game quality must be excludable from the structural determinants of crime as well as strongly correlated with video game sales. While the excludability assumption is not testable, it's unlikely that reviewer opinions on the quality of a game could impact crime except through its effect on game sales and game play itself. We show that expert reviews of video games are highly correlated with sales.

Our main findings are summarized here. Unlike experimental studies, we do not find evidence for a positive effect on crime. Our most robust evidence supports the opposite conclusion for a negative elasticity of crime with respect to games. Our basic 2SLS results indicate that violent crimes fall with non-violent video game popularity but are virtually unaffected by changes in weekly "intensely violent" video game sales. These results are consistent with non-violent games having only an incapacitation effect with no offsetting behavior effects while these two effects roughly offset for violent games. We estimate an elasticity of violent crime with respect to non-violent game sales on an order of -0.1 .

The rest of our paper is organized as follows: Section 6.2 provides background; Section 6.3 describes our data and empirical strategy; Section 6.4 describes our empirical findings; and Section 6.5 concludes.

\subsection{Background}

From the sensational crime stories of the $19^{\text {th }}$ century (Comstock and Buckly 1883), to the garish comic books of the early $20^{\text {th }}$ century (Hadju 2009), to the contemporary debate over violent games, Americans have always been concerned about the harmful effects of violent media on children. Unlike comic books and pulp "true crime" stories, violence in media, including video games, have received substantial attention by psychologists and media specialists. Anderson and Bushman (2001) and Anderson, Gentile and Buckely (2007) discuss hundreds of controlled studies on the

\footnotetext{
${ }^{44}$ http://www.vgchartz.com

${ }^{45}$ http://www.esrb.org

${ }^{46}$ http://www.gamespot.com
} 
effects of violence in media, whereas the number of studies on violence in print media is particularly smaller in comparison.

There are two broadly considered conceptual pathways by which violent games impose costs on society: either violent games draw individuals out of more productive activities ("time use"), or the games fundamentally alter the individual's brain development such that harmful activities become more likely in the future ("general aggression model"). Of the two, the general aggression model (GAM) has received more scientific attention (see Anderson and Bushman, 2001 and Anderson, Gentile and Buckley, 2007, for a review). But since time use on games is substantial - both on a per game basis, and as a share of time expenditures - this aspect warrants careful consideration. The time spent on video game consumption cannot be spent on other activities, legitimate or otherwise, if time use is rival in consumption. The substitution patterns from video games may derive more from time use effects than from pecuniary costs (Becker, 1965).

For most, it is easy to conclude from finding that exposure to violent media causes aggression in the lab that it will therefore cause aggression when exposure occurs outside the laboratory. Psychologists have adapted GAM to the video game setting (Bushman and Anderson, 2002 and Anderson and Bushman, 2002). GAM hypothesizes that violent media, including violent video games, increases a person's aggressive tendencies through a process of social learning that occurs simultaneous to the exposure itself. Violent media causes the person to mistakenly develop certain scripts, or rules of thumb, that are used to interpret social situations both before they occur, as well as afterwards. GAM posits, in other words, that violent video games cause aggression by biasing individuals towards forming incorrect beliefs about relative danger that they are in. Perception biases towards hostility, therefore, can in turn cause the person to respond in either a "fight or flight" fashion. It may also permanently alter a person's point of view, creating an aggressive personality as an outcome (Bushman and Anderson 2002). ${ }^{47}$

The evidence for the video game time use can be found in industry publications or national statistics on time use. Modern video games typically involve intense narratives with complex plots and characterization taking dozens of hours to complete, if they can be completed at all. A typical video game may require dozens, and sometimes several hundreds, of hours to complete. ${ }^{48}$

\footnotetext{
${ }^{47}$ A variant of the Becker and Murphy (1988)'s rational addiction model may approximate GAM. The key insight for GAM is that consumption of a good in one particular not only affects current utility directly, but through a capital stock accumulation mechanism, it also affects future utility indirectly.

${ }^{48}$ The website, How Long to Beat, http://www.howlongtobeat.com, provides user-submitted statistics on completion times. The 2011 blockbuster, The Elder Scrolls V: Skyrim, lists completion times between 100
} 
Stinebrickner and Stinebricker (2008) found that students randomly assigned a roommate in college with a video game console caused students to study less often, and in turn, perform worse in school. The American Time Use Survey (ATUS) indicates that individuals aged $15-19$ spent an average 0.85 hours per weekday playing games and using computers, but only 0.12 hours reading, 0.11 thinking, and 0.67 in outdoor recreation, such as sports or exercising. Ward (2012) uses ATUS data to show that, when the currently available video games' sales are higher, individuals' time spent gaming increases significantly while time spent in class or doing homework falls.

Possibly because GAM and time use effects offset, to date, there is no evidence that violent video games cause violence or crime. Two recently published studies analyzed the effect of violent media (movies and video game stores) on crime, and found increased exposure may have caused crime rates to decrease (Dahl and Dellavegna 2009; Ward 2011). These studies, unlike the laboratory studies, were conducted with observational data, which poses unique scientific challenge to establishing causality. However, since laboratory studies have never shown that video game violence causes crime or violence, despite researchers out-of-sample predictions (Anderson 2004), observational studies may be the only ethical and practical way to test for such a causal effect.

\subsection{Data and Methodology}

Randomized assignment of a treatment with comparison groups used to make comparative counterfactuals is widely considered the "gold standard" in the social sciences (Fisher 1935; Campbell and Stanley 1963; Rosenbaum 2002). Yet, it is widely known that experimentalism may fail to identify true causal effects for a variety of reasons (Berk 2005; Deaton, 2010; Heckman and Urzua, 2010; Imbens 2010). While others have noted the failure of researchers in this literature to satisfy the rigorous conditions for establishing causality (Ferguson and Kilburn 2008; Olson and Kuttner 2009) our study will focus on a separate statistical challenge not mentioned in these earlier studies: the challenge of internal versus external validity.

A positive effect of violent games on aggression, and of aggression on crime, does not necessarily imply that the net effect of violent video games on crime is positive if the incapacitation effects from time use swamp the marginal increase in aggression. By design, laboratory studies - both by ignoring alternative time use and by

and 330 hours. The 2008 hit, Grand Theft Auto IV, lists 12 to 162 hours, with the lower bound 12 hours recorded for a "speed trial" effort to complete the game as fast as possible. 
treating both treatment and control groups with this separate effect - cannot be used to guide researchers as to what expect outside the lab. In this sense, the studies have internal validity, but may not have external validity on the incidence of socially costly aggression from violent video game play (Campbell and Stanley 1963). Quasi-experimental methods, such as panel econometric methods, regression discontinuity and instrumental variables, as well as field experimentation (Harrison and List 2004; Angrist 2006) may be more suitable estimating the social costs of violent video games since they allow for the estimation of all known and unknown theoretical mechanisms. In this section, we explain our research design and the data used to overcome some of the limitations of a purely experimental methodology.

\subsubsection{Estimation Strategy}

The models of video game violence suggest that the effect of violent video game play on crime will depend on whether a sizable stock of aggressive tendencies accumulates and on the games' time use intensities. Since the theoretical predictions are ambiguous and the policy relevance of the laboratory studies is unclear, empirical work outside of a laboratory context is warranted. However, without experimental data, causal inference is problematic.

We begin by estimating a standard multivariate regression model of the incidence of various crimes as functions of, among other controls, the prevalence of nonviolent and violent video games. Our outcome variables of interest, $C_{t}$, are the total number of reported criminal incidents in week $t$ that are classified as violent or nonviolent. While one might interpret any criminal incident as reflecting some level of aggression, we interpret violent crimes as reflecting more aggression than nonviolent crimes. While the dataset we use documents criminal offenses on a daily basis, since the video game sales data are available only on a weekly basis, we aggregate crimes into weekly measures to focus on same-week exposure. Accordingly, we employ a simple least squares estimator so as to more easily instrument for video game exposure. ${ }^{49}$

A game purchased by a gamer in one week is often played in subsequent weeks until the gamer loses interest and moves on to another game. To address this possibility, we experimented with the effect of game sales on crime up to an eight-week lag. Our main explanatory variables are aggregated current and lagged values of weekly sales volumes for both non-violent and violent video games. Video games appear to depreciate quickly with use. This may be because new games are played

\footnotetext{
${ }^{49}$ Our empirical methodology is in large part based on Dellavegna and Dahl's (2008) study of the effect of movie violence on crime.
} 
intensively for a few weeks after purchase and are not replaced with a new game until after some diminishing returns have been reached, or it may suggest that firms typically stagger the release dates of games. We measure the cumulative effect of games with the sales volume of the current week's sales, along with the various lags of previous weeks' sales, so as to capture the effect of higher volume of gameplay with an unknown time lag to trigger crime.

Our model of criminal offenses, $C_{t}$, is:

$\ln \left(C_{t}\right)=\sum_{\tau} \beta_{v}^{\tau}\left[\ln \left(G_{t-\tau}^{v}\right)\right]+\sum_{\tau} \beta_{m v}^{\tau}\left[\ln \left(G_{t-\tau}^{m w}\right)\right]+\beta_{\tau} \operatorname{trend} d_{t}^{I}+\beta_{m} \operatorname{mont} h_{t}+a_{t}$

The number of crime incidents depends on the exposure to violent video game sales $G_{t}^{v}$ and non-violent games $G_{t}^{m v}$. The sum over $\tau$ of $\beta_{v}^{\tau}$ can be interpreted as the cumulative percentage increase in criminal incidents over the $\tau$ weeks for each percent increase in violent video games sold in week $t$ while the similar sum for $\sigma_{w}^{\tau}$ can be similarly interpreted for non-violent video games. We control for weekly linear trends and month fixed effects to account for secular increases and seasonality in both video game purchases and crime. Thus, identification of the parameters of interest comes from within-month variation around the linear trend.

Correlations between video game play and crime may or may not reflect a causal relationship if the unobserved determinants of crime are correlated with the determinants of video game play. For instance, bad weather such as rain or heavy snow which causes individuals to remain at home would both increase the likelihood of playing video games and decrease the returns to crime through higher chances of finding a resident at home. Hence, negative correlations between crime and violent video game play could purely be a consequence of omitted variable bias. Similarly, video game publishers could strategically release violent video games during periods of time when gamers have a lower value of time. But a low opportunity cost of time would affect both video game sales and the relative return to criminal activity (Jacob \& Lefgren, 2003). For example, both video game sales and the crime rate increase during the summer when most teenagers are out of school. Finally, changing economic conditions which increase unemployment may in turn increase crime rates while decreasing video games purchases creating positive correlations between video game play and crime (Raphael and Winter-Ebmer 2001; Gould, Weinberg and Mustard 2002). We address the potential endogeneity of video games using expert reviews of each title as an instrument for purchases. 
One solution to omitted variable bias when there is time-variant heterogeneity is to employ instrumental variables (IVs). The researcher must have instruments that are strongly correlated with individual game play but uncorrelated with the determinants of crime. Our approach exploits plausibly exogenous variation in violent game sales caused by products receiving higher quality ratings by professional reviewers in the industry.

Zhu and Zhang (2010) show that consumer reviews of video games are positively related to game sales. Ratings are valuable pieces of information for video games because games are complex experience goods for which gamers cannot know their preferences without playing. Our data on professional ratings contain rich information that communicates the kinds of information that gamers value in forecasting their beliefs about the game, and as beliefs and anticipation are drivers of the game sales, we would expect these rating institutions to play important roles in forming consumer prior beliefs about the game and therefore their purchases. But we also have some evidence from other industries that would suggest scores would independently cause purchases to rise, independent of the unobserved factors that cause expert opinion and purchases to be highly correlated. Reinstein and Snyder (2005) used exogenous variation in Siskel and Ebert movie ratings due to disruptions in their pair's reviewing to determine a causal effect on movie demand. More recently, Hilger Rafert and Villas-Boas (2010) found that randomly assigned expert scores on bottles of wine in a retail grocery store caused an increase in sales for the higher rated, but less expensive, wines. While these studies do not confirm that there are exogenous forces in video game ratings that drive consumer purchases, they are suggestive.

The measured effect from this specification can represent a confluence of multiple effects. It is possible for there to be a positive behavioral effect, as found in the laboratory, and a negative voluntary incapacitation effect. Our specification will typically only measure the net effect. However, it may be possible to disentangle the behavioral effects from the incapacitation effect from the estimated cumulative effects from non-violent and violent games. Both should incorporate incapacitation effects but only the latter should include a behavioral effect toward aggression. The difference between the two provides a possible estimate of a pure aggression effect. However, the purchasers of violent games tend to be older than purchasers of non-violent video games. If the incapacitation effects differ across these groups, disentangling the two effects will be more complicated.

Besides the benchmark specification we employ three additional specifications as robustness checks. These specifications identify specific segments of the population and locations where we expect a differential a gaming-to-violence link, e.g. crimes 
committed by teens and young adults, crimes committed in proximity of high school and college campuses, and crimes that vary by the county's youth population. We measure criminal incidents using the National Incident Based Reporting System (NIBRS) as it provides detailed information on the criminal offense, including the exact date of the incident, the offender's age and the location of the incident. In the first robustness check, we select a sub-sample of offenders aged between 15 and 30 years and compare these results to the results obtained from a sub-sample of offenders who are 35 to 50 years old. In our second check, we extend our estimation procedure to compare the effects on the number of incidents reported on school campuses to the number committed at other locations. And in our third check, we examine how the effect varies by the fraction of the county population that is 15-24 years old.

\subsubsection{Video Game Data}

VGChartz reports US retail video and computer game unit sales for each week's top 50 selling video console based games each week consistently beginning in $2005 .^{50}$ We harvested these data using a web-scraping program to create a panel of weekly sales by title for the period from January, 2005 to December, 2008. We matched each game title with information about the game's violent content provided by ESRB's online database. Finally, we matched each game title with information about game quality from the game review website, Gamspot.com.

Our video game sales dataset consists of 1,117 separate titles over 208 weeks with some of these titles being the same game for different gaming consoles. In sum, the games are provided from 47 different publishers and designed for 9 different gaming consoles. While VGChartz includes the top 50 selling console-based games each week, it only covers a portion of all sales in the US video game market. A game's week of release is almost always its top selling week. Figure 5 indicates that most games stay in the top 50 for only a few weeks. Moreover, as Figure 6 indicates, games sales by title fall quickly with game age. These features suggest that there is considerable week-to-week variation in the composition of video games being played.

Table 6.1 compares VGChartz data to the Entertainment Software Association (ESA) and indicates that VGChartz account for about one-quarter of all units in 2005 (ESA

\footnotetext{
${ }^{50}$ Among other information, VGChartz reports worldwide sales, as well as several geographic regions including the US, Japan, Europe, Middle East, Africa and Asia. Disaggregated sales within a given country or continent is unfortunately not available.
} 
Annual Report, 2010). ${ }^{51}$ The ESA also includes sales of non-console based games such as computer and smartphone games. Still, this fraction rises to almost one-half in 2008.

Table 6.1: Unit Sales of Video Games (millions) from VGChartz and ESA

\begin{tabular}{|c|c|c|c|}
\hline Year & VGChartz & ESA & Percent \\
\hline 2005 & 56.7 & 226.3 & $25.1 \%$ \\
\hline 2006 & 76.2 & 240.7 & $31.7 \%$ \\
\hline 2007 & 107.0 & 267.8 & $40.0 \%$ \\
\hline 2008 & 141.3 & 298.2 & $47.4 \%$ \\
\hline
\end{tabular}

Figure 5: Number of Weeks a Game is in the Top 50 Sellers

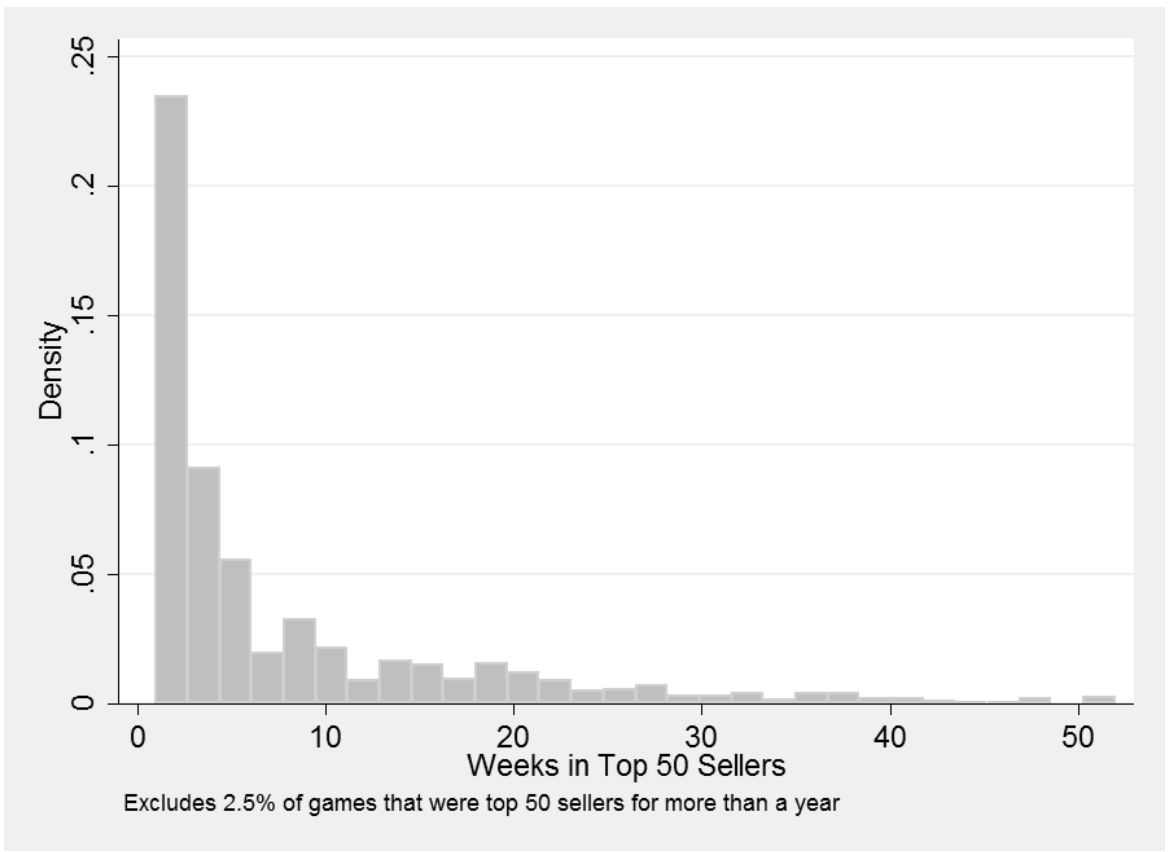

\footnotetext{
${ }^{51} \mathrm{http}: / /$ www.theesa.com - The reported numbers from ESA also include games for personal computers which amount to about 10 percent of the market each year and are intentionally not included in VGChartz.
} 
Figure 6: Average US Video Game Unit Sales by Weeks after Release

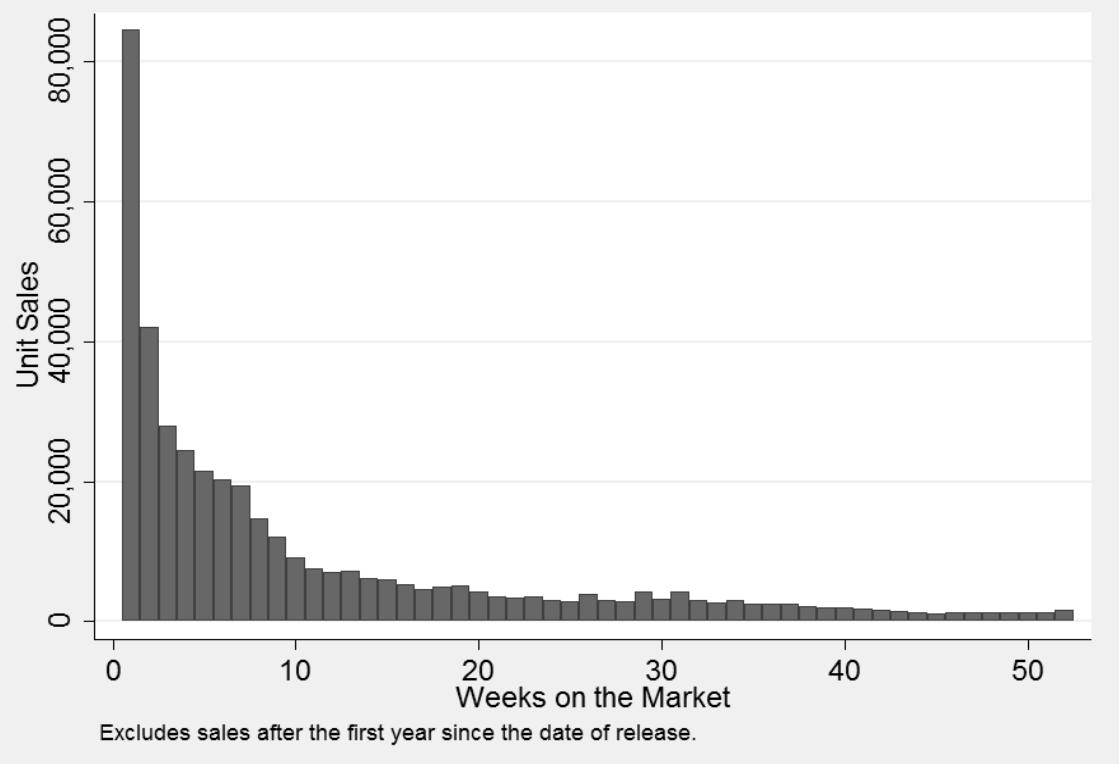

We record the violence content of each game using the ESRB's rating and descriptions of the game's content. This non-profit body independently assigns a technical rating $(E, E 10, T, M$, and $A)$ which defines the audience the game is appropriate for where E classifies games for everybody, E10 for everyone aged 10 and up, T for teens, $\mathrm{M}$ games for a mature audience, and $\mathrm{A}$ for adult content. In addition, ESRB provides detailed description of the content in each game on which the rating was made, including the style of violence, e.g. language, violence, or adult themes. For all of the 1,117 titles in our sample we collected the appropriate ESRB-rating and all content descriptors. Based on this content information, we identify 672 non-violent and 445 violent games, of which 113 titles are described as intensely violent. Almost all violent games are rated T or $\mathrm{M}$. All intensely violent games are rated $\mathrm{M}$. Since most of the policy concern stems from these mature games, we concentrate on the intensely violent games. ${ }^{52}$ Merging both data sources together we can construct measures of the aggregate unit sales of non-violent and intensely violent video games for each week. The weekly sales are depicted in Figure 7 for all games and for intensely violent games. Overall, the two graphs follow a similar pattern with a large peak around the Christmas gift-purchasing period. In the mid of 2008, however, the intensely violent games seem to account for almost all sales of the violent games.

\footnotetext{
52 We have also performed our analysis for the broader "violent" and "intensely violent" definition of a violent game. Qualitatively, all of our general results described below hold however parameter estimates are smaller (in absolute value terms) and are less precisely estimated.
} 
Figure 7: Weekly Sales of Video Games

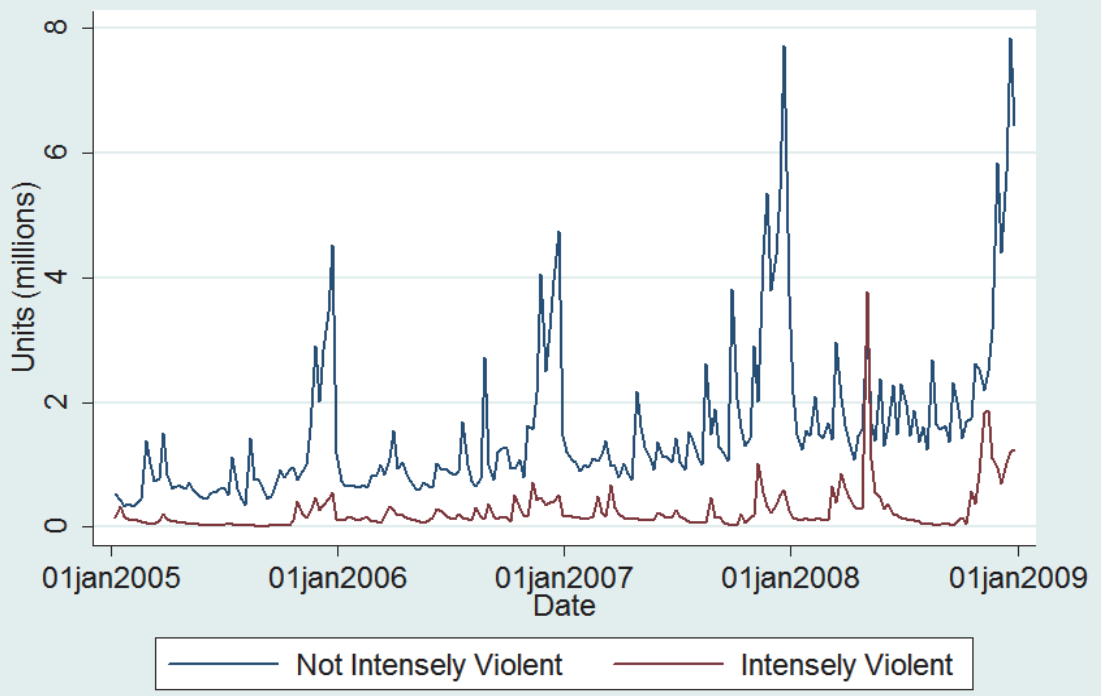

Our expert review data comes from the GameSpot website. GameSpot provides news, reviews, previews, downloads and other information for video games. Launched in May 1996 GameSpot's main page has links to the latest news, reviews, previews and portals for all current platforms. It also includes a list of the most popular games on the site and a search engine for users to track down games of interest. The GameSpot staff reviewed all but a handful of the games in our sample and rated the quality of the titles on a scale from 1 to 10 with 10 being the best possible rank. These so-called GameSpot-scores assigned to each game are intended to provide an at-a-glance sense of the overall quality of the game. The overall rating is based on evaluations of graphics, sound, gameplay, replay value and reviewer's tilt. A possible issue with this measure is that GameSpot changed the rating system in mid of 2007 to employ guidelines and a philosophy focusing more on a prospective customer rather than a hardcore-fan that the reviewers had focused on before. Nevertheless, the five mentioned aspects are essential parts of a game that are still reviewed in detail by a GameSpot reviewer but will not get an aspectspecific rating score anymore. We do not consider this change in the GameSpot focus to noticeably affect the overall GameSpot-score.

We expect the quality rating of the games to be positively correlated with their sales as better-rated games usually are more highly demanded. It is possible that some games have the opposite relationship if they are based on a popular tie-in from a 
movie, e.g. Harry Potter, or sequels, e.g. the Final Fantasy series. Developers know that these games will sell well due to their popular tie-in which may lower the returns to investment in game quality. However, in Table 6.2 we show that, a game title's weekly sales are positively related to the Game Spot score for games of different violence profiles.

Table 6.2: The Effect of Game Quality (Game Spot Score) on Log Sales

\begin{tabular}{|c|c|c|c|}
\hline & $\begin{array}{c}\text { All } \\
\text { Games }\end{array}$ & $\begin{array}{c}\text { Intensely Violent } \\
\text { Games }\end{array}$ & $\begin{array}{c}\text { Not Intensely Violent } \\
\text { Games }\end{array}$ \\
\hline GameSpot & $0.0803^{* * *}$ & $0.1221^{* * *}$ & $0.0769 * * *$ \\
\hline Score & $(0.0060)$ & $(0.0181)$ & $(0.0065)$ \\
\hline Week of Re- & & $-0.0081 * * *$ & $-0.0036 * * *$ \\
\hline lease & $(0.0002)$ & $(0.0008)$ & $(0.0003)$ \\
\hline \multirow[t]{2}{*}{ Trend } & $0.0058^{* * *}$ & $0.0040 * * *$ & $0.0060 * * *$ \\
\hline & $(0.0001)$ & $(0.0003)$ & $(0.0001)$ \\
\hline \multirow[t]{2}{*}{ February } & $-0.0902 * *$ & $-0.2169 * *$ & $-0.0663^{*}$ \\
\hline & $(0.0361)$ & $(0.1020)$ & $(0.0385)$ \\
\hline \multirow[t]{2}{*}{ March } & -0.0212 & -0.0576 & -0.0081 \\
\hline & $(0.0348)$ & $(0.0967)$ & $(0.0371)$ \\
\hline \multirow[t]{2}{*}{ April } & $-0.1770 * * *$ & $-0.3466 * * *$ & $-0.1361 * * *$ \\
\hline & $(0.0344)$ & (0.0945) & $(0.0369)$ \\
\hline \multirow[t]{2}{*}{ May } & $-0.2838 * * *$ & $-0.4069 * * *$ & $-0.2485^{* * *}$ \\
\hline & $(0.0355)$ & $(0.1004)$ & $(0.0378)$ \\
\hline \multirow[t]{2}{*}{ June } & $-0.1663 * * *$ & $-0.3593 * * *$ & $-0.1217 * * *$ \\
\hline & $(0.0363)$ & $(0.1036)$ & $(0.0386)$ \\
\hline \multirow[t]{2}{*}{ July } & $-0.2251 * * *$ & $-0.5266 * * *$ & $-0.1732 * * *$ \\
\hline & $(0.0358)$ & $(0.1059)$ & $(0.0378)$ \\
\hline \multirow[t]{2}{*}{ August } & $-0.3607 * * *$ & $-0.6881 * * *$ & $-0.3126 * * *$ \\
\hline & $(0.0364)$ & $(0.1151)$ & $(0.0381)$ \\
\hline \multirow[t]{2}{*}{ September } & $-0.2700 * * *$ & $-0.4117^{* * *}$ & $-0.2422 * * *$ \\
\hline & $(0.0358)$ & $(0.1200)$ & $(0.0374)$ \\
\hline \multirow[t]{2}{*}{ October } & $-0.1326 * * *$ & 0.0065 & $-0.1333 * * *$ \\
\hline & $(0.0365)$ & $(0.1159)$ & $(0.0383)$ \\
\hline \multirow[t]{2}{*}{ November } & $0.6122 * * *$ & $0.6812 * * *$ & $0.6051 * * *$ \\
\hline & $(0.0361)$ & $(0.1052)$ & $(0.0382)$ \\
\hline
\end{tabular}




\begin{tabular}{lccc} 
& All & Intensely Violent & Not Intensely Violent \\
& Games & Games & Games \\
\hline December & $1.2038^{* * *}$ & $1.1363^{* * *}$ & $1.2153^{* * *}$ \\
& $(0.0349)$ & $(0.1073)$ & $(0.0367)$ \\
Constant & $-4.8503^{* * *}$ & -0.5994 & $-5.3472^{* * *}$ \\
& $(0.2957)$ & $(0.8309)$ & $(0.3189)$ \\
\hline Observations & 10,648 & 1,345 & 9,303 \\
R-squared & 0.38 & 0.40 & 0.38 \\
\hline Notes: Standard errors in parentheses; ${ }^{*}$ significant at 10\%; ${ }^{* *}$ significant at 5\%; ${ }^{* * *}$ \\
significant at 1\%
\end{tabular}

\subsubsection{Crime Data}

For our measure of weekly crime, we used the NIBRS. NIBRS is a federal data collection program begun by the Bureau of Justice Statistics in 1991 for gathering and distributing detailed information on criminal incidents for participating jurisdictions and agencies. Participating agencies and states submit detailed information about criminal incidents not contained in other data sets, such as the Uniform Crime Reports. For instance, whereas the Uniform Crime Reports contain information on all arrests and cleared offenses for the eight Index crimes, NIBRS consists of individual incident records for all eight index crimes and the 38 other offenses (Part II offenses) at the calendar date and hourly level (Rantala and Edwards 2001).

Because of the detailed information about the incident, including the precise time and date of the incident, economists such as Dahl and Dellavegna (2009), Card and Dahl (2009), Jacob and Lefgren (2003) and Jacob, Lefgren, and Moretti (2007) have used it for event studies. In our case, we exploit detailed information about the age of offenders and the crime's location - on school campuses or not - for our robustness checks.

One potential drawback of NIBRS is its limited coverage. Unlike the FBI's Uniform Crime Reports, a subset of localities participate. Only 32 states currently participate, and many states with large markets - California, New York, DC 1- do not participate at all. Moreover, not all jurisdictions participate within states over time. To address possible selection problems, we limit our sample to a balanced panel of agencies that participated with NIBRS at the start of our sample and continued each year.

Crimes follow a seasonal pattern. Figure 8 indicates a consistent pattern of gradual increases in both total and violent crimes from winter to summer. Our method was developed to account for seasonality in both of our main variables of interest crime 
and games. Much of the seasonality in crimes is believed to be due to weather while seasonality in games is likely due to holiday gift giving (Lefgren, Jacobs and Moretti, 2007)..$^{53}$ Failure to address these may create spurious correlations between crime and video game sales. As indicated above, we accommodate this in two ways. First, month dummy variables should capture much of the seasonality. Second, using Game Spot scores as IVs should isolate the variation in game sales due to game quality.

Figure 8: Total and Violent Crimes by Week

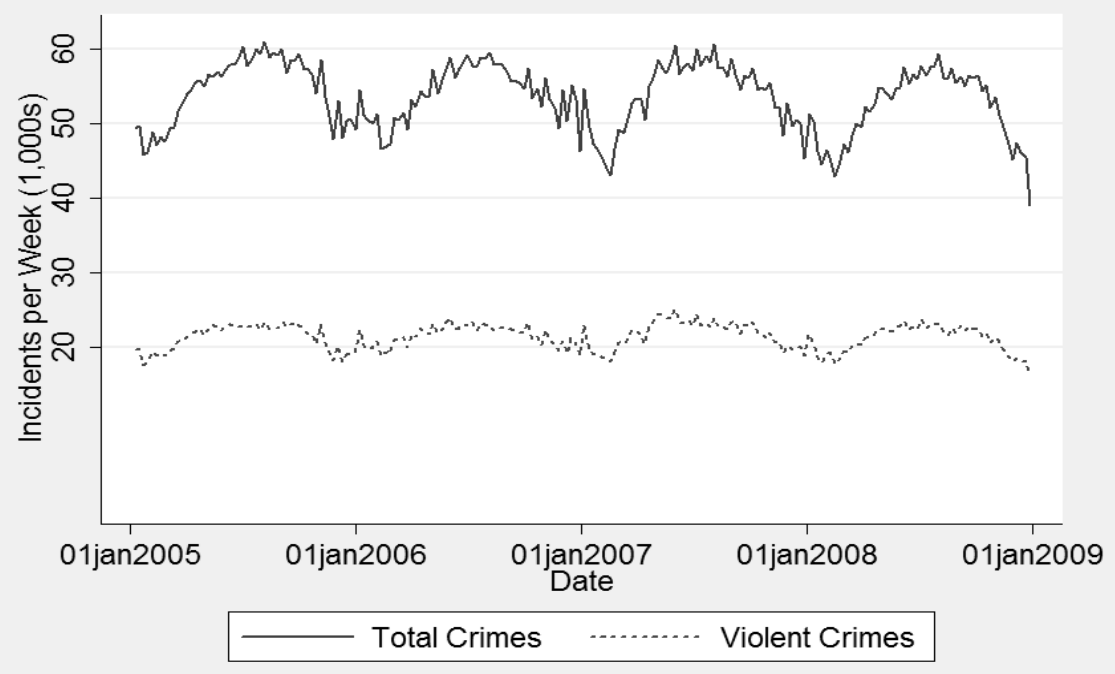

Our final sample includes 208 weekly observations on video games sales and crimes from early 2005 through 2008. However, eight observations are excluded from final regressions because of the use of lagged video game sales. Table 6.3 reports basic descriptive statistics for our sample.

\footnotetext{
${ }^{53}$ One concern is that our results are driven by the pronounced increase in video game sales around the Christmas holiday season. To address this, we also estimated what follows without observations from these periods. Our general results are qualitatively unchanged but, with the loss of degrees of freedom, fewer of the estimates are significantly different from zero.
} 
Table 6.3: Summary Statistics

\begin{tabular}{lrr} 
Variable & Mean & Std. Dev. \\
\hline Ln All Video Game Sales & 14.188 & 0.646 \\
Ln Intensely Violent Video Game Sales & 11.900 & 1.022 \\
Ln Not Intensely Violent Video Game Sales & 14.041 & 0.646 \\
Average GameSpot Score & 7.584 & 0.519 \\
Average Intensely Violent GameSpot Score & 8.584 & 0.658 \\
Average Not Intensely Violent GameSpot Score & 7.420 & 0.662 \\
Ln All Crimes & 10.884 & 0.086 \\
Ln Violent Crimes & 9.968 & 0.083 \\
Ln All Crimes on Campuses & 7.469 & 0.414 \\
Ln Violent Crimes on Campuses & 6.663 & 0.506 \\
Ln All Crimes Not on Campuses & 10.847 & 0.093 \\
Ln Violent Crimes Not on Campuses & 9.925 & 0.091 \\
Ln All Crimes Offender Aged 15-30 & 9.848 & 0.073 \\
Ln Violent All Crimes Offender Aged 15-30 & 9.360 & 0.084 \\
Ln All Crimes Offender Aged 35-50 & 9.036 & 0.083 \\
Ln Violent All Crimes Offender Aged 35-50 & 8.603 & 0.095 \\
\hline
\end{tabular}

Notes: Descriptive statistics of the 208 observations used in later tables.

\subsection{Results}

\subsubsection{Basic Results}

Our basic regression results are presented in Table 6.4 and Table 6.5. Table 6.4 reports estimates of specifications for various lags of the effect video games sales on all crimes. Video games are separated between those that the ESRB rated as "intensely violent" and those that are not. Recall that the lesser rating of merely "violent" does not warrant an ESRB rating of "Mature." ${ }^{54}$ Control variables include month dummies to capture seasonality and a time trend to capture any secular trend. The columns from left to right add more lags of video games to the specification so as to measure possible inter-temporal effects of game purchases in one week affecting crime in subsequent weeks through continued play. It is important to note that the columns do not represent independent tests of the video game to crime linkage. Finally, each regression employs a 2SLS estimator with the same set of current and eight lags of Game Spot scores averaged over intensely violent games

\footnotetext{
${ }^{54}$ Unreported regressions comparing games that are either "intensely violent" or "violent" versus all other games generally yield much less precisely estimated parameters.
} 
and over games that are not intensely violent. Since the specifications are overidentified, we test for possible endogeneity of the instrument set. As expected, in all cases, we fail to reject the exogeneity of GameSpot scores with respect to the level of crime. ${ }^{55}$

The estimated effect of video games sales in any single week is small. Most individual coefficient estimates are negative but few are significantly different from zero. It appears that lags of up to five weeks of video game sales may be associated with current crime. It is not clear from this table whether violent games have a different effect from those that are not violent. For ease of comparison, we report the sum of the coefficients for various lags for both in the top panel of Table 6.6 to calculate the cumulative effect of a change in video games over time. Here it becomes clearer that non-violent video games are estimated to have an overall negative effect on crime for specifications that include from two to six lags. However, violent games do not appear to be associated with reductions in crimes. Since our specification is double log, these estimates can be interpreted as elasticities with values of up to 0.137 for non-violent games. These estimates suggest that, over all the mechanisms through which videogame play can affect crime, the net effect is to reduce crime.

\footnotetext{
${ }^{55}$ Estimates assuming that game sales are exogenously determined typically generated smaller (in absolute value terms) and much less precisely estimated coefficients.
} 
Table 6.4: The Effects of Video Game (VG) Sales on the Log of both Violent and Non-Violent Crime

\begin{tabular}{|c|c|c|c|c|c|c|c|}
\hline & (1) & (2) & (3) & (4) & (5) & (6) & (7) \\
\hline Ln VG Sales Not & -0.012 & 0.017 & 0.015 & 0.026 & 0.035 & 0.031 & 0.069 \\
\hline Intensely viol. & $(0.023)$ & $(0.029)$ & $(0.033)$ & $(0.037)$ & $(0.038)$ & $(0.041)$ & $(0.056)$ \\
\hline $\begin{array}{l}\text { Ln VG Sales Not } \\
\text { Intensely }\end{array}$ & & $-0.061^{*}$ & -0.052 & -0.054 & -0.055 & -0.058 & -0.059 \\
\hline Violent lag 1 & & $(0.032)$ & $(0.036)$ & $(0.039)$ & $(0.041)$ & $(0.043)$ & $(0.051)$ \\
\hline $\begin{array}{l}\text { Ln VG Sales Not } \\
\text { Intensely }\end{array}$ & & & -0.027 & -0.017 & -0.022 & -0.014 & -0.028 \\
\hline Violent lag 2 & & & $(0.030)$ & $(0.035)$ & $(0.036)$ & $(0.039)$ & $(0.046)$ \\
\hline $\begin{array}{l}\text { Ln VG Sales Not } \\
\text { Intensely }\end{array}$ & & & & -0.023 & -0.016 & -0.021 & -0.002 \\
\hline Violent lag 3 & & & & $(0.032)$ & $(0.034)$ & $(0.036)$ & $(0.044)$ \\
\hline $\begin{array}{l}\text { Ln VG Sales Not } \\
\text { Intensely }\end{array}$ & & & & & -0.024 & 0.000 & -0.037 \\
\hline Violent lag 4 & & & & & $(0.036)$ & $(0.040)$ & $(0.055)$ \\
\hline $\begin{array}{l}\text { Ln VG Sales Not } \\
\text { Intensely }\end{array}$ & & & & & & $-0.052^{*}$ & -0.043 \\
\hline Violent lag 5 & & & & & & $(0.032)$ & $(0.039)$ \\
\hline $\begin{array}{l}\text { Ln VG Sales Not } \\
\text { Intensely }\end{array}$ & & & & & & & -0.036 \\
\hline Violent lag 6 & & & & & & & $(0.044)$ \\
\hline $\begin{array}{l}\text { Ln Intensely } \\
\text { Violent Video }\end{array}$ & 0.002 & 0.000 & 0.002 & 0.008 & 0.005 & 0.001 & -0.007 \\
\hline Game Sales & $(0.007)$ & $(0.011)$ & $(0.016)$ & $(0.018)$ & $(0.019)$ & $(0.020)$ & $(0.024)$ \\
\hline $\begin{array}{l}\text { Ln Intensely } \\
\text { Violent VG }\end{array}$ & & 0.000 & 0.002 & 0.008 & 0.006 & 0.005 & 0.005 \\
\hline Sales lag 1 & & $(0.012)$ & $(0.013)$ & (0.014) & $(0.014)$ & (0.015) & $(0.018)$ \\
\hline $\begin{array}{l}\text { Ln Intensely } \\
\text { Violent VG }\end{array}$ & & & -0.006 & 0.001 & 0.005 & 0.004 & 0.012 \\
\hline Sales lag 2 & & & $(0.017)$ & $(0.019)$ & $(0.020)$ & $(0.020)$ & $(0.024)$ \\
\hline $\begin{array}{l}\text { Ln Intensely } \\
\text { Violent VG }\end{array}$ & & & & $-0.023 *$ & -0.018 & -0.021 & -0.011 \\
\hline Sales lag 3 & & & & $(0.012)$ & $(0.015)$ & $(0.016)$ & $(0.020)$ \\
\hline $\begin{array}{l}\text { Ln Intensely } \\
\text { Violent VG }\end{array}$ & & & & & -0.003 & -0.007 & -0.009 \\
\hline Sales lag 4 & & & & & $(0.012)$ & $(0.014)$ & $(0.016)$ \\
\hline $\begin{array}{l}\text { Ln Intensely } \\
\text { Violent VG }\end{array}$ & & & & & & 0.017 & $0.029 *$ \\
\hline Sales lag 5 & & & & & & $(0.012)$ & $(0.017)$ \\
\hline $\begin{array}{l}\text { Ln Intensely } \\
\text { Violent VG }\end{array}$ & & & & & & & -0.023 \\
\hline Sales lag 6 & & & & & & & $(0.018)$ \\
\hline \multicolumn{8}{|c|}{$\begin{array}{l}\text { Sample includes } 200 \text { weekly observations from } 2004-2008 \text {. Month dummy variables and a time trend } \\
\text { were also included but are not reported. Average GameSpot scores for intensely violent and not and for } \\
\text { the current period and eight lags are used as IVs. The Sargan statistic for over-identification always fails } \\
\text { to reject the exogeneity of the instrument set. Absolute value of z-statistics in parentheses. * significant } \\
\text { at } 10 \% ;{ }^{* *} \text { significant at } 5 \% \text {; }\end{array}$} \\
\hline
\end{tabular}


As mentioned above, these estimates may also allow us to make some inferences that distinguish between potential mechanisms. While both violent and non-violent games are hypothesized to have incapacitation effects, only violent games are hypothesized to alter behaviors. Indeed, the top panel of Table 6.6 indicates that the difference in effects between violent and non-violent games is for violent games to reduce crime by a smaller amount and that this difference is statistically significant for specifications that include five lags. This provides some support for the laboratory findings of a reinforcing behavioral effect that partially counterbalances the incapacitation effect. However, such a comparison assumes the same magnitude for the incapacitation effect for both types of games. It is likely that the population playing the two types of games differs considerably, especially by age. It is possible that the typical incapacitation effect for older players of relatively more violent games differs from that of younger players of relatively less violent games, though we cannot test this hypothesis. Table 6.5 repeats these specifications where the dependent variable is now the log of violent crimes. By doing so, we focus on criminal acts that clearly entail an element of aggression. Again, we include various lags for the effects of video games and, again, more individual estimates are negative than positive but few are significantly different from zero. The bottom panel of Table 6.6 reports the aggregation of the lagged video game coefficients to calculate the cumulative effects. From this panel we usually find an overall negative effect of video games on the number of violent criminal incidents. These estimates are quite similar to those for all crimes in upper panel of this table. If anything, these parameter estimates are slightly larger (in absolute value terms) and aggregations with more specifications yield results significantly different from zero. These estimates also indicate that non-violent video game play, but not violent video game play, is associated with reductions in the number of violent crimes. 
Table 6.5: The Effects of Video Game Sales on the Log of Violent Crime

\begin{tabular}{|c|c|c|c|c|c|c|c|}
\hline & (1) & (2) & (3) & (4) & (5) & (6) & (7) \\
\hline $\begin{array}{l}\text { Ln Video Game Sales } \\
\text { Not Intensely Violent }\end{array}$ & $\begin{array}{l}-0.029 \\
(0.025)\end{array}$ & $\begin{array}{c}0.008 \\
(0.033)\end{array}$ & $\begin{array}{c}0.009 \\
(0.037)\end{array}$ & $\begin{array}{c}0.013 \\
(0.039)\end{array}$ & $\begin{array}{c}0.028 \\
(0.042)\end{array}$ & $\begin{array}{c}0.021 \\
(0.044)\end{array}$ & $\begin{array}{r}0.048 \\
(0.058)\end{array}$ \\
\hline $\begin{array}{l}\text { Ln VG Sales Not } \\
\text { Intensely Violent lag } 1\end{array}$ & & $\begin{array}{c}-0.077^{* *} \\
(0.036)\end{array}$ & $\begin{array}{l}-0.071^{*} \\
(0.040)\end{array}$ & $\begin{array}{l}-0.067 \\
(0.043)\end{array}$ & $\begin{array}{l}-0.070 \\
(0.045)\end{array}$ & $\begin{array}{l}-0.073 \\
(0.047)\end{array}$ & $\begin{array}{l}-0.073 \\
(0.053)\end{array}$ \\
\hline $\begin{array}{l}\text { Ln VG Sales Not } \\
\text { Intensely Violent lag } 2\end{array}$ & & & $\begin{array}{l}-0.025 \\
(0.034)\end{array}$ & $\begin{array}{l}-0.023 \\
(0.038)\end{array}$ & $\begin{array}{l}-0.032 \\
(0.039)\end{array}$ & $\begin{array}{l}-0.029 \\
(0.042)\end{array}$ & $\begin{array}{l}-0.040 \\
(0.048)\end{array}$ \\
\hline $\begin{array}{l}\text { Ln VG Sales Not } \\
\text { Intensely Violent lag } 3\end{array}$ & & & & $\begin{array}{l}-0.004 \\
(0.035)\end{array}$ & $\begin{array}{c}0.009 \\
(0.037)\end{array}$ & $\begin{array}{c}0.006 \\
(0.039)\end{array}$ & $\begin{array}{r}0.020 \\
(0.046)\end{array}$ \\
\hline $\begin{array}{l}\text { Ln VG Sales Not } \\
\text { Intensely Violent lag } 4\end{array}$ & & & & & $\begin{array}{l}-0.040 \\
(0.040)\end{array}$ & $\begin{array}{l}-0.021 \\
(0.043)\end{array}$ & $\begin{array}{l}-0.048 \\
(0.058)\end{array}$ \\
\hline $\begin{array}{l}\text { Ln VG Sales Not } \\
\text { Intensely Violent lag } 5\end{array}$ & & & & & & $\begin{array}{l}-0.037 \\
(0.035)\end{array}$ & $\begin{array}{l}-0.031 \\
(0.041)\end{array}$ \\
\hline $\begin{array}{l}\text { Ln VG Sales Not } \\
\text { Intensely Violent lag } 6\end{array}$ & & & & & & & $\begin{array}{l}-0.025 \\
(0.046)\end{array}$ \\
\hline $\begin{array}{l}\text { Ln Intensely Violent } \\
\text { Video Game Sales }\end{array}$ & $\begin{array}{c}0.001 \\
(0.007)\end{array}$ & $\begin{array}{l}-0.005 \\
(0.013)\end{array}$ & $\begin{array}{l}-0.005 \\
(0.018)\end{array}$ & $\begin{array}{c}0.004 \\
(0.020)\end{array}$ & $\begin{array}{l}-0.002 \\
(0.021)\end{array}$ & $\begin{array}{l}-0.005 \\
(0.022)\end{array}$ & $\begin{array}{l}-0.011 \\
(0.025)\end{array}$ \\
\hline $\begin{array}{l}\text { Ln Intensely Violent } \\
\text { VG Sales lag } 1\end{array}$ & & $\begin{array}{c}0.003 \\
(0.013)\end{array}$ & $\begin{array}{c}0.005 \\
(0.014)\end{array}$ & $\begin{array}{c}0.012 \\
(0.015)\end{array}$ & $\begin{array}{c}0.008 \\
(0.016)\end{array}$ & $\begin{array}{c}0.006 \\
(0.016)\end{array}$ & $\begin{array}{r}0.006 \\
(0.019)\end{array}$ \\
\hline $\begin{array}{l}\text { Ln Intensely Violent } \\
\text { VG Sales lag } 2\end{array}$ & & & $\begin{array}{l}-0.002 \\
(0.019)\end{array}$ & $\begin{array}{c}0.002 \\
(0.021)\end{array}$ & $\begin{array}{c}0.007 \\
(0.022)\end{array}$ & $\begin{array}{c}0.007 \\
(0.022)\end{array}$ & $\begin{array}{c}0.013 \\
(0.026)\end{array}$ \\
\hline $\begin{array}{l}\text { Ln Intensely Violent } \\
\text { VG Sales lag } 3\end{array}$ & & & & $\begin{array}{l}-0.023 * \\
(0.013)\end{array}$ & $\begin{array}{l}-0.016 \\
(0.016)\end{array}$ & $\begin{array}{l}-0.019 \\
(0.017)\end{array}$ & $\begin{array}{l}-0.011 \\
(0.020)\end{array}$ \\
\hline $\begin{array}{l}\text { Ln Intensely Violent } \\
\text { VG Sales lag } 4\end{array}$ & & & & & $\begin{array}{l}-0.004 \\
(0.013)\end{array}$ & $\begin{array}{l}-0.011 \\
(0.015)\end{array}$ & $\begin{array}{l}-0.013 \\
(0.017)\end{array}$ \\
\hline $\begin{array}{l}\text { Ln Intensely Violent } \\
\text { VG Sales lag } 5\end{array}$ & & & & & & $\begin{array}{r}0.020 \\
(0.013)\end{array}$ & $\begin{array}{l}0.030^{*} \\
(0.018)\end{array}$ \\
\hline $\begin{array}{l}\text { Ln Intensely Violent } \\
\text { VG Sales lag } 6\end{array}$ & & & & & & & $\begin{array}{l}-0.017 \\
(0.018)\end{array}$ \\
\hline
\end{tabular}

Sample includes 200 weekly observations from 2004-2008. Month dummy variables and a time trend were also included but are not reported. Average GameSpot scores for intensely violent and not and for the current period and eight lags are used as IVs. The Sargan statistic for over-identification always fails to reject the exogeneity of the instrument set. Absolute value of $\mathrm{z}$-statistics in parentheses. ${ }^{*}$ significant at $10 \%$; ${ }^{* *}$ significant at $5 \% ;{ }^{* * *}$ significant at $1 \%$.

The test for a difference in the effects for violent and non-violent games may be more informative. There are no known previously hypothesized mechanisms through which non-violent games would affect violent crimes. Notwithstanding the 
caveats mentioned above, under the assumption of identical incapacitation effects by game violence content, we test for violent video games affecting violent behavior as the difference in these effects by game type. In this case, the marginal effect of violent video games, relative to non-violent games, is to increase violent crimes. However, an increase in both types of games, as we in fact have experienced, implies a reduction in violent crime.

Table 6.6: The Cumulative Effect of Video Games on Crimes

A. Cumulative Effect on All Crimes (from Table 6.4)

\begin{tabular}{lccccccc} 
& \multicolumn{7}{c}{ Number of Lags Included } \\
\cline { 2 - 8 } All Crimes & $\mathbf{0}$ & $\mathbf{1}$ & $\mathbf{2}$ & $\mathbf{3}$ & $\mathbf{4}$ & $\mathbf{5}$ & $\mathbf{6}$ \\
\hline $\begin{array}{l}\text { Not Intensely } \\
\text { Violent }\end{array}$ & -0.012 & $-0.044^{*}$ & $-0.064^{* *}$ & $-0.068^{* *}$ & $-0.081^{*}$ & $-0.114^{*}$ & $-0.137^{*}$ \\
$\begin{array}{l}\text { Coefs. } \\
\begin{array}{l}\text { Intensely } \\
\text { Violent }\end{array}\end{array}$ & $(0.023)$ & $(0.030)$ & $(0.038)$ & $(0.044)$ & $(0.054)$ & $(0.059)$ & $(0.080)$ \\
$\begin{array}{l}\text { Coefs. } \\
\text { Chi-Sq test of } \\
\text { difference }\end{array}$ & 0.002 & 0.000 & -0.001 & -0.006 & -0.005 & -0.001 & -0.004 \\
\hline
\end{tabular}

B. Cumulative Effect on Violent Crimes (from Table 6.5)

\begin{tabular}{lccccccc} 
& \multicolumn{7}{c}{ Number of Lags Included } \\
\cline { 2 - 8 } Violent Crimes & $\mathbf{0}$ & $\mathbf{1}$ & $\mathbf{2}$ & $\mathbf{3}$ & $\mathbf{4}$ & $\mathbf{5}$ & $\mathbf{6}$ \\
\hline Not Intensely & -0.029 & $-0.069^{* *}$ & $-0.087^{* *}$ & $-0.081^{* *}$ & $-0.105^{* *}$ & $-0.133^{* *}$ & $-0.147^{* *}$ \\
Violent Coefs. & $(0.025)$ & $(0.033)$ & $(0.043)$ & $(0.047)$ & $(0.060)$ & $(0.064)$ & $(0.083)$ \\
$\begin{array}{l}\text { Intensely } \\
\text { Violent Coefs. }\end{array}$ & 0.001 & -0.001 & -0.002 & -0.007 & -0.006 & -0.001 & -0.003 \\
\hline $\begin{array}{l}\text { Chi-Sq test of } \\
\text { difference }\end{array}$ & 1.246 & $3.821^{* *}$ & $3.857^{* *}$ & 2.361 & 2.561 & $3.921^{* *}$ & $2.821^{*}$ \\
\hline
\end{tabular}

For both the top and bottom panels, each column represents results from a separate instrumental variables regression. Each row reports the sum of coefficients for a variable for different possible lag lengths. Not reported are coefficients of month dummies and a time trend. Absolute value of z-statistics in parentheses.

* significant at $10 \% ; * *$ significant at $5 \%$; *** significant at $1 \%$ 


\subsubsection{Age of Offender Results}

A potential robustness check is to examine the effects of video games on criminal offenders by age of offender. While the age profile of video game players is increasing, video games are still primarily played by children, teens and younger adults and not more mature adults. For most offenses, the NIBRS data records information on the age of the offenders for an incident. We separately examine the effects of video game sales on offenders aged 15-30, the prime video game playing population, versus those 35-50, a population for which video game play is not as popular. If our basic results were spurious and did not reflect any direct link between video game play and criminal acts, we would have no reason to expect a differential effect by age group. In contrast, under our hypotheses, we would expect larger effects for the younger group.

The top panel of Table 6.7 reports cumulative estimates for all crimes for both these younger and older groups. The specifications are otherwise identical to those reported in Table 6.4. However, rather than report the individual estimates as in Table 6.4 and Table 6.5, we report the estimated sums over all lags as in Table 6.6. As before, specifications with lags from between two and five achieve some level of statistical significance for both the young and the old. As before, the estimated effect of non-violent video games is negative. There is no effect from violent games. That is, there are few, if any, qualitative differences across the two groups.

The lower panel of Table 6.7 reports cumulative estimates where the dependent variable is violent crimes, for both these younger and older groups. The specifications are otherwise identical to those reported in Table 6.5 and again we report the estimated sum of effects over all lags as in Table 6.6 Now, there are noticeable differences across the two groups. Few of the estimates for the older group approach traditional levels of statistical significance. In contrast, the estimates for the younger group are generally larger (in absolute value) and many are statistically significant. In addition, the differences in estimates between violent and nonviolent games are often statistically significant. We again find that, for the younger group, non-violent games, but not violent games, reduce the number of violent crimes. In these specifications, the measured difference between the coefficients in the two rows is about 0.07-0.18. Thus, this is evidence that the behavioral effect of violent video games on violent behavior is stronger within the younger population that tends to play video games more intensively. 
Table 6.7: Crimes by Age of Offender

A. Cumulative Effect on All Crimes

\begin{tabular}{|c|c|c|c|c|c|c|c|}
\hline Aged 15-30 & 0 & 1 & 2 & 3 & 4 & 5 & 6 \\
\hline & -0.010 & $-0.040^{*}$ & $-0.050+$ & -0.052 & -0.061 & $-0.091^{*}$ & $-0.121^{*}$ \\
\hline Not Intensely Violent Coefs. & $(0.023)$ & $(0.029)$ & $(0.036)$ & $(0.042)$ & $(0.051)$ & $(0.056)$ & (0.079) \\
\hline Intensely & -0.001 & -0.004 & -0.005 & -0.009 & -0.009 & -0.006 & -0.008 \\
\hline Violent Coefs. & $(0.007)$ & $(0.008)$ & $(0.008)$ & (0.009) & $(0.009)$ & $(0.010)$ & $(0.012)$ \\
\hline Chi Sq. Diff & 0.150 & 1.502 & 1.498 & 1.038 & 0.957 & 2.171 & 1.922 \\
\hline \multirow[t]{2}{*}{ Aged $35-50$} & 0 & 1 & 2 & 3 & 4 & 5 & 6 \\
\hline & -0.012 & $-0.046^{*}$ & $-0.071 *$ & -0.061 & $-0.100 * *$ & $-0.125^{*}$ & $-0.164 *$ \\
\hline Not Intensely Violent Coefs. & $(0.024)$ & $(0.033)$ & $(0.044)$ & $(0.048)$ & $(0.064)$ & $(0.068)$ & $(0.100)$ \\
\hline Intensely & -0.006 & -0.006 & -0.007 & -0.011 & -0.010 & -0.005 & -0.008 \\
\hline Violent Coefs. & $(0.007)$ & $(0.009)$ & $(0.010)$ & $(0.010)$ & $(0.011)$ & $(0.012)$ & $(0.015)$ \\
\hline Chi Sq. Diff & 0.063 & 1.317 & 2.109 & 1.036 & 1.847 & $2.890^{*}$ & 2.329 \\
\hline
\end{tabular}

\section{B. Cumulative Effect on Violent Crimes}

\begin{tabular}{|c|c|c|c|c|c|c|c|}
\hline Aged 15-30 & 0 & 1 & 2 & 3 & 4 & 5 & 6 \\
\hline Not Intensely & -0.030 & $-0.072 * *$ & $-0.086^{* *}$ & $-0.092 * *$ & $-0.126^{* *}$ & $-0.154 * *$ & $-0.180 * *$ \\
\hline Violent Coefs. & $(0.027)$ & $(0.036)$ & $(0.045)$ & $(0.051)$ & $(0.066)$ & $(0.070)$ & (0.098) \\
\hline Intensely & 0.003 & 0.001 & 0.001 & -0.003 & -0.002 & 0.003 & 0.000 \\
\hline Violent Coefs. & $(0.008)$ & $(0.010)$ & $(0.010)$ & $(0.011)$ & $(0.012)$ & $(0.012)$ & $(0.015)$ \\
\hline Chi Sq. Diff & 1.371 & $3.984 * *$ & $3.645^{*}$ & $2.969 *$ & $3.330^{*}$ & $4.604 * *$ & $3.183^{*}$ \\
\hline Aged $35-50$ & 0 & 1 & 2 & 3 & 4 & 5 & 6 \\
\hline Not Intensely & -0.023 & $-0.062 * *$ & -0.089 & -0.072 & -0.112 & -0.130 & -0.153 \\
\hline Violent Coefs. & $(0.026)$ & $(0.038)$ & $(0.049)$ & $(0.053)$ & $(0.071)$ & $(0.074)$ & $(0.102)$ \\
\hline Intensely & -0.005 & -0.004 & -0.005 & -0.009 & -0.008 & -0.004 & -0.006 \\
\hline Violent Coefs. & $(0.008)$ & $(0.010)$ & $(0.011)$ & $(0.011)$ & $(0.012)$ & $(0.013)$ & $(0.016)$ \\
\hline Chi Sq. Diff & 0.401 & 2.194 & 2.837 & 1.366 & 2.030 & 2.684 & 1.950 \\
\hline
\end{tabular}

Sample includes 200 weekly observations from 2004-2008. Month dummy variables and a time trend were also included but are not reported. IVs include average GameSpot scores for by intensely violent content for the current period and eight lags. The Sargon statistic for over-identification always fails to reject the exogeneity of the instrument set. Absolute value of z-statistics in parentheses.

* significant at $10 \%$; ${ }^{* *}$ significant at $5 \%$; ${ }^{* *}$ significant at $1 \%$. 


\subsubsection{On Campus Results}

Another potential robustness check is to distinguish between crimes committed at schools and colleges and those committed elsewhere. Schools and colleges tend to aggregate people who are of video game playing age. The NIBRS data record the location of each incident as a categorical variable where one possible choice out of eleven is "school or college campus." One advantage of this variable over the age of offender variable is that it is recorded for all incidents while the age of offender can be missing if no one witnessed the incident in progress. One disadvantage is that crimes committed at schools and colleges need not be committed by a member of the younger video game playing demographic, though most are. Perhaps a bigger problem is that many of the younger video gamers commit crimes away from schools. Finally, since such a small number of crimes are committed on campus, we may lose statistical power for that sub-sample while the off-campus sub-sample will be quite similar to the overall sample.

The top panel of Table 6.8 reports cumulative estimates for all crimes both committed on campuses and off-campus. The specifications are otherwise identical to those reported in Table 6.4 but we report the estimated cumulative effect over all lags as in Table 6.6. As before, specifications with lags from between two and five achieve some level of statistical significance for both the young and the old. The pattern of estimated effects for both violent and non-violent video games is similar to before except that they are much larger for the on-campus sample than offcampus sample. For the off-campus group, the estimates are qualitatively similar to the base results in Table 6.6. However, the on-campus estimates are about five times larger. Other than the difference in magnitudes, the pattern of effects oncampus is unchanged. There is still a negative effect for non-violent video games in columns 2-6 that we interpret as an incapacitation effect. The estimated effect for violent video games is statistically significantly smaller (in absolute value) and we interpret the difference as a possible estimate of a behavioral effect of violent video games on crime for this sub-sample.

The lower panel of Table 6.8 reports cumulative estimates where the dependent variable is the number of violent crimes, for both crimes on and off campus. The specifications are otherwise identical to those reported in Table 6.4 and again we report the estimated sum of effects over all lags as in Table 6.6. In this case, fewer effects are estimated to be significantly different from zero. However, the pattern is similar to those for all crimes in the upper panel. The magnitudes are about five times larger for the on-campus sub-sample relative to the off-campus sub-sample. As expected, the off-campus results are more similar to our basic results reported in the bottom panel of Table 6.6. 
Table 6.8: Effect of Video Games by Campus Location

A. Cumulative Effect on All Crimes

\begin{tabular}{|c|c|c|c|c|c|c|c|}
\hline On Campus & 0 & 1 & 2 & 3 & 4 & 5 & 6 \\
\hline Not Intensely & 0.012 & -0.141 & $-0.253^{*}$ & $-0.408^{* *}$ & $-0.400 *$ & $-0.526 * *$ & $-0.591 * *$ \\
\hline Violent Coefs. & $(0.130)$ & $(0.148)$ & $(0.180)$ & $(0.216)$ & $(0.270)$ & $(0.290)$ & $(0.344)$ \\
\hline Intensely & 0.034 & 0.001 & 0.000 & -0.015 & -0.020 & -0.010 & -0.009 \\
\hline Violent Coefs. & $(0.039)$ & $(0.040)$ & $(0.040)$ & $(0.046)$ & $(0.048)$ & $(0.051)$ & $(0.053)$ \\
\hline Chi Sq. Diff & 0.025 & 0.883 & 1.919 & $3.207^{*}$ & 1.862 & $2.941 *$ & 2.695 \\
\hline Off Campus & 0 & 1 & 2 & 3 & 4 & 5 & 6 \\
\hline $\begin{array}{l}\text { Not Intensely } \\
\text { Violent Coefs. }\end{array}$ & $\begin{array}{l}-0.011 \\
(0.022)\end{array}$ & $\begin{array}{c}- \\
0.039 * \\
(0.029)\end{array}$ & $\begin{array}{l}-0.057^{*} \\
(0.037)\end{array}$ & $\begin{array}{l}-0.057^{*} \\
(0.043)\end{array}$ & $\begin{array}{l}-0.070 * \\
(0.053)\end{array}$ & $\begin{array}{c}-0.100 * * \\
(0.057)\end{array}$ & $\begin{array}{l}-0.123^{*} \\
(0.079)\end{array}$ \\
\hline Intensely & 0.001 & 0.000 & -0.001 & -0.006 & -0.005 & -0.001 & -0.004 \\
\hline Violent Coefs. & $(0.007)$ & $(0.008)$ & $(0.008)$ & $(0.009)$ & $(0.009)$ & $(0.010)$ & $(0.012)$ \\
\hline Chi Sq. Diff & 0.268 & 1.681 & 2.156 & 1.374 & 1.389 & $2.778^{*}$ & 2.150 \\
\hline
\end{tabular}

B. Cumulative Effect on Violent Crimes

\begin{tabular}{lccccccc} 
On Campus & 0 & 1 & 2 & 3 & 4 & 5 & 6 \\
\hline Not Intensely & 0.060 & -0.120 & -0.208 & $-0.360^{*}$ & -0.326 & $-0.464^{*}$ & $-0.522^{*}$ \\
Violent Coefs. & $(0.148)$ & $(0.169)$ & $(0.209)$ & $(0.247)$ & $(0.310)$ & $(0.335)$ & $(0.396)$ \\
& 0.018 & -0.021 & -0.020 & -0.037 & -0.044 & -0.031 & -0.027 \\
Intensely & $(0.044)$ & $(0.045)$ & $(0.047)$ & $(0.053)$ & $(0.055)$ & $(0.059)$ & $(0.061)$ \\
\hline Violent Coefs. & 0.071 & 0.323 & 0.794 & 1.658 & 0.776 & 1.561 & 1.475 \\
\hline Chi Sq. Diff & & & & & & & \\
\hline
\end{tabular}

\begin{tabular}{lrrrrrrr} 
Off Campus & 0 & 1 & 2 & 3 & 4 & 5 & 6 \\
\hline Not Intensely & -0.030 & $-0.065^{* *}$ & $-0.082^{* *}$ & $-0.071^{* *}$ & $-0.096^{*}$ & $-0.120^{* *}$ & $-0.134^{*}$ \\
Violent Coefs. & $(0.025)$ & $(0.034)$ & $(0.043)$ & $(0.047)$ & $(0.060)$ & $(0.064)$ & $(0.083)$ \\
Intensely & 0.000 & -0.001 & -0.002 & -0.006 & -0.006 & -0.001 & -0.004 \\
Violent Coefs. & $(0.007)$ & $(0.009)$ & $(0.010)$ & $(0.010)$ & $(0.011)$ & $(0.011)$ & $(0.013)$ \\
\hline Chi Sq. Diff & 1.293 & $3.479 *$ & $3.427^{*}$ & 1.794 & 2.123 & $3.221^{*}$ & 2.299 \\
\hline
\end{tabular}

Sample includes 200 weekly observations from 2004-2008. Month dummy variables and a time trend were also included but are not reported. IVs include average GameSpot scores for by intensely violent content for the current period and eight lags. The Sargon statistic for over-identification always fails to reject the exogeneity of the instrument set. Absolute value of z-statistics in parentheses.

${ }^{*}$ significant at $10 \%$; ${ }^{* *}$ significant at $5 \% ; * * *$ significant at $1 \%$. 


\subsubsection{Results by County Youth Population}

Our final potential robustness check is to distinguish between video game effects in areas with high or low concentrations of potential video game players. This is done by calculating the fraction of each county's population aged between 15 and 25 . We separate the counties with a fraction above the mean of $14.1 \%$ from those with a fraction below the mean. Under the assumption that this age group plays video games more, our model should find that the measured effects will be larger for counties with a high youth population.

Table 6.9: Effect of Video Games by Youth Fraction of County Population

A. Cumulative Effect on All Crimes

\begin{tabular}{lccccccc} 
High Youth & $\mathbf{0}$ & $\mathbf{1}$ & $\mathbf{2}$ & $\mathbf{3}$ & $\mathbf{4}$ & $\mathbf{5}$ & $\mathbf{6}$ \\
\hline Not Intensely & -0.008 & -0.036 & -0.054 & -0.061 & -0.078 & $-0.111^{*}$ & $-0.139^{*}$ \\
Violent Coefs. & $(0.024)$ & $(0.030)$ & $(0.039)$ & $(0.046)$ & $(0.056)$ & $(0.060)$ & $(0.083)$ \\
& 0.006 & 0.005 & 0.003 & -0.001 & -0.001 & 0.003 & 0.001 \\
Intensely & $(0.007)$ & $(0.008)$ & $(0.009)$ & $(0.039)$ & $(0.010)$ & $(0.011)$ & $(0.013)$ \\
\hline Violent Coefs. & 0.30 & 1.68 & 2.12 & 1.68 & 1.78 & $3.32^{*}$ & 2.68 \\
\hline Chi Sq. Diff & & & & & & & \\
\hline & $\mathbf{0}$ & $\mathbf{1}$ & $\mathbf{2}$ & $\mathbf{3}$ & $\mathbf{4}$ & $\mathbf{5}$ & $\mathbf{6}$ \\
\hline Low Youth & -0.025 & $-0.063^{* *}$ & $-0.089^{* *}$ & $-0.091^{* *}$ & $-0.112^{*}$ & $-0.147^{* *}$ & $-0.169^{* *}$ \\
\hline $\begin{array}{l}\text { Not Intensely } \\
\text { Violent Coefs. }\end{array}$ & $(0.024)$ & $(0.032)$ & $(0.042)$ & $(0.046)$ & $(0.059)$ & $(0.064)$ & $(0.086)$ \\
Intensely & 0.003 & 0.000 & -0.001 & -0.004 & -0.004 & 0.002 & -0.001 \\
Violent Coefs. & $(0.007)$ & $(0.009)$ & $(0.009)$ & $(0.042)$ & $(0.010)$ & $(0.011)$ & $(0.013)$ \\
\hline Chi Sq. Diff & 1.18 & $3.67^{*}$ & $4.42^{* *}$ & $3.40^{*}$ & $3.15^{*}$ & $4.95^{* *}$ & $3.58^{*}$ \\
\hline
\end{tabular}


B. Cumulative Effect on Violent Crimes

\begin{tabular}{|c|c|c|c|c|c|c|c|}
\hline High Youth & 0 & 1 & 2 & 3 & 4 & 5 & 6 \\
\hline Not Intensely & -0.038 & $-0.077 * *$ & $-0.099 * *$ & -0.084 & $-0.119 *$ & $-0.155^{* *}$ & $-0.170 *$ \\
\hline Violent Coefs. & $(0.028)$ & $(0.037)$ & $(0.049)$ & $(0.052)$ & $(0.068)$ & $(0.074)$ & $(0.097)$ \\
\hline Intensely & 0.005 & 0.002 & 0.003 & -0.001 & 0.000 & 0.006 & 0.003 \\
\hline Violent Coefs. & $(0.008)$ & $(0.010)$ & $(0.011)$ & (0.049) & $(0.012)$ & $(0.013)$ & $(0.015)$ \\
\hline Chi Sq. Diff & 2.04 & $4.34 * *$ & $4.33^{* *}$ & 2.46 & $2.87^{*}$ & $4.45^{* *}$ & $2.98^{*}$ \\
\hline Low Youth & 0 & 1 & 2 & 3 & 4 & 5 & 6 \\
\hline Not Intensely & -0.029 & $-0.067 * *$ & $-0.082^{*}$ & $-0.081^{*}$ & $-0.103^{*}$ & $-0.128 * *$ & $-0.146 *$ \\
\hline Violent Coefs. & $(0.025)$ & $(0.034)$ & $(0.043)$ & $(0.049)$ & $(0.060)$ & $(0.064)$ & $(0.082)$ \\
\hline Intensely & 0.001 & 0.000 & -0.002 & -0.007 & -0.006 & -0.002 & -0.004 \\
\hline Violent Coefs. & $(0.008)$ & $(0.009)$ & $(0.010)$ & $(0.043)$ & $(0.011)$ & $(0.011)$ & $(0.013)$ \\
\hline Chi Sq. Diff & 1.21 & $3.75^{*}$ & $3.46^{*}$ & 2.26 & 2.39 & $3.61^{*}$ & $2.84^{*}$ \\
\hline
\end{tabular}

Sample includes 200 weekly observations from 2004-2008. Month dummy variables and a time trend were also included but are not reported. IVs include average GameSpot scores for by intensely violent content for the current period and eight lags. The Sargon statistic for over-identification always fails to reject the exogeneity of the instrument set. Absolute value of z-statistics in parentheses.

* significant at $10 \% ;{ }^{* *}$ significant at $5 \% ;{ }^{* *}$ significant at $1 \%$.

As before, the top panel of Table 6.9 reports the cumulative effects for all crimes and the bottom panel reports results for violent crimes. The general pattern observed above is also evident here. Non-violent games are associated with reductions in crimes while violent games have no significant effects. In both the top and bottom panels, there appear to be no substantial differences between counties with high and low fractions of youths. While these results do not bolster confidence in the overall effect, they also do not contradict it.

\subsection{Conclusion}

Regulation of the content of video games is usually predicated on the notion that the industry has large and negative social costs through games' effect on aggression. Many researchers have argued that these games may also have caused extreme violence, such as school shootings, because of the abundance of laboratory evidence linking violent media to measured psychological aggression. Yet to date, the field has not moved beyond suggestive laboratory studies, and as these studies 
are not designed to study the impact of games on time use, we argue their external validity to understanding the impact on crime is limited. With the exception of Ward (2011), social scientists have yet to move beyond the laboratory to understand whether concerns about movie game violence's causal effect on crime are warranted. Similar to Dahl and Dellavegna (2009) our evidence finds robust evidence that violence in media may even have significant social benefits by reducing crime. Consistent with these studies, we find that the short and medium run social costs of violent video games may be considerably lower, or even non-existent, which we suggest may be due to modern video games' intensive time use requirements.

Our failure to find an effect for violent video games simply could be due to a lack of power in our estimator. However, our estimate of effect of violent games on violent crimes across the specifications from the bottom panel of Table 6.6 has a $95 \%$ confidence interval no greater than -0.028 to 0.021 . Even the upper end of this is only about one-fifth the estimated magnitude for the non-violent games. That is, while we find a net zero effect, it is a relatively precisely estimated zero effect.

One interpretation for our finding is that violent video games incapacitate individuals by shifting recreational leisure indoors. Insofar as outdoor activities make the social interactions associated with crime more likely, then violent video games may paradoxically reduce shortrun crime simply by making the interactions less likely at all (Glaeser, Sacerdote and Scheinkman 1996). Note that our study does not reject the possibility that violent video games, even lengthy ones, increase shortrun aggression - we only note that the shortrun aggression is seemingly dominated by the incapacitation effect on average.

We argue that since both aggression and time use are a consequence of playing violent video games, then the policy relevance of violent video game research requires an evaluation of the relative magnitudes of these two components of the criminal supply function. If, as we find in our study, the time use effect of violent video games reduces crime by more than the aggression effects increase it, then the case for regulatory intervention depends critically on whether violent video games increase aggression in the longrun as opposed to merely the shortrun. While some early work has been done on the long-term effects of video game play, nearly all the laboratory evidence that currently exists has only uncovered very short-term effects, which is when time use effects could be the most important. ${ }^{56}$

\footnotetext{
${ }^{56}$ Anderson (2004) notes the lack of longitudinal studies of effects of violent video games on aggression and calls for more studies aimed at investigating the long-term effects. The best evidence we have at present from laboratory studies is primarily short-run, making our study more suitable for comparison.
} 
Using our approach we find a negative inelastic relationship between weekly nonviolent video game sales and weekly crime of -0.1 . As our research design exploits shortrun variation in weekly sales up to a six week lag, caution should be used in applying it outside our sample frame. For instance, if behavioral effects from popular, higher quality games diverge from that of popular, lower quality games, then our approach may misstate the average elasticity of games independent of quality. Furthermore, our elasticity is exclusively based on shortrun variation in sales, which may be different from effects in the longrun. For instance, the substitution out of schooling to video gameplay as Stinebrickner and Stinebrickner (2008) and Ward (2012) show might imply that longrun effects of violent games on crime are positive by reducing human capital and wages (Grogger 1998). With this caveat, we use this elasticity to construct a simple counterfactual for US crimes from 2005 to 2008.

To provide context for the magnitude of our estimated effects, we consider a numerical based on the growth in video game sales over our sample period. From

Table 6.1, we calculate that video game unit sales increased by an average of $9.6 \%$ per year. From our estimated video game-to-violent crime elasticity of approximately -0.1 , our model would predict almost $1 \%$ fewer violent crimes per year due to video game sales. Nationwide, this would translate to about 33 fewer violent crimes committed per day. ${ }^{57}$ By comparison, the estimated incapacitation effect from Jacob and Lefgren (2003) of $13.3 \%$ more property crimes due teacher in-service days, would translate into about 2,300 property crimes for a hypothetical national inservice day. ${ }^{58}$ Since the video game effect occurs year round, this suggests that there are potentially large social externalities associated with crime that violent games are disrupting in the shortrun.

One advantage of our approach is that we can attempt to disentangle the separate effects of both a behavioral change toward more aggression and incapacitation due to time use. Our results provide some support for the psychological finding that, absent incapacitation, violent video games lead to more aggression as measured by violent crimes. However, our results also suggest that this is offset by possible incapacitation and selection effects leading to a net reduction in violent crimes.

This approach can help guide investigators to develop more holistic research designs, such as field experimentation and other quasi-experimental methodologies, to determine the net social costs of violent games. The main shortcoming of our

\footnotetext{
${ }^{57}$ This is based on a total of over 1.2 million violent crimes reported in the FBI's "Crime in the United States" http://www.fbi.gov/about-us/cjis/ucr/crime-in-the-u.s/2010/crime-in-the-u.s.-2010/tables/10tbl01.xls.

${ }^{58}$ This is based on 6.2 million annual property crimes reported in the FBI's "Crime in the United States" http://www.fbi.gov/about-us/cjis/ucr/crime-in-the-u.s/2010/crime-in-the-u.s.-2010/tables/10tbl01.xls.
} 
approach is due to the limitations of our data on game sales. Unfortunately, the industry does not report cross-sectional variation in game sales - only the national weekly sales of the top 50 highest grossing games are available. As a result, our paper follows a methodology similar to Dahl and Dellavegna (2009), who estimated the impact of violent movies, as proxied by daily ticket sales, on crime using only time series methods. These analyses are suggestive of the hypothesis that violent video games, like all video games, paradoxically may reduce violence while increasing the aggressiveness of individuals by simply shifting these individuals out of alternative activities where crime is more likely to occur. Insofar as our findings suggest that the operating mechanism by which violent gameplay causes crime to fall is the gameplay itself, and not the violence, then regulations should be carefully designed so as to avoid inadvertently reducing the time intensity, or the appeal, of video games.

Our findings also suggest unique challenges to game regulations. Because GAM proposes that the individual playing violent video games is developing, accidentally, a biased hermeneutic towards people wherein they believe they are in danger, then the decrease in violent outcomes that we observe in our study - the incapacitation effect from time use - may be masking the long-run harm to society if these violent behaviors are developing within gamers. This suggests that regulation aimed at reducing violent imagery and content in games could in the long-run reduce the aggression capital stock among gamers, but potentially also cause crime to increase in the short-run if the marginal player is being drawn out of violent activities. This may be too costly a tradeoff, and may not pass any cost-benefit test. But another possibility is that individuals who play games could be regularly taught to recognize these errors in their framing of situations, which theoretically would reduce the aggressive capital and thus reduce any negative outcome that is determined by the amount of aggression the person has built up, without losing the short-run gains from crime reduction. 


\section{Chapter 7}

\section{Conclusion and limitations}

\subsection{Overall summary}

The thesis explores the impacts of and behavioral changes induced by recent software applications on firms and people in three different setups. In detail, these setups feature the impacts of enterprise systems on productivity and innovation in the chapters 2 to 4 , the determinants of the adoption of most recent social enterprise software in chapter 5 and the influence of violent video games on crimes in chapter 6 .

In brief, enterprise systems are company-wide suites of business software devoted to particular process integration across the value chain. They offer a wide range of software products which support decision-making and several day-to-day business operations. Social enterprise software, on the other hand, links enterprise systems with social software applications like wikis, social networks and instant messaging and is expected to provide several benefits in information storing and handling, knowledge acquisition, management and customer relations.

Positive impacts of enterprise systems on business performance are expected and for some performance measures already shown in the literature (e.g. Hitt et al. 2002, Aral et al. 2006, Shin 2006). Chapter 2 contributes to this strand of analysis as it further disentangles the impacts of enterprise systems on labor productivity. In chapter 2, the results show that the performance impacts are not only based on the adoption of single enterprise software systems but also on complementary effects realized if the three most common enterprise systems enterprise resource planning (ERP), supply chain management (SCM) and customer relationship management (CRM) are adopted in concert. The results are obtained using the ZEW ICT survey, a unique German firm-level data set, and are based on two different complementarity testing procedures, i.e. simple interaction terms and a multiple restrictions test.

Chapter 3 and 4 analyze the impact of enterprise systems on a different measure firm performance, i.e. the firm's innovative behavior. Overall, the relationship be- 
tween enterprise system usage and the firms' innovation activity was not tackled in the economic literature yet. For the analysis, Chapter 3 relies on the ZEW ICT survey exploring the impact of the three main enterprise software systems ERP, SCM and CRM on product and process innovations. Based on a zero-inflated model the results reveal that SCM systems increase the firms' likelihood of accomplishing process innovations. In addition, ERP systems positively impact the number of process innovations realized. Concerning product innovation performance, CRM systems enhance the firms' likelihood of realizing product innovations. The number of expected product innovations, however, is increased if firms rely on a SCM system. Chapter 4 extends the analysis in chapter 3 by focusing on a different set of enterprise software applications, i.e. customized and business sector specific software, and a different type of innovations, i.e. service innovations. Relying on the letterbased survey among the "service providers of the information society" conducted by the ZEW as data base the results estimated by a probit model suggest that customized enterprise software is related to the realization of service innovation. On the other hand, no relationship between sector specific enterprise software and innovation activity could be confirmed. In sum, innovative activity seems to be highly related to the adoption of appropriate enterprise software.

Chapter 5 moves away from the analysis of the direct impacts of enterprise software into exploring persistence in ICT innovations based on the case of social enterprise software (SES) adopted. SES is a nested innovation as its adoption in general requires an established ICT infrastructure. In order to adequately picture the data generating process the analysis exploits two recent waves of the ZEW ICT survey relying on a two step bivariate probit model controlling for sample selection. Overall, the results reveal persistence in ICT innovations along two channels, i.e., via the adoption of prior ICT innovations and prior process innovation success. The estimated correlations also provide weak evidence for complementarity between prior ICT innovations, prior process innovations and SES.

Chapter 6 explores a new setup, transcending the firm-level analysis and exploring the aggregate level. In addition to social software, the public can be expected to be remarkably affected by entertainment software which nowadays relies on nearly photorealistic graphics and a vast array of gameplay experiences due to, e.g., different genres or storylines. Accordingly, people can be expected to voluntarily incapacitate themselves playing video games and being thereby unable to engage in criminal behavior. On the contrary, such engagement might also depend on the violent content a game offers as psychologists expect people to get more aggressive if they are exposed to violence, perhaps even more, if the violence is displayed photorealistically. Hence, it is unclear whether the incapacitation effect dominates the behavioral effect of increased aggressiveness. For the analysis of these effects the 
analysis relies on a US database composed from several sources, i.e., the National Incident Based Reporting Systems capturing crime incidents, the VGChartz-Website picturing console game unit sales, the Entertainment Software Rating Board providing age appropriateness rating and content classification for the featured games and the Gamespot-Website evaluating and rating the quality of each game. The results show that an increase in non-violent games is associated with a decrease in overall crime as well as violent crime in particular. Intensely violent games, however, seem to have no effect on crime rates.

In sum, the results confirm that ICT is able to change behaviors of firms and people alike, be it in form of affected innovative behavior or in decreased engagement in criminal activity.

\subsection{Limitations and further research}

Overall, the analyses presented in this thesis are not without their limitations. Beginning with the firm-level analysis, most limitations are data driven. Although planned as a panel, the ICT survey and the survey among the "service providers of the information society" feature high panel mortality as several firms do not respond in consecutive survey waves. This leaves only lagged cross-sections for the analyses which in general cannot exclude biases due to reverse causality although a high number of controls and the established time lag reduce this bias. Additionally, the analyses including enterprise software applications features no "go live" events as used, e.g., in Aral et al. (2006) which would also help to reduce the mentioned bias. Still, the analyses carried out are the first in a very recent technology field offering a baseline for further research to build on. With new panel data possibly available in the future, the analyses started out here should be continued as the impacts of enterprise software on firm performance and innovation activity could be additionally confirmed and their robustness would be proven. As for future research, it is still not clear if social software or social enterprise software in particular contributes to firms' labor productivity. Although the benefits of both systems are quite obvious the time needed for implementation and the size of implementation costs are still hard to observe and anticipate. Accordingly, future research could clarify this issue and empirically confirm if the benefits or the costs of these most recent software packages dominate the impact of these software applications on firm performance.

The analysis relating video game to crime rates faces the limitation that the proxy for video game play is only available at the national level and there is no information about individual game play. Nevertheless, the analysis presented in this thesis forms a strong baseline for future analyses in this field. Based on the availabil- 
ity of new data, preferably on the individual level with reported gaming activity, the analysis should be repeated to confirm the results obtained. 


\section{References}

1. Acemoglu, D., P. Aghion, C. Lelarge,, J. Van Reenen, and F. Zilibotti. 2007. Technology, Information, and the Decentralization of the Firm. Quarterly Journal of Economics 122, no. 4: 1759-1799.

2. Aghion, P., N. Bloom, R. Blundell, R. Griffith, and P. Howitt. 2002. Competition and Innovation: an Inverted-U Relationship, The Quarterly Journal of Economics 120(2):701-728.

3. Anderson, C. A. 2004. An update on the effects of playing violent video games. Journal of Adolescence 27: 113-122.

4. Anderson, C. A., D. A. Gentile, and K. E. Buckley. 2007 Violent video game effects on children and adolescents: theory, research and public policy. Oxford: Oxford University Press

5. Anderson, C. A. and B. J. Bushman. 2002. Human aggression. Annual Review of Psychology 53: 27-51.

6. Angrist, J. D. 2006. Instrumental variables methods in experimental criminological research: what, why and how. Journal of Experimental Criminology 2: 23-44.

7. Aral, S., E. Brynjolfsson, and D. J. Wu. 2006. Which came first, IT or productivity? The virtuous cycle of investment and use in enterprise systems. Milwaukee: Proceedings of the $27^{\text {th }}$ Conference on Information Systems.

8. Aral, S., E. Brynjolfsson, and L. Wu. 2012. Three-Way Complementarities: Performance Pay, Human Resource Analytics and Information Technology. Management Science 58, no. 5: 913-931.

9. Athey, S., and S. Stern. 1998. An empirical framework for testing theories about complementarity in organizational design. NBER working paper 6600.

10. Athey, S., and S. Stern. 2002. The Impact of Information Technology on Emergency Health Care Outcomes. The RAND Journal of Economics 33, no. 3: 399432.

11. Atrostic, B. K., and S. Nguyen. 2005. Computer Investment, Computer Networks and Productivity. Center for Economic Studies, U.S. Census Bureau. Working Papers 05-01.

12. Bach, D., and J. Sallet. 2005. The challenges of classification: emerging VolP regulation in Europe and the United States. IE Working Paper 05-19.

13. Baldwin, J. R., and W. Gu. 2004. Export-market Participation and Productivity Performance in Canadian Manufacturing. Canadian Journal of Economics 36, no. 3: 634-657.

14. Baumol, W., J. C. Panzar, and R.D. Willig. 1988. Contestable Markets and the Theory of Industry Structure. San Diego: Harcourt Brace Jovanovich.

15. Becker, Gary S. 1965. A theory of the allocation of time. Economic Journal 75, no. 299: 493-517. 
16. Becker, G. and K. M. Murphy. 1988. A theory of rational addiction. The Journal of Political Economy 96: 675-700.

17. Belderbos, R., M. Carree, and B. Lokshin. 2006. Complementarity in R\&D cooperation strategies. Review of Industrial Organization 28, no. 4: 401-426.

18. Berinsky, A. 2004. Silent Voices: Opinion Polls and Political Representation in America. Princeton: Princeton University Press, NJ.

19. Berk, R. 2005. Randomized experiments as the bronze standard. Journal of Experimental Criminology 1: 41- 433.

20. Bernard, A. B., and J. B. Jensen. 2004. Exporting and Productivity in the USA. Oxford Review of Economic Policy 20: 343-357.

21. Bertschek, I. 1995. Product and Process Innovation as a Response to Increasing Imports and Foreign Direct Investment. Journal of Industrial Economics 43, no. 4: 341-357.

22. Bertschek, I., H. Fryges, and U. Kaiser. 2006. B2B or Not to Be: Does B2B ECommerce increase Labour Productivity? International Journal of the Economics of Business 13, no. 3: 387-405.

23. Börsch-Supan, A., I. Düzgün, and M. Weiss. 2006. Sinkende Produktivität alternder Belegschaften? Zum Stand der Forschung. in Länger leben, arbeiten und sich engagieren. Chancen wertschaffender Beschäftigung bis ins Alter. Gürtersloh: Bertelsmann Stiftung.

24. Bond, S., and J. Van Reenen. 2007. Microeconomic Models of Investment and Employment. Handbook of Econometrics 6, no. 1: 4417-4498.

25. Bresnahan, T. F., and M. Trajtenberg. 1995. General Purpose Technologies: Engines of Growth? Journal of Econometrics 65: 83-108.

26. Bresnahan, T. F., E. Brynjolfsson, and L. M. Hitt. 2002. Information Technology, Workplace Organization, and the Demand for Skilled Labor: Firm-level Evidence. The Quarterly Journal of Economics 117, no. 1: 339-376.

27. Brynjolfsson, E., and L. M. Hitt. 2000. Beyond Computation: Information Technology, Organizational Transformation and Business Performance. Journal of Economic Perspectives 14, no. 4: 23-48.

28. Brynjolfsson, E., and A. Saunders. 2010. Wired for Innovation: How Information Technology is Reshaping the Economy. Cambridge: MIT Press, MA.

29. Bushman, B. J. and C. A. Anderson. 2002. Violent video games and hostile expectations: a test of the general aggression model. Personality and Social Psychology Bulletin 28, no. 12: 1679-1686.

30. Cachon, G., and M. Fisher. 2000. Supply Chain Inventory Management and the Value of shared Information. Management Science 46, no. 8: 1032-1048.

31. Cameron, A. C. , and P.K. Trivedi. 2009. Microeconometrics Using Stata. College Station Texas: Stata Press.

32. Campbell, D. T. and J. C. Stanley. 1963. Experimental and quasi-experimental designs for research. Chicago: Rand McNally. 
33. Card, D. and G. B. Dahl. 2011. Family violence and football: the effect of unexpected emotional cues on violent behaviour. Quarterly Journal of Economics. forthcoming

34. Carree, M., B. Lokshin, and R. Belderbos. 2007. A note on testing for complementarity and substitutability in the case of multiple practices. Journal of Productivity Analysis 35: 263-269.

35. Cassiman, B. and R. Veugelers. 2006. In Search of Complementarity in Innovation Strategy: Internal R\&D and External Knowledge Acquisition. Management Science 52, no 1: 68-82.

36. Cefis, E. 2003. Is there Persistence in Innovation Activities? International Journal of Industrial Organization 21, no. 4: 489-513.

37. Chang, M. H., and J.E. Harrington Jr. 2000. Centralization vs. Decentralization in a Multi-Unit Organization: A Computational Model of a Retail Chain as a Multi-Agent Adaptive System. Management Science 46, no. 11: 1427-1440.

38. Charkari, N. M., and N. Abdolvand. 2004. A Proposed Model in Integrating SCM, CRM and ERP. In: The First International Conference on Information and Knowledge Technology: 18-24.

39. Chen, I. J. 2001. Planning for ERP Systems: Analysis and future Trends. Business Process Management 7, no. 5: 374-386.

40. Chesbrough, H. M. 2003. Open Innovation. Harvard Business School Press, Boston.

41. Chess Media Group 2010. Guide to Understand Social CRM, Accessed March 3, 2011: http://www.chessmediagroup.com/wpcontent/uploads/resource/95dd4dd11f5def709a3683f4efd97d26.pdf

42. Cohen, M. A., N. Agrawal, and V. Agrawal. 2006. Winning in the Aftermarket. Harvard Business Review 84, no. 5: 129-138.

43. Comstock, A. and J. M. Buckley. 1883. Traps for the young. Cambridge: Beknap Press

44. Conlon, G. 1999. Wired Executive: Growing Sales from existing Customers. Sales and Marketing Management: 135.

45. Cotteleer, M. J., and E. Bendoly. 2006. Order lead-time Improvement following Enterprise-IT Implementation: An empirical Study. Management Information Systems Quarterly 30, no. 3: 643-660.

46. Crépon, B., E. Duguet, and J. Mairesse. 1998. Research, Innovation and Productivity: An Econometric Analysis at the Firm-Level. Economics of Innovation and New Technology 7, no. 2: 115-158.

47. Criscuolo, C., J. Haskel, and M. Slaughter. 2005. Why are some firms more innovative? Knowledge inputs, knowledge stocks and the role of global engagement. NBER working paper, No. 11479.

48. Dahl, G. and S. D. Vigna. 2009. Does movie violence increase violent crime? Quarterly Journal of Economics 124, no. 2: 637-675. 
49. Davenport, T. H. 1998. Putting the Enterprise into the Enterprise system. Harvard Business Review 76, no. 4: 121-132.

50. Deaton, A. 2010. Instruments, randomization, and learning about development. Journal of Economic Literature 48: 424-455.

51. Dehning, B., V. J. Richardson, and R. W. Zmud. 2007. The financial Performance Effects of IT-Based Supply Chain Management Systems in manufacturing Firms. Journal of Operations Management 25, no. 1: 806-824.

52. De Vany, A. 2004. Hollywood economics: how extreme uncertainty shapes the film industry. London: Routledge Press.

53. Draca, M., R. Sadun, and J. Van Reenen. 2007. Productivity and ICTs: A Review of the Evidence. The Oxford Handbook of Information and Communication Technologies, comps. Mansell R., Avgerau, C. Quah, D. and Silverstone, R. Oxford University Press, 100-147.

54. Engelstätter, B. 2012a. It's not all about Performance Gains - Enterprise Software and Innovations. Economics of Innovation and New Technology Vol. 21, Number 3, 223-245

55. Engelstätter, B. 2012b. Enterprise Systems and Labor Productivity: Disentangling Combination Effects. International Journal of Engineering Research and Applications (forthcoming).

56. Ettlie, J. E., W. P. Brigdes, and R. D. O'Keefe. 1984. Organization Strategy and Structural Differences for Radical versus Incremental Innovation. Management Science 30, no. 6: 682-695

57. Federal Trade Commission. 2009. Marketing Violent Entertainment to Children: A Sixth Follow-Up Review of Industry Practices in the Motion Picture, Music Recording \& Electronic Game Industries: A Federal Trade Commission Report to Congress. Washington DC.

58. Ferguson, C. J. and J. Kilburn 2008. The public health risks of media violence: a meta-analytic review. The Journal of Pediatrics 154, no. 4: 759-763.

59. Fisher, R. A. 1935. The design of experiments. Edinburgh: Oliver and Boyd

60. Flaig, G., and M. Stadler. 1994. Success breeds success. The Dynamics of the Innovation Process. Empirical Economics 19: 55-68.

61. Freel, M. 2006. Patterns of Technological Innovation in Knowledge-Intensive Business Services. Industry and Innovation 13, no. 3: 335-358.

62. Gallouj, F., and O. Weinstein. 1997. Innovation in Services. Research Policy 26, no. 4-5: 537-556.

63. Gartner. 2012. Predicts 2012: Marketers Must Adapt, Differentiate and Innovate in Social CRM, SaaS and IMM. Gartner

64. Gera, S., and W. Gu. 2004. The Effect of Organizational Innovation and Information and Communications Technology on Firm Performance. International Productivity Monitor 9: 37-51. 
65. Geroski, P. A., J. van Reenen and C. F. Walters. 1997. How persistently do firms innovate? Research Policy 26, no. 1: 33-48.

66. Gilbert, R. 2006. Looking for Mr. Schumpeter: Where Are We in the Competition-Innovation Debate?. Innovation Policy and the Economy 6: 159-215.

67. Glaeser, E., B. Sacerdote and J. Scheinkman. 1996. Crime and social interactions, Quarterly Journal of Economics 111, no. 2: 507-548.

68. Glaeser, E., B. Sacerdote and J. Scheinkman. 2003. The social multiplier, Journal of the European Economic Association 1, no. 2-3

69. Gould, E. D., B. A. Weinberg and D. B. Mustard. 2002. Crime rates and local labor market opportunities in the United States: 1979-1997. The Review of Economics and Statistics 84, no. 1: 45-61

70. Gourieroux, C., and J. Jasiak. 2007. The Econometrics of Individual Risk: Credit, Insurance, and Marketing. Princeton: Princeton University Press, NJ.

71. Greenan, N., and J. Mairesse. 2000. Computers and Productivity In France: Some Evidence. Economics of Innovation and New Technology 9, no. 3: 275315.

72. Greene, W. H. 2003. Econometric Analysis. Prentice Hall Inc.

73. Greenstein, S. and J. Prince. 2007. Internet Diffusion and the Geography of the Digital Divide in the United States, in: The Oxford Handbook of Information and Communication Technologies, ed. Mansell, R., D. Quah and R. Silverstone, 168-195. Oxford University Press.

74. Griliches, Z. 1979. Issues in assessing the contribution of R\&D to productivity growth. Bell Journal of Economics 10: 92-116.

75. Grogger, J. 1998. Market wages and youth crime. Journal of Labor Economics 16, no. 4: 756-791.

76. Gronau, N. 2010. Enterprise Resource Planning. Oldenbourg Verlag, 2. extended edition.

77. Gruber, H., and F. Verboven. 2001. The Diffusion of Mobile Telecommunications Services in the European Union. European Economic Review 45: 577-588.

78. Hadju, D. 2009. The ten-cent plague: the great comic-book scare and how it changed America. New York: Farrar, Strauss and Giroux.

79. Hall, D. B. 2000. Zero-inflated Poisson and Binomial Regression with Random Effects: A Case Study. Biometrics 56, no. 4: 1030-1039.

80. Hall, B. H., F. Lotti, and J. Mairesse. 2009. Innovation and Productivity in SMEs: Empirical Evidence for Italy. Small Business Economics 33: 13-33.

81. Harrison, G. W. and J. A. List. 2004. Field experiments. Journal of Economic Literature 42, no. 4: 1013-1059.

82. Heckman, J. 1979. Sample Selection Bias as a Specification Error, Econometrica 47: 153-161.

83. Heckman, J. and S. Urzua. 2010. Comparing IV with structural models: what simple IV can and cannot identify. Journal of Econometrics 156, no. 1: 27-37. 
84. Hempell, T. 2005. Does Experience Matter? Innovations and the Productivity of Information and Communication Technologies in German Services. Economics of Innovation and New Technology 14, no. 4: 277-303.

85. Hempell, T., and T. Zwick. 2008. New Technology, Work Organisation, and Innovation. Economics of Innovation and New Technology 17, no. 4: 331-354.

86. Hendricks, K. B., V. R. Singhal, and J. K. Stratman. 2007. The Impact of Enterprise Systems on Corporate Performance: A Study of ERP, SCM and CRM System Implementations. Journal of Operations Management 25, no. 1: 65-82.

87. Hilger, J., G. Rafert and S. Villas-Boas. 2010. Expert opinion and the demand for experience goods: an experimental approach in the retail wine market. $R e$ view of Economics \& Statistics. forthcoming.

88. Hipp, C., and H. Grupp. 2005. Innovation in the Service Sector: The Demand for Service-Specific Innovation Measurement Concepts and Typologies. Research Policy 34, no. 1: 517-535.

89. Hitt, L. M., D. J. Wou, and X. Zhou. 2002. Investment in Enterprise Resource Planning: Business Impact and Productivity Measures. Journal of Management Information Systems 19, no. 1: 71-98.

90. Hunton, J. E., B. Lippincott, and J. L. Reck. 2003. Enterprise resource planning systems: comparing firm performance of adopters and nonadopters. International Journal of Accounting Information Systems 4, no. 3: 165-184.

91. Imbens, G. W. 2010. Better LATE Than Nothing: Some Comments on Deaton (2009) and Heckman and Urzua (2009). Journal of Economic Literature 48, no.2: 399-423.

92. Jacob, B. A., and L. Lefgren. 2003. Are idle hands the devil's workshop? incapacitation, concentration, and juvenile crime. The American Economic Review 93, no. 5: 1560-1577.

93. Jacob, B. A., L. Lefgren and E Moretti. 2007. The dynamics of criminal behavior: evidence from weather shocks. Journal of Human Resources 42, no. 3: 489-527.

94. Jacobsen, S., J. Shepherd, M. D’Aquila, and K. Carter. 2007. The ERP Market Sizing Report, 2006-2011. AMR Research 20495.

95. Jancic, Z., and V. Zabkar. 2002. Interpersonal vs. Personal Exchanges in Marketing Relationships, Journal of Marketing Management 18, no. 7-8: 657-671.

96. Joshi, A. W., and S. Sharma. 2004. Customer knowledge development: antecedents and impact on new product performance. Journal of Marketing 68: 47-59.

97. Karshenas, M., and P. Stoneman. 1995. Technological Diffusion. A Handbook of the Economics of Innovation and Technological Change, Oxford: Blackwell Publishers.

98. Katz, H. 2002. How to embrace CRM and make it succeed in an organization. Costa Mesa: SYSPRO White Paper. 
99. Koch, A., and H. Strotmann. 2006. Determinants of Innovative Activity in Newly Founded Knowledge-Intensive Business Service Firms, in Entrepreneurship in the Region. International Studies in Entrepreneurship 14: 195-224.

100. Kretschmer, T., E. J. Miravete and J. C. Pernías. 2012. Competitive Pressure and the Adoption of Complementary Innovations. American Economic Review 102, no. 4: 1540-1570.

101. Kutner, L. and C. Olson. 2008. Grand theft childhood: the surprising truth about violent video games and what parents can do. New York: Simon \& Schuster.

102. Lambert, D. 1992. Zero-inflated Poisson regression with an application to defects in manufacturing. Technometrics 34: 1-14.

103. Leiponen, A. 2005. Organisation of Knowledge and Innovation: The Case of Finnish Business Services. Industry and Innovation 12, no. 2: 185-203.

104. Licht, G., and D. Moch. 1999. Innovation and Information Technology in Services. Canadian Journal of Economics 32, no. 2: 363-383.

105. Lo, S. and D. Sutthiphisal. 2010. Crossover Inventions and Knowledge Diffusion of General Purpose Technologies: Evidence from the Electrical Technology. The Journal of Economic History 70, no. 3, 744-764.

106. Mabert, V. A., A. K. Soni, and M. A. Venkataramanan. 2000. Enterprise resource planning survey of US manufacturing firms. Production \& Inventory Management Journal 41, no. 20: 52-58.

107. Mairesse, J. and P. Mohnen. 2010. Using Innovation Surveys for Econometric Analysis, in: The Handbook of the Economics of Innovation, ed. Hall, B. H. and N. Rosenberg, 1130-1155. Elsevier Amsterdam.

108. Malhorta, A., A. Majchrzak, R. Carman, and V. Lott. 2001. Radical Innovation Without Collocation: A Case Study at Boeing-Rocketdyne. MIS Quarterly 25, no. 2: 225-249.

109. Matolcsy, Z. P., P. Booth, B. and Wieder. 2005. Economic Benefits of Enterprise Resource Planning Systems: Some empirical Evidence. Accounting and Finance 45, no. 3: 439-456.

110. McAfee, A. 1999. The impact of enterprise resource planning systems on company Performance, Wharton Electronic Supply Chain Conference.

111. McAfee, A. 2002. The Impact of Enterprise Information Technology Adoption on Operational Performance: An Empirical Investigation. Productions and Operations Management 11, no. 1: 33-53.

112. McAfee, A., and D. Upton. 1996. Vandelay Industries. Harvard Business School Case 9-697-037. Harvard Business School Publishing, Boston.

113. Meyer, J. 2010. Does Social Software Support Service Innovation? International Journal of the Economics of Business 17, no. 3: 289-311. 
114. Mendelson, H., and R. Pillai. 1999. Information Age Organizations, Dynamics and Performance. Journal of Economic Behaviour and Organization 38, 253281.

115. Miles, I. 2005. Innovation in Services. The Oxford Handbook of Innovation, Oxford: Oxford University Press

116. Miles, I. 2008. Patterns of Innovation in Service Industries. IBM Systems Journal 47, 115-128.

117. Milgrom, P., and J. Roberts. 1990. The Economics of Modern Manufacturing: Technology, Strategy, and Organization. American Economic Review 80, no. 3: 511-528.

118. Miravete, E. J. and J. C. Pernías. 2006. Innovation Complementarity and Scale of Production. Journal of Industrial Economics 54, no. 1: 1-29.

119. Mithas, S., M. S. Krishnan, and C. Fornell 2005. Why do Customer Relationship Management Applications affect Customer Satisfaction? Journal of Marketing 69, no. 4: 201-209.

120. Mohnen, P., and L. H. Röller. 2005. Complementarities in Innovation Policy. European Economic Review 49, no. 6: 1431-1450.

121. Morgan, R. M., and S. D. Hunt. 1994. The Commitment-trust Theory of Relationship Marketing. Journal of Marketing 58: 20-38.

122. Nicolaou, A. I. 2004. Firm Performance Effects in Relation to the Implementation and Use of Enterprise Resource Planning Systems. Journal of Information Systems 18, no. 2: 79-105.

123. Nicolaou, A. I., T. Stratopoulus, and B. Dehning. 2003. Financial Analysis of Potential Benefits from ERP Systems Adoption. Journal of Business and Information Technology 2, no. 1: 40-50.

124. OECD. 2005. Oslo Manual: Guidelines for Collecting and Interpreting Innovation Data. OECD

125. Ohnemus. J. 2007. Does IT Outsourcing Increase Firm Success? An Empirical Assessment using Firm-Level Data. ZEW Discussion Paper 07-087.

126. Parisi, M. L., F. Schiantarelli and A. Sembenelli. 2006. Productivity, Innovation Creation and Adoption, and R\&D: Micro Evidence for Italy. European Economic Review 50, no. 8: 2037-2061.

127. Pavlou, P., and O. El Sawy. 2006. From IT Leveraging Competence to Competitive Advantage in Turbulent Environments: The Case of New Product Development. Information Systems Research 17, no.3: 198-227.

128. Peters, B. 2009. Persistence of Innovation: Stylized Facts and Panel Data Evidence. Journal of Technology Transfer 34, no. 2: 226-243.

129. Polder, M., G. van Leeuwen, P. Mohnen, and W. Raymond. 2010. Product, Process and Organizational Innovation: Drivers, Complementarity and Productivity Effects. United Nations University - Maastricht Economic and Social Re- 
search and Training Centre on Innovation and Technology Working Paper Series, no. 035.

130. Rantala, R. R. and T. J. Edwards. 2000. Effects of NIBRS on crime statistics. NCJ Publication 178890. US Department of Justice.

131. Raphael, S. and R. Winter-Ebmer. 2001. Identifying the effect of unemployment on crime. Journal of Law and Economics 44: 259-283.

132. Raymond, W., P. Mohnen, F. Palm and S. S. von der Loeff. 2010. Persistence of Innovation in Dutch Manufacturing: Is it spurious? The Review of Economics and Statistics 92, no. 3: 495-504.

133. Reinstein, D. and C. Snyder. 2005. The influence of expert reviews on consumer demand for experience goods: A case study of movie critics. Journal of Industrial Economics 53, no. 1: 27-51.

134. Roper, S., J. Du, and J.H. Love. 2006. Knowledge sourcing and innovation. Aston Business School Research Paper 0605.

135. Roper, S., J. Du, and J.H. Love. 2008. Modeling the innovation value chain. Research Policy 37: 961-977.

136. Rosenbaum, P. R. 2002. Observational studies. New York: Springer.

137. Rosenbaum, P. R. 2002. Covariance adjustment in randomized experiments and observational studies. Statistical Science 17, no. 3: 286-304.

138. SAP. 2010. Presentation for Deutsche Bank European TMT Conference 2010: SAP. Accessed November 2010: http://www.sap.com/about/investor/presentations/pdf/WB_DB_London_8Se p2010.pdf

139. Scott, J.E., and I. Vessey. 2000. Implementing enterprise resource planning systems: The role of learning from failure. Information Systems Frontiers 2, no. 2: 213-232.

140. Shapiro, A. 1985. Asymptotic Distribution of Test Statistics in the Analysis of Moment Structures under Inequality Constraints. Biometrika 72, no. 1: 133144.

141. Shang, S., and P.B. Seddon. 2002. Assessing and managing the benefits of enterprise systems: the business manager's perspective. Information Systems Journal 12: 271-299.

142. Sheth, J. N., R. S. Sisodia, and A. Sharma. 2000. The Antecedents and Consequences of customercentric Marketing. Journal of the Academy of Marketing Science 28, no. 1: 55-66.

143. Sheu, M., T. Hu, T.E. Keeler, M. Ong, and H.-Y. Sung. 2004. The effect of a major cigarette price change on smoking behavior in California: a zero-inflated negative binomial model. Health Economics 13: 781-791.

144. Shih, C. 2010. The Facebook Era: Tapping Online Social Networks to Market, Sell and Innovate ( $2^{\text {nd }}$ Edition). Prentice Hall, New Jersey. 
145. Shin, I. 2006. Adoption of Enterprise Application Software and Firm Performance. Small Business Economics 26, no. 3: 241-256.

146. Stinebrickner, R. and T. R. Stinebrickner. 2008. The causal effect of studying on academic performance. The B.E. Journal of Economic Analysis \& Policy: Frontiers 8, no. 1: 14

147. Sundbo, J. 1997. Management of Innovation in Services. The Service Industries Journal 17, no. 3: 432-455.

148. Suresh, H. 2004. What is customer relationship management (CRM)? Supply Chain Planet, April.

149. Tambe, P., L. Hitt, and E. Brynjolfsson. 2011. The Extroverted Firm: How External Information Practices Affect Innovation and Productivity. Management Science, forthcoming.

150. Tether, B. S. 2005. Do Services Innovate (Differently)? Insights from the European Innobarometer Survey. Industry and Innovation 12, no. 2: 153-184.

151. Terza, J. V. 1998. Estimating count data with endogenous switching: Sample selection and endogenous treatment effects. Journal of Econometrics 84: 129154.

152. Thomke, S. H. 1998. Simulation, Learning and R \& D Performance: Evidence from Automotive Development. Research Policy 27, no. 1: 55-74

153. Tirole, J. 1988. The Theory of Industrial Organization .Cambridge: MIT Press, MA.

154. Tsai, W. 2001. Knowledge transfer in intraorganizational networks: Effects of network position and absorptive capacity on business unit innovation and performance. Academy of Management Journal 44: 996-1004.

155. Vanberg, M. 2003. Die Konjunkturumfrage bei Dienstleistern der Informationsgesellschaft. ZEW Dokumentation 03-09, Mannheim: Zentrum für Europäische Wirtschaftsforschung

156. Van Reenen, J., N. Bloom, M. Draca, T. Kretschmer, R. Sadun, H. Overman, and M. Schankerman. 2010. The Economic Impact of ICT. Final Report. London: Centre for Economic Performance, London School of Economics.

157. Vinding, A. L. 2006. Absorptive Capacity and Innovative Performance: A Human Capital Approach. Economics of Innovation and New Technology 15, no. 4-5: 507-517.

158. Vuong, Q. H. 1989. Likelihood ratio tests for model selection and non-nested hypothesis. Econometrica 57, no. 2: 307-333.

159. Ward, M. R. 2011. Video games and crime. Contemporary Economic Policy. 29, no. 2: 261-273.

160. Ward, M. R. 2012. Does time spent playing video games crowd out time spent studying? unpublished manuscript 
161. Wieder, B., P. Booth, Z. P. Matolcsy, and M. L. Ossimitz. 2006. The Impact of ERP Systems on Firm and Business Process Performance. Journal of Enterprise Information Management 19, no. 1: 13-29.

162. Wier, B., J.E. Hunton, and H. R. Hassab Elnaby. 2007. Enterprise resource planning systems and non-financial performance incentives: The joint impact on corporate performance. International Journal of Accounting Information Systems 8, no. 3: 165-190.

163. Winkelmann, R. 1998. Count Data Models with selectivity. Econometric Review 17, no. 4: 339-359.

164. Wooldridge, J. 2002. Econometric Analysis of Cross Section and Panel Data. Cambridge: MIT Press, MA

165. Zhu, F. and X. Zhang. 2010. Impact of online consumer reviews on sales: the moderating role of product and consumer characteristics. Journal of Marketing 74:133-148.

166. Zwick, T. 2003. Works Councils and the Productivity Impact of Direct Employee Participation. ZEW Discussion Paper 03-47 



\section{Curriculum Vitae}

\section{Benjamin Engelstätter}

Centre for European Economic Research (ZEW)

Research Group Information and Communication Technologies (ICT)

L 7,1 68161 Mannheim

Phone: + 0049-6211235-134

Fax: + 0049-6211235-333

Email: engelstaetter@zew.de

<http://www.zew.de/en/mitarbeiter/mitarbeiter.php3?action=mita\&kurz=ben>

Benjamin Engelstätter studied economics with the focus on econometrics and statistics at the Christian-Albrechts-University of Kiel. He wrote his diploma thesis at the Research Centre of the German Bundesbank. Since July 2007 he has been working for the Research Group Information and Communication Technologies at the Centre for European Economic Research (ZEW). In 2009 he became external PhDstudent at the Maastricht University/UNU-Merit. Benjamin Engelstätter is regular visiting researcher at the University of Texas at Arlington and teaching assistant at the University of Mannheim.

His fields of research include the effects of the usage of different information and communication technologies, in particular those of enterprise systems, on firm performance and innovation activities. His current research focuses on competition and cannibalization in high-tech industries, e.g. the video game industry, as well as on social network formation and peer effects in different economic settings, for instance among video gamers, movie actors and firms collaborating in R\&D projects. 

UNU Merit Thesis Overview

2012

\section{Fulvia Farinelli}

Natural Resources, Innovation and Export Growth: The Wine Industry in Chili and Argentina

\section{Rodolfo Lauterbach}

Innovation in Manufacturing: From Product Variety and Labor Productivity Growth to Economic Development in Chile

\section{Kirsten Wiebe}

Quantitative assessment of sustainable development and growth in SubSaharan Africa

\section{Julio Miguel Rosa.}

Organizational Strategies, Firms' Performance and Spatial Spillovers. The Canadian Case in Research and Development.

\section{Johannes Wilhelmus Marie Boels}

Joseph Schumpeter, honderd jaar economische ontwikkeling. Een historischtheoretische beschouwing.

\section{1}

\section{Daniel Vertesy}

Interrupted Innovation: Emerging economies in the structure of the global aerospace industry.

\section{Tina Saebi}

Successfully managing alliance portfolios: an alliance capability view.

\section{Nora Engel}

Tuberculosis in India - A case of innovation and control.

\section{Evans Mupela}

Connectivity and growth in Sub-Saharan Africa: The role of communication satellites 


\section{Nantawan Kwanjai}

Cross cultural intelligence amid intricate cultural webs - A tale of the UnDutchables in the land of 1002 smiles

\section{Lina Sonne}

Innovation in Finance to Finance Innovation: Supporting pro-poor entrepreneurbased innovation

2010

\section{Fernando Santiago}

Human Resources Management Practices and Learning for Innovation in Developing Countries: Pharmaceutical Firms in Mexico

\section{Zakaria Babutsidze}

Essays on Economies with Heterogenous Interacting Consumers

\section{Bertha Vallejo}

Learning and Innovation Under Changing Market Conditions: The Auto Parts Industry in Mexico

\section{Donatus Ayitey}

Technical Change, Competitiveness and Poverty Reduction: A Study of the Ghanaian Apparel Industry

\section{Sergey Fillipov}

Multinational Subsidiary Evolution: Corporate Change in New EU Member States

\section{Asel Doranova}

Technology Transfer and Learning under the Kyoto regime; Exploring the Technological Impact of CDM projects in developing countries

\section{9}

\section{Alexis Habiyaremye}

From Primary Commodity Dependence to Diversification and Growth". "Absorptive Capacity and Technological Catch Up in Botswana and Mauritius".

\section{Yoseph Getachew}

The Role of Public Capital in Economic Development 


\section{Sandra Leitner}

Embodied Technological Change and Patterns of Investment in Austrian Manufacturing

\section{Semih Akçomak}

The Impact of Social Capital on Economic and Social Outcomes

\section{Abraham Garcia}

The Role of Demand in Technical Change

\section{Saurabh Arora}

Coherence in socio-technical systems: a network perspective on the innovation process

2008

\section{Rutger Daems}

Medicines for the developing world

\section{Johannes Hanel}

Assessing Induced Technology - Sombart's Understanding of Technical Change in the History of Economics

\section{Rifka Weehuizen}

Mental Capital: the economic significance of mental health

\section{Danielle Cloodt}

The relationship between R\&D partnership formation, social embeddedness and innovative performance

\section{Sabine Fuss}

Sustainable Energy Development under Uncertainty

2007

\section{Tobias Kronenberg}

Reconciling Environmental Conservation with Economic Prosperity: The Feasibility of Double Dividends in the Short and Long Run

\section{Viktoria Kravtsova}

Assessing the Impact of Foreign Direct Investment in Transition Economies 


\section{Suhail Sultan}

The Competitive Advantage of Small and Medium Sized Enterprises: The Case of Jordan's Natural Stone Industry

2006

\section{Bulat Sanditov}

Essays on Social Learning and Imitation

\section{Mamata Parhi}

Dynamics of New Technology Diffusion: A Study of the Indian Automotive Industry

\section{Andreas Reinstaller}

Social structures and the innovation process: Their role in the demand of firms and consumers

\section{Rose Kiggundu}

Innovation systems and development : the journey of a Beleaguered Nile Perch Fishery in Uganda

\section{Thomas Pogue}

The Evolution of Research Collaboration in South African Gold Mining: 1886-1933

\section{Geoffrey Gachino}

Foreign Direct Investment, Spillovers and Innovation: The Case of Kenyan Manufacturing Industry

\section{0. Önder Nomaler}

Technological Change, International Trade and Growth - An Evolutionary, MultiAgents-Based Modeling Approach

2005

\section{Samia Satti Osman Mohamed-Nour}

Change and Skill Development in the Arab Gulf Countries

\section{Elad Harison}

Intellectual Property Rights: Economics and Policy Analysis 


\section{Daniel Dalohoun}

The relationship between R\&D partnership formation, social embeddedness and innovative performance: a multi-level approach of social embeddedness

\section{Müge Ozman}

Networks, Organizations and Knowledge

\section{Bas Straathof}

Product variety and economic growth - The counteracting effects of scale and idiosyncrasy

\section{Wilfred Schoenmakers}

Knowledge Flows between Multinational Companies: A Patent Data Analysis

\section{Myriam Cloodt}

Mergers and Acquisitions (M\&As) in High-Tech Industries: Measuring the Post-M\&A Innovative Performance of Companies

2004

\section{Paola Criscuolo}

R\&D Internationalisation and Knowledge Transfer. Impact on MNEs and their Home Countries

\section{Maarten Verkerk}

Trust and Power on the Shop Floor

\section{Gottfried Leibbrandt}

Adoption, harmonization and succession of network technologies across countries

\section{Mark Sanders}

Skill Biased Technical change - Its Origins, the Interaction with the Labour Market and Policy Implications

2003

\section{Nadine Roijakkers}

Inter-firm cooperation in high-tech industries: a study of R\&D partnerships in pharmaceutical biotechnology

\section{Viki Sonntag}

Speed, Scale and Sustainability 
26. Masaru Yarime

From End-of-Pipe Technology to Clean Technology

\section{Stéphane Malo}

The combinatorial Chemistry Revolution - Sustaining a Superior Performance Position through Technological Learning

2002

\section{Annelies Hogenbirk}

Determinants of Inward Foreign Direct Investment: the Case of the Netherlands

2001

\section{John Adeoti}

Technology Investment in Pollution Control in Sub-Saharan Africa: The Case of the Nigerian Manufacturing Industry

\section{Edward Huizenga}

Innovation Management: How Frontrunners Stay Ahead. An Empirical Study on Key Success Factors in the ICT sector

2000

21. Machiel van Dijk

Technological Change and the Dynamics of Industries. Theoretical Issues and Empirical evidence from Dutch Manufacturing

1999

20. Jan Cobbenhagen

Managing Innovation at the Company Level: A Study on Non-Sector-Specific Success Factors

\section{Marjolein Caniëls}

Regional Growth Differentials: The Impact of Locally Bounded Knowledge Spillovers 


\section{Aldo Geuna}

Resource allocation and knowledge production: Studies in the economics of university research

1996

\section{Reinoud Joosten}

Dynamics, Equilibria, and Values

\section{Hugo Kruiniger}

Investment, R\&D, and the Financing Decisions of the Firm

1995

\section{Hans van Meijl}

Endogenous Technological Change: The Case of Information Technology. Theoretical Considerations and Empirical Results

\section{René Kemp}

Environmental Policy and Technical Change. A Comparison of the Technological Impact of Policy Instruments

\section{Rohini Acharya}

The Impact of New Technologies on Economic Growth and Trade. A Case Study of Biotechnology

\section{Geert Duysters}

The Evolution of Complex Industrial Systems. The Dynamics of Major IT Sectors

\section{Marjan Groen}

Technology, Work and Organisation, A Study of the Nursing Process in Intensive Care Units

1994

\section{Huub Meijers}

On the Diffusion of Technologies in a Vintage Framework; Theoretical Considerations and Empirical Results 


\section{Theon van Dijk}

The Limits of Patent Protection. Essays on the Economics of Intellectual Property Rights

\section{Hans Voordijk}

Naar Integrale Logistiek in Bedrijfsketens, Ontwikkelingen in de Bouw

\section{3}

\section{Paul Diederen}

Technological Progress in Enterprises and Diffusion of Innovations. Theoretical Reflections and Empirical Evidence.

\section{Ben Dankbaar}

Economic Crisis and Institutional Change. The crisis of Fordism from the perspective of the automobile industry

\section{Hanno Roberts}

Accountability and Responsibility: The Influence of Organisation Design on Management Accounting

\section{2}

\section{Bart Verspagen}

Uneven Growth Between Interdependent Economies. An Evolutionary View on Technology Gaps, Trade and Growth

\section{Sjoerd Romme}

A Self-organization Perspective on Strategy Formation

1989

\section{John Spangenberg}

Economies of Scale, and Atmosphere in Research Organisations

1988

\section{John Hagedoorn}

Evolutionary and heterodox innovation analysis : a study of industrial and technological development in process control and information technology 